\title{
ESTIMATIVA DA DINÂMICA DO ÍNDICE DE ÁREA FOLIAR EM UMA MICROBACIA HIDROGRÁFICA POR MEIO DE TÉCNICAS DE SENSORIAMENTO REMOTO
}

\author{
ALEXANDRE CÂNDIDO XAVIER \\ Engenheiro Agrícola
}

Orientador: Prof. Dr. CARLOS ALBERTO VETTORAZZI

Tese apresentada à Escola Superior de Agricultura "Luiz de Queiroz", Universidade de São Paulo, para obtenção do título de Doutor em Agronomia, Área de Concentração: Irrigação e Drenagem.

PIRACICABA

Estado de São Paulo - Brasil

Novembro -2002 


\section{ERRATA}

Alexandre Cândido Xavier: Estimativa da dinâmica do índice de área

foliar em uma microbacia hidrográfica por meio de técnicas de

sensoriamento remoto.

\begin{tabular}{llll}
\hline p. & linha & onde se lê & leia-se \\
\hline 9 & 13 & (espécie Quercus ilex totundifolia) & (espécie Quercus ilex rotundifolia) \\
13 & 19 & Agrissolo Vermelho Amarelo, & Argissolo Vermelho Amarelo, \\
& & Agrissolo Vermelho..... & Argissolo Vermelho.... \\
\hline
\end{tabular}




\section{Dados Internacionais de Catalogação na Publicação (CIP)}

DIVISÃO DE BIBLIOTECA E DOCUMENTAÇÃO - ESALQJUSP

\section{Xavier, Alexandre Cândido}

Estimativa da dinâmica do índice de área foliar ẹm uma microbacia hidrográfica por meio de técnicas de sensoriamento remoto / Alexandre Cândido Xavier. - - Piracicaba, 2002.

111 p. : il.

Tese (doutorado) - Escola Superior de Agricultura Luiz de Queiroz, 2002.

Bibliografia.

1. Bacia hidrográfica 2. Índice de área foliar 3. Sensoriamento remoto 4. Vegetação 5. Uso do solo 1. Título

CDD 551.483 
Dedico este trabalho aos meus pais, João B. M. Xavier e Benedita C. Xavier, pela educação e amor recebido. 


\section{AGRADECIMENTOS}

Ao Professor Carlos Alberto Vettorazzi, pela amizade e orientação deste trabalho;

Ao professor Mauro Antônio Homem Antunes pela amizade, ajuda na correção dos efeitos atmosféricos das imagens e sugestões na qualificação;

Aos professores do Departamento d e Engenharia Rural, Rubens Angulo Filho e Rubens Duarte Coelho pelas sugestões ao aprimoramento trabalho;

À CAPES, pelo suporte através de bolsa no primeiro ano do doutoramento;

À FAPESP, pelo suporte através de bolsa e pela concessão de auxílio financeiro para execução do projeto;

Aos colegas da pós-graduação: Ezequiel, Diniz, Luiz Geraldo, João, José Roberto, Juan, Nicolas, Parise, Manuel, Ronalton etc., pelo convívio nestes anos;

À Juliana, pela alegria que me oferece de estar a seu lado durante todos estes dias, além, é claro, das revisões preliminares deste documento;

Aos meus irmãos César, José e Eduardo pela inspiração nos trabalhos, principalmente na hora do estudo;

Ao Sr. Edegar e à Sra. Thaïs por terem me recebido tão amistosamente durante estes últimos anos. 


\section{SUMÁRIO}

Página

LISTA DE ABREVIATURAS E SÍMBOLOS................................................ vii

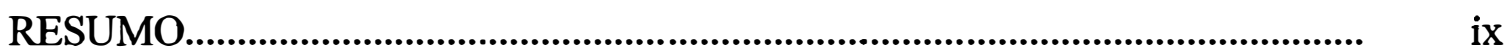

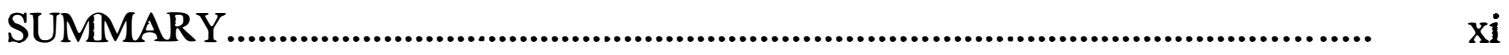

1 INTRODUÇÃO .................................................................................. 1

2 REVISÃO DE LITERATURA .............................................................. 4

2.1 Índices de vegetação .............................................................................. 4

$2.2 \quad$ Modelo linear de mistura espectral ........................................................... 7

3 RELAÇÃO ENTRE ÍNDICE DE ÁREA FOLIAR E ÍNDICES DE VEGETAÇÃO EM UMA MICROBACIA RURAL EM REGIÃO DE CLIMA

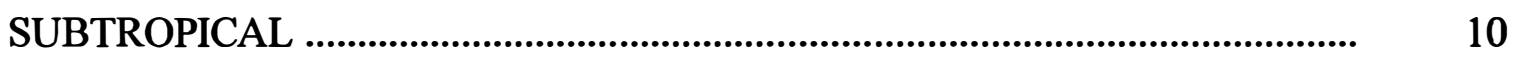

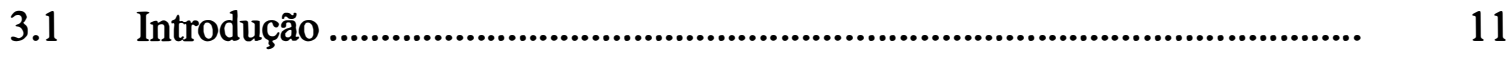

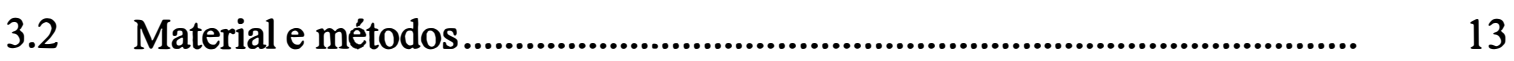

3.2.1 Área de estudo ...................................................................................... 13

3.2.2 Estimativa do Índice de Área Foliar ......................................................... 16

3.2.3 Processamento da imagem..................................................................... 20

3.2.4 Avaliação estatística das relações IVs-IAF ................................................ 21

$3.3 \quad$ Resultados e discussão ......................................................................... 21

3.3.1 Campanha de campo ............................................................................... 21 
3.3.2 Relação entre IAF e bandas individuais (ver e $i V P$ )..................................... 24

3.3.3 Relação entre IAF e IVs (SR, NDVI e SAVI)............................................. 26

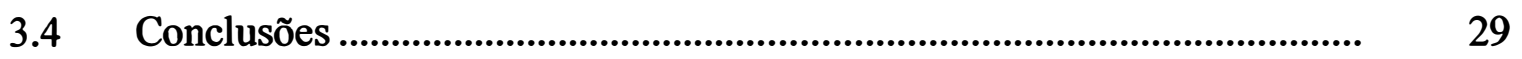

4 RELAÇÃO DO ÍNDICE DE ÁREA FOLIAR COM AS FRAÇÕES DE COMPONENTES PUROS E COM O NDVI.................................................... 30

4.1 Introdução .............................................................................................. 31

4.2 Material e métodos................................................................................ 34

4.2.1 Área de estudo e dados de IAF ............................................................. 34

4.2.2 Processamento da imagem ....................................................................... 34

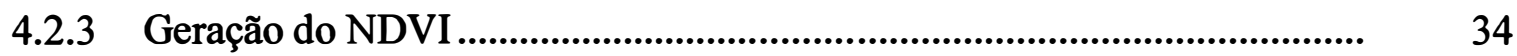

4.2.4 Geração das frações dos componentes puros............................................ 34

4.2.5 Avaliação estatística das relações: frações de componentes puros-IAF e NDVI-IAF ........................................................................................................ 38

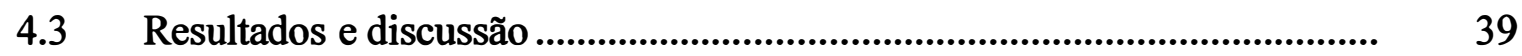

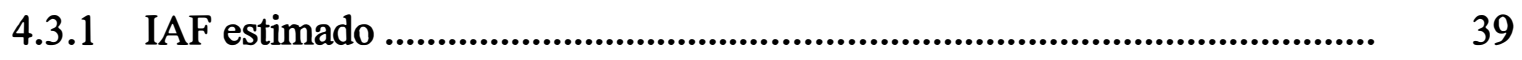

4.3.2 Relação IAF-NDVI................................................................................ 39

4.3.3 Relações IAF-FCPs ................................................................................ 41

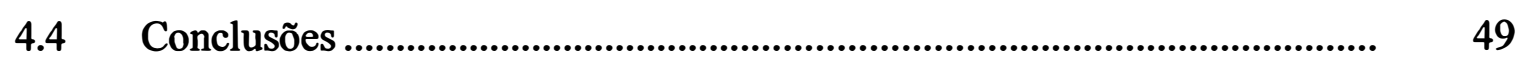

5 ESTIMATIVA DO ÍNDICE DE ÁREA FOLIAR MENSAL EM UMA MICROBACIA HIDROGRÁFICA COM DADOS DE SENSORIAMENTO REMOTO............................................................................................... 50

5.1 Introdução ............................................................................................... 51

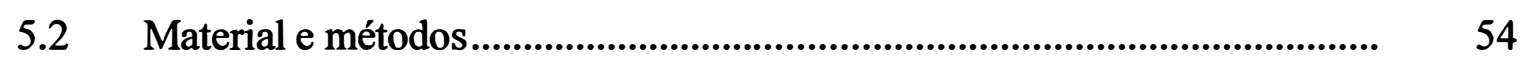

5.2.1 Área de estudo e dados de IAF ............................................................. 54

5.2.2 Processamento das imagens................................................................... 54

5.2.3 Avaliação estatística ................................................................................. 56

$5.3 \quad$ Resultados e discussão .......................................................................... 57

5.3.1 Precipitação e temperatura (ano de 2001) .............................................. 57

5.3.2 Avaliação dos dados de IAF ......................................................................... 58 
5.3.3 Relação do IAF com as bandas individuais e com o NDVI

5.3.4 Análise dos mapas de IAF .

5.3.5 Estimativa do IAF mensal

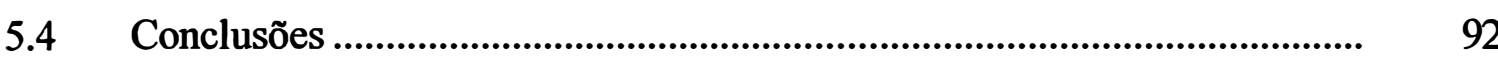

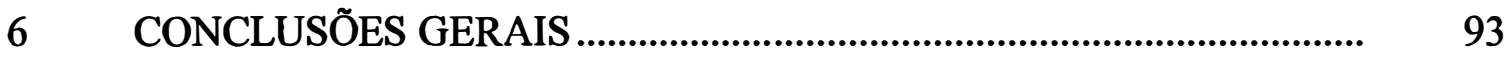

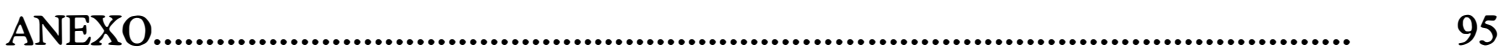

REFERÊNCIAS BIBLIOGRÁFICAS............................................................. 97 


\section{LISTA DE ABREVIATURAS E SÍMBOLOS}

$\mu$ - densidade da folhagem

$\theta, \phi$ - direção do feixe de luz na direção do ângulo zenital e ângulo azimutal, respectivamente

AZS - Ângulo Zenital Solar

$\mathrm{F}_{\mathrm{SOL}}$ - frações de componente puro de solo

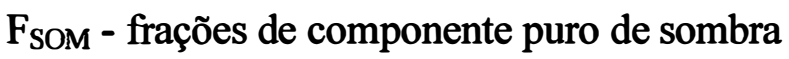

$\mathrm{F}_{\mathrm{VEG}}$ - frações de componente puro de vegetação

$G$ - fração da folhagem projetada na direção do feixe de luz

IAF - Índice de Área Foliar

IV - Índice de Vegetação

iVP - reflectância nas regiões do infravermelho próximo

$K$ - freqüência de contatos entre os elementos foliares e a radiação

MLME - Modelo Linear de Mistura Espectral

NC - Nível de Cinza

NDVI - Índice de Vegetação da Diferença Normalizada

R2 - coeficiente de determinação

$S$ - comprimento do caminho (metros) de um feixe de luz de um extremo a outro do dossel na direção

SAVI - Índice de Vegetação Ajustado para Influência do Solo

se - erro padrão

SR - Razão Simples

$T$ - probabilidade da não interceptação da radiação difusa

ver - reflectância nas regiões do vermelho

$z$ - altura do dossel 


\title{
ESTIMATIVA DA DINÂMICA DO ÍNDICE DE ÁREA FOLIAR EM UMA MICROBACIA HIDROGRÁFICA POR MEIO DE TÉCNICAS DE SENSORIAMENTO REMOTO
}

\author{
Autor: ALEXANDRE CÂNDIDO XAVIER \\ Orientador: Prof. CARLOS ALBERTO VETTORAZZI
}

\section{RESUMO}

A variável biofisica Índice de Área Foliar (IAF) está diretamente relacionada com a evapotranspiração e a produtividade e para estimá-la em nível regional podem ser utilizadas técnicas de sensoriamento remoto. Este trabalho estuda a relação do IAF com índices de vegetação (Razão Simples, SR; Índice de Vegetação da Diferença Normalizada, NDVI; e Índice de Vegetação Ajustado para Influência do Solo, SAVI) e frações de componente puro de vegetação $\left(\mathrm{F}_{\mathrm{VEG}}\right)$, solo $\left(\mathrm{F}_{\mathrm{SOL}}\right)$ e sombra $\left(\mathrm{F}_{\mathrm{SOM}}\right)$, calculados pelo Modelo Linear de Mistura Espectral (MLME). A área de estudo foi a microbacia rural do Ribeirão dos Marins, no município de Piracicaba. SP. O IAF em campo foi estimado mensalmente, durante o ano de 2001, com o equipamento LAI-2000 para diferentes tipos de cobertura vegetal (cana-de-açúcar, pastagem, milho, eucalipto e floresta ripária). Foram adquiridas 4 imagens do Landsat-7/ETM+ (meses de janeiro, março, agosto e novembro) corrigidas para os efeitos atmosféricos pelo modelo $6 \mathrm{~S}$. O IAF máximo observado na bacia foi de 4,90. O IAF de cana-de-açúcar apresentou a maior variação devido ao manejo agrícola e características intrínsecas desta cultura. Foi observado que, dentre os índices de vegetação e as frações de componente puro, o IAF apresentou melhor relação com o índice de vegetação NDVI, todavia não diferiu 
estatisticamente da relação IAF-SR. Quando analisada a relação IAF-NDVI para as quatro datas, foi verificada a sensibilidade do NDVI a variações do ângulo zenital solar e brilho do solo. O IAF explicou de $57 \%$ à $72 \%$ da variação do NDVI. Relações NDVIIAF foram utilizadas para se gerar mapas de IAF para a bacia em estudo, tendo sido verificada uma alta correlação do IAF médio da bacia com a precitação acumulada de três meses. Este trabalho representa o início de um estudo que procura avaliar a potencialidade de utilização de dados de sensoriamento remoto como preditores do IAF, para futuras aplicações em modelos de cálculo da evapotranspiração. 


\title{
LEAF AREA INDEX DYNAMICS ESTIMATE IN A WATERSHED THROUGH REMOTE SENSING TECHNIQUES
}

\author{
Author: ALEXANDRE CÂNDIDO XAVIER \\ Adviser: Prof. CARLOS ALBERTO VETTORAZZI
}

\section{SUMMARY}

The biophysical variable Leaf Area Index (LAI) is directly related to the evapotranspiration and the productivity and to estimate it on a regional level, remote sensing techniques can be employed. This work studies the relationship between LAI and spectral vegetation indices (Simple Ratio, SR; Normalized Difference Vegetation Index, NDVI; and Soil Adjusted Vegetation Index, SAVI) and vegetation, soil, and shadow endmember fractions, calculated through Linear Spectral Mixture Modelling (LSMM). The LAI in the field was monthly collected along 2001 with the LAI-2000 equipment for different land covers (sugar-cane, pasture, corn, eucalypt, and riparian forest). Four Landsat-7/ETM+ images (from January, March, August, and November) were acquired and corrected for atmospheric effects through the $6 \mathrm{~S}$ model. The maximum LAI value observed in the watershed was 4.90. The sugar-cane LAI presented the greater variation due to the management and characteristics of this crop. It was observed that LAI was better related to the NDVI, although it was not statistically different of the relationship LAI-SR. When LAI-NDVI relationship was analyzed for the four dates, it was verified the NDVI sensitivity to soil brightness and solar zenith angles variation. The IAF explained $57 \%$ to $72 \%$ of the variability in the NDVI. This 
relationship was inverted to generate LAI maps for the watershed, being observed a high correlation between mean LAI and precipitation. This work represents the beginning of a study that aims at the evaluation of remote sensing techniques as LAI predictors to future applications in evapotranspiration models. 


\section{INTRODUÇÃO}

Nestas últimas décadas o meio ambiente tornou-se motivo de grande preocupação para a humanidade, uma vez que as interferências antrópicas têm provocado sérias alterações nos ecossistemas. Como exemplo, as alterações no uso do solo e/ou a sua utilização inadequada em uma bacia hidrográfica (p.ex.: ausência de terraceamento e de proteção das margens de rios) podem provocar o assoreamento dos rios, pois promovem mudanças em suas propriedades hidrológicas, fazendo com que ela fique mais susceptível a fenômenos como enchentes e desertificação, além de causar um desequilíbrio para as espécies de animais e vegetais que ali vivem.

Os recursos naturais, como a água e o solo, também encontram-se ameaçados em sua sustentabilidade em várias regiões do planeta. A água, em particular, tem-se tornado um recurso cada vez mais escasso, tanto para áreas urbanas quanto rurais, daí a necessidade de técnicas cada vez mais aprimoradas para avaliar sua circulação e ocorrência (p.ex.: água infiltrada, escoamento superficial e evapotranspiração). No ciclo hidrológico, a perda de água por evapotranspiração tem grande importância. Tomemos como exemplo ilustrativo o continente norte-americano, onde aproximadamente $30 \%$ da água é drenada superficialmente ou percolada para o subsolo, enquanto os outros $70 \%$ retomam para a atmosfera, na forma direta de evaporação e transpiração (Rosenberg et al., 1983).

A variável biofísica Índice de Área Foliar (IAF), total de área foliar por área de superfície, está diretamente relacionada com a evapotranspiração (Rosenberg et al., 1983; Lang \& McMurtrie, 1992), sendo a principal variável de entrada descritora da vegetação nos modelos para este cálculo (Tiktak \& Grinsven, 1995). O IAF também está 
relacionado com a capacidade de interceptação da chuva pelo dossel, sendo que esta freqüentemente aumenta com maiores valores de IAF (Kergoat, 1998; Dijk \& Bruijnzeel, 2001).

Plummer (2000) fez uma revisão sobre a perspectiva da combinação de modelos de processos ecológicos e dados de sensoriamento remoto, que poderiam ser utilizados para guiar os modelos ecológicos. Os dados derivados de sensores remotos seriam, por exemplo, variáveis meteorológicas da superfície (p.ex. temperatura) e aquelas relacionadas à vegetação (p.ex.: IAF, fração de cobertura, altura). Pode-se citar como exemplo Running et al. (1989) que, no cálculo da evapotranspiração e produtividade, utilizou dados de sensoriamento remoto para estimar o IAF.

A estimativa do IAF, em campo, para as condições de clima subtropical, é escassa na bibliografia. Entender a dinâmica do IAF é o primeiro passo para aplicá-lo em modelos de cálculo da evapotranspiração e da produtividade, em menor escala. $\mathrm{O}$ sensoriamento remoto tem-se mostrado um instrumento viável para se obter o IAF de maneira rápida e em escala regional, com nível aceitável de exatidão. Todavia, não é possível desenvolver um algoritmo simples para estimar o IAF com acurácia e que seja válido para todos os locais (Gobron et al., 1997), pois ele depende das condições de solo e da fisionomia da vegetação. Vários trabalhos têm sido realizados para estimar o IAF por meio de dados de sensoriamento remoto, sendo que no Brasil esta estimativa ainda é bastante incipiente. $\mathrm{O}$ objetivo geral deste trabalho foi avaliar a utilização de técnicas de sensoriamento remoto orbital para estimar a dinâmica temporal do IAF em uma bacia hidrográfica rural, com diferentes coberturas e usos do solo.

Os objetivos específicos deste trabalho são:

a) avaliar a relação de diferentes índices de vegetação (Razão Simples, SR; Índice de Vegetação da Diferença Normalizada, NDVI; e Índice de Vegetação Ajustado para a Influência do Solo, SAVI) e frações de componentes puros de vegetação, solo e sombra, com IAF de diferentes classes de uso do solo da bacia hidrográfica em estudo; 
b) estruturar e avaliar dados mensais de IAF, para as diferentes classes de uso do solo da bacia hidrográfica em estudo, ao longo de um ano;

c) gerar mapas de IAF, por meio da inversão da imagem índice selecionada e dos dados de IAF da campanha de campo.

Quanto à organização da tese, no capítulo que vem a seguir (Capítulo 2) é apresentada uma revisão bibliográfica referente aos temas estudados neste trabalho. Em seguida, são apresentados mais quatro capítulos: i) o Capítulo 3, em que é avaliada a relação entre IAF e diferentes índices de vegetação (SR, NDVI e SAVI); ii) o Capítulo 4, onde é escolhida a melhor relação IAF-índice de vegetação e esta é comparada com as relações IAF-frações de componentes puros; iii) o Capítulo 5, em que a melhor relação IAF-índice de vegetação/fração de componentes puros é utilizada para gerar mapas de IAF para a área de estudo, sendo também apresentada uma avaliação dos dados de IAF ao longo do ano; e, por final, o Capítulo 6, com as conclusões gerais da tese. 


\section{REVISÃO DE LITERATURA}

É apresentada neste capítulo uma breve revisão bibliográfica de duas técnicas de sensoriamento remoto utilizadas, neste trabalho, para estimar o IAF: i) índices de vegetação (SR, NDVI e SAVI) e ii) Frações de Componentes Puros (FCPs), oriundos de modelo linear de mistura espectral (MLME).

\section{1 Índices de vegetação}

Uma das maneiras de se caracterizar o dossel vegetal, por meio de dados de sensoriamento remoto, é utilizando índices de vegetação (IVs) (Goel, 1989). Os IVs são dados obtidos de medidas radiométricas da vegetação, sendo utilizados para: avaliar variações temporais e espaciais de dados biofísicos, como o IAF (Best \& Harlan, 1985;

Friedl et al., 1994; Curran \& Williamson, 1995); calcular a fração da radiação fotossinteticamente ativa absorvida pelo dossel (Asrar et al., 1984; Wiegand et al., 1990; Epiphanio \& Huete, 1995); a percentagem ou fração de cobertura verde (Carlson \& Ripley, 1997; Purevdorj et al., 1998; McGwire et al., 2000); e a biomassa (Tucker, 1979; Cusack et al., 1999). A base física dos IVs é atribuída à alta absorção da radiação pelos pigmentos responsáveis pela fotossíntese e ao seu espalhamento pelas folhas, nas regiões espectrais do vermelho e do infravermelho próximo, respectivamente (Gates et al., 1965; Liu \& Huete, 1995).

O IV Razão Simples (SR), baseado em estudo de Jordan (1969) para estimar o IAF, é um dos mais utilizados. O SR é calculado pela razão entre a reflectância nas regiões do infravermelho próximo ( $i V P, \lambda \sim 0,8 \mu \mathrm{m})$ e vermelho (ver, $\lambda \sim 0,6 \mu \mathrm{m})$, ou seja, $\mathrm{SR}=i V P / v e r$. Outro importante IV é o "Normalized Difference Vegetation Index", ou 
seja, Índice de Vegetação da Diferença Normalizada, dado por: NDVI=(iVP-ver)/(iVP+ver). Em áreas onde há considerável variação de brilho devida a diferenças de umidade, variações de rugosidade, sombra ou diferentes teores de matéria orgânica no solo, podem ocorrer mudanças no IV (Huete, 1988; Jackson \& Huete, 1991). Na Figura 1 são mostradas isolinhas do modelo teórico do NDVI no espaço de comprimentos de onda do ver-iVP. Nota-se que as isolinhas do modelo NDVI convergem para a origem. Entretanto, uma vegetação que se encontra na condição de solo seco (ponto A) ao passar para a condição de solo úmido, estará em $\mathrm{B}$, e não em C como pressupõe o modelo NDVI, ou seja, as isolinhas não convergem para a origem (Huete, 1988).

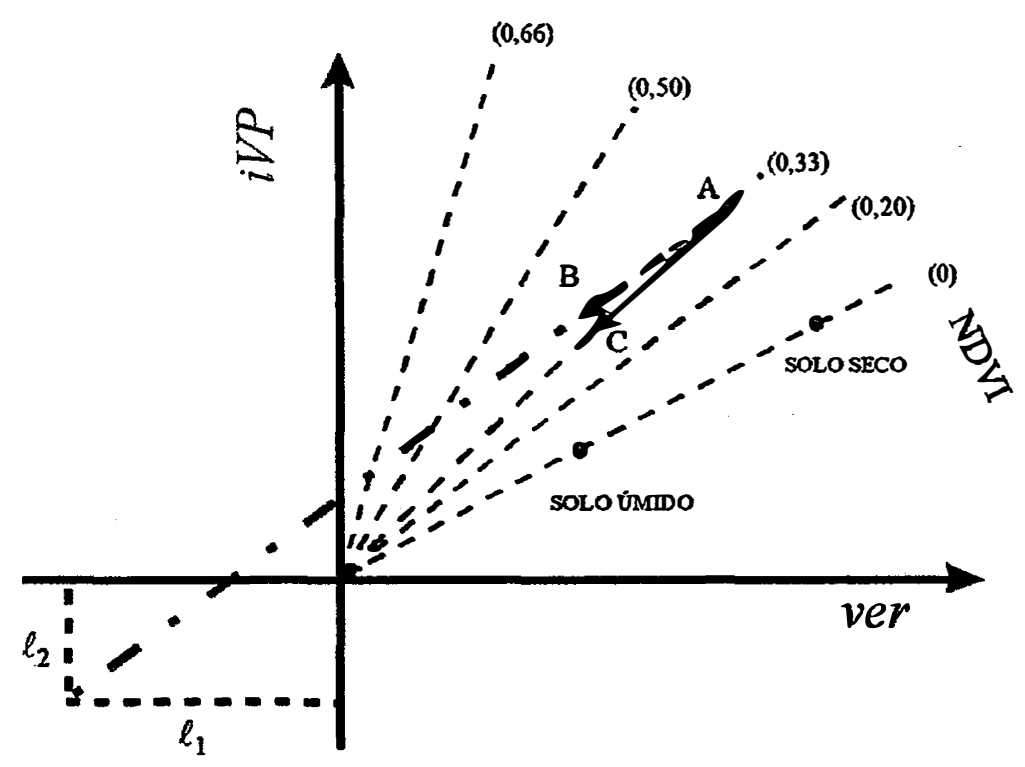

Figura 1 - Linhas de espectro de vegetação nos comprimentos de onda nas regiões do. vermelho e do infravermelho próximo, obtidas pelo NDVI.

FONTE: Adaptado de Huete (1988), p. 297.

Huete (1988) propôs uma modificação do NDVI, com o deslocamento da origem, adicionando a constante $\ell$ para ver e $i V P$, denominando-o "Soil-Adjusted Vegetation Index" (SAVI), ou seja, Índice de Vegetação Ajustado para Influência do Solo:

$$
\mathrm{SAVI}=\left(\left(i V P+\ell_{2}\right)-\left(v e r+\ell_{1}\right)\right) /\left(\left(i V P+\ell_{2}\right)+\left(v e r+\ell_{1}\right)\right),
$$


sendo que $\ell_{1}$ e $\ell_{2}$ podem ser assumidos como equivalentes e, assim, pode-se utilizar $\mathrm{L}=\ell_{1}+\ell_{2}=2 \ell$ tornando-se a forma simplificada do SAVI (Equação 2). $\mathrm{O}$ fator de multiplicação (1+L) é utilizado para fazer com que os resultados do modelo variem de -1 $\mathrm{a}+1$.

$$
\mathrm{SAVI}=(1+\mathrm{L})(i V P-v e r) /(i V P+v e r+\mathrm{L})
$$

Os IVs variam de maneira não linear às variações das bandas individuais, sendo que o NDVI é mais sensível às variações de ver do que de $i V P$, enquanto o SAVI é mais sensível às variações do iVP (Epiphanio \& Huete, 1995). Como o IV SR pode ser calculado como uma simples função do NDVI, sem informação adicional (Perry \& Lautenshlager, 1984), isto é, $\mathrm{SR}=f(\mathrm{NDVI})=(1+\mathrm{NDVI}) /(1-\mathrm{NDVI})$, espera-se uma forte relação entre estes.

O comportamento geral dos IVs com o IAF é de saturar para maiores valores de IAF, como verificado para as relações: IAF-SR (Peterson et al., 1987); IAF-NDVI (Holben et al., 1980); e IAF com SR, NDVI e SAVI (Turner et al., 1999). Para Chen \& Cihlar (1996), por exemplo, a saturação dos IVs em culturas agrícolas e florestais ocorreria, aproximadamente, em IAF de 2,50 e de 5,00, respectivamente. Já Turner et al. (1999) observaram que a saturação ocorreu em IAF entre 3,00 e 5,00, em vegetação de clima temperado.

Como os IVs aqui estudados são função do ver e do iVP, temos que estes serão afetados, além do IAF, por outros fatores, entre eles: i) estrutura do dossel como um todo (p.ex.: estrutura foliar; a altura da planta; a distribuição do ângulo foliar etc.) (Asrar et al., 1985; Myneni et al., 1997); ii) geometria sol-sensor-alvo (Middleton, 1991; Walter-Shea et al., 1997; Deering et al., 1999); iii) substrato (Huete, 1988); e iv) atmosfera (Myneni \& Asrar, 1994). Estudos relacionando o NDVI com ângulo zenital solar (AZS) já foram realizados, podendo-se citar: Deering et al. (1999), que observaram que o NDVI aumentou com o aumento do AZS para áreas florestais de abeto negro ("black spruce") e pinho do Canadá ("jack pine") e permaneceu constante para áreas de 
choupo ("aspen"); Middleton (1991), que observou os seguintes comportamentos na relação NDVI/SR-AZS em gramíneas: i) relação linear positiva; ii) relação linear negativa; iii) valor de NDVI alto e constante; e iv) valor de NDVI baixo e constante; todavia, os comportamentos mais comuns foram o i) e o iv). Quanto ao brilho do solo tem-se que, com o aumento deste o NDVI diminui (Liu \& Huete, 1995) e diminui em maior magnitude para dosséis mais abertos (Bausch, 1993).

A geração de mapas de IAF por meio de relações entre IAF e índices de vegetação vem sendo realizada com bastante sucesso. Um exemplo recente foi o trabalho realizado por Chen et al. (2002), que geraram mapas de IAF para todo o Canadá com auxílio do índice de vegetação SR (iVP/ver).

\subsection{Modelo linear de mistura espectral}

Quando fótons interagem com um simples componente dentro do campo de visada do sensor, a mistura pode ser modelada como a soma de cada componente, mas quando fótons são espalhados e interagem com múltiplos componentes, como espalhamento pelas folhas da radiação no comprimento de onda $i V P$, a mistura tem um potencial de tornar-se não linear (Robertson et al., 1993; Borel \& Gerstl, 1994), sendo que modelos não lineares podem ser utilizados para estimar as frações de cada componente (Ray \& Murray, 1996). Considerando o espalhamento múltiplo desprezível (Roberts et al., 1998), pode-se aplicar o modelo linear de mistura espectral (MLME), onde uma relação linear é usada para representar a mistura espectral de alvos dentro do elemento de resolução do sistema sensor (pixel). As frações de cada um dos componentes puros considerados no modelo vêm sendo utilizadas para: identificar diferentes fases de plantios de eucalipto e diferentes espécies de pinheiros (Hlavka \& Spanner, 1995; Shimabukuro \& Smith, 1995); correlacioná-las com a biomassa, área basal e IAF (Hall et al, 1995a; Bernardes 1996); identificar e mapear feições de degradação da terra relacionadas com processo de erosão do solo (Metterncht \& Fermat, 1998); classificar imagens (Novo \& Shimabukuro, 1997; Adams et al., 1995; CasalsCarrasco et al., 2000); mapear desflorestamento (Shimabukuro et al., 1994); estimar 
abundância de vegetação em área urbana (Small, 2001); e interpretar dados geológicos (Adams et al., 1986).

A resposta de cada pixel em qualquer comprimento de onda pode ser considerada como uma combinação linear das respostas de cada componente da mistura. Deste modo, cada pixel contém informações sobre a fração e a resposta espectral de cada componente dentro da resolução unitária do terreno (Shimabukuro \& Smith, 1991), podendo-se, desta forma, aplicar o MLME, conforme:

$$
r_{i}=\sum_{j=1}^{n}\left(a_{i j} x_{j}\right)+e_{i}
$$

sendo: $r_{i}=$ reflectância de superfície de um pixel, para a i-ésima banda espectral; $a_{i j}=$ reflectância do $j$-ésimo componente puro do pixel para a $i$-ésima banda espectral; $x_{j}=$ fração do $j$-ésimo componente puro no pixel; $e_{i}=$ resíduo da modelagem para a $i$-ésima banda espectral; $j=1,2,3, \ldots, n$ (índice de componentes); $i=1,2,3, \ldots, m$ (índice de bandas espectrais consideradas).

Cada um dos valores, $r_{i}$ e $a_{i j}$, são admitidos como conhecidos. $\mathrm{O}$ termo $x_{j}=0$ determina a ausência deste componente e o valor $x_{j}=1$ indica que o pixel contém apenas o componente puro considerado. Para estimar as frações de componentes puros (FCPs) $\left(x_{j}\right)$ do MLME, utilizam-se vários métodos, tais como: método dos mínimos quadrados com restrições e dos mínimos quadrados ponderados (Shimabukuro, 1991) e componentes principais (Adams et al., 1986). Neste trabalho, a estimativa das FCPs foi feita pela metodologia dos mínimos quadrados com restrição, que é realizada com a minimização da função $\mathrm{F}=\sum_{i=1}^{m} e_{i}^{2}$, em que $m$ corresponde ao número de bandas espectrais do sensor ETM+ do satélite Landsat-7. Maiores detalhes desta solução podem ser encontrados em Shimabukuro \& Smith (1991).

Segundo Shimabukuro \& Smith (1995), para cada pixel da imagem, após estimadas as frações por um dos métodos citados anteriormente, é possível calcular o erro médio 
da estimativa para cada pixel (Equação 4) e o erro médio da imagem (Equação 5). $O$ erro médio da imagem indica quão bem a variabilidade espectral foi explicada com os componentes puros selecionados, sendo utilizado para avaliar a acurácia do mapeamento da superfície.

$$
\text { Erro } \text { médio }_{k}=\sum_{i=1}^{m}\left|e_{i}\right| / m
$$

sendo: $m$ o número de bandas espectrais; $k$ o k-ésimo pixel; e $e_{i}=r_{i}-\sum_{j=1}^{n}\left(a_{i j} x_{j}\right)$. Desta forma o erro médio da imagem é dado por:

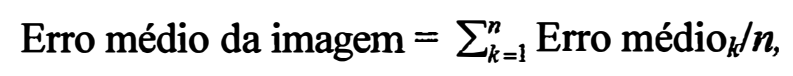

sendo $n$ o número total de pixels.

Como exemplos de estudos de frações de componentes puros "versus" IAF podem-se citar os rabalhos García-Haro et al. (1996) e Hall et al. (1995a). García-Haro et al. (1996) observaram: i) comportamento linear entre fração do componente puro vegetação (espécie Quercus ilex totundifolia) e IAF (valores de IAF menores que 2,40); ii) diminuição da fração de componente solo com o aumento do IAF; e iii) diminuição do componente sombra com aumento do IAF. Hall et al. (1995a) observaram que a melhor relação do IAF de Picea mariana e de Populus tremuloides foi encontrada com a fração do componente sombra, com coeficiente de determinação variando de 0,49 a 0,72 para os ângulos zenital solar de $60^{\circ} \mathrm{e} 40^{\circ}$, respectivamente. 


\section{RELAÇÃO ENTRE ÍNDICE DE ÁREA FOLIAR $E$ ÍNDICES DE VEGETAÇÃO EM UMA MICROBACIA RURAL EM REGIÃO DE CLIMA SUBTROPICAL}

\section{Resumo}

O Índice de Área Foliar (IAF) vem sendo associado com a evapotranspiração e a produtividade em modelos matemáticos. Estimativa dessa variável biofísica, em nível regional, pode ser feita com suficiente exatidão com o auxílio de índices de vegetação (IVs), gerados a partir de imagens de sensoriamento remoto. Todavia, há escassez de trabalhos que relatem a relação IAF-IV em regiões de clima subtropical. $O$ objetivo deste trabalho foi explorar a relação IAF-IV em uma microbacia rural de clima subtropical, para diferentes usos e coberturas do solo. A microbacia de estudo está localizada no município de Piracicaba, no Estado de São Paulo. O IAF foi estimado em 32 pontos de coleta, com o equipamento LAI-2000, em áreas de cana-de-açúcar, pastagem, milho, eucalipto e floresta ripária. Os IVs estudados neste trabalho foram SR, NDVI e SAVI, gerados a partir de dados do Landsat-7, sensor ETM+. Como resultados, tem-se que o menor e o maior valores de IAF medidos foram de 0,47 e 4,48. Os padrões das relações IAF-IVs foram similares, sendo que o modelo potencial foi o que mais adequadamente ajustou-se às relações. Observou-se que a relação IAF-NDVI (coeficiente de determinação $(R 2)=0,72)$ não diferiu estatisticamente da IAF-SR $(\mathrm{R} 2=0,70)$. O SAVI apresentou a menor correlação com o IAF $(\mathrm{R} 2=0,56)$. 


\section{Summary}

Leaf Area Index (LAI) has been associated to vegetation productivity and evapotranspiration in mathematical models. On a regional level, LAI can be estimated with enough accuracy, through spectral vegetation indices (SVIs), derived from remote sensing imagery. However, there are few studies showing LAI-SVIs relationship in subtropical regions. The objective of this work was to examine the relationship between LAI and SVIs in a subtropical rural watershed, in Piracicaba, State of São Paulo, Brazil, for different land covers. LAI was measured in 32 plots on the field, with LAI-2000 instrument, in areas of sugar-cane, pasture, corn, eucalypt, and riparian forest. The SVIs studied were Simple Ratio (SR), Normalized Difference Vegetation Index (NDVI), and Soil Adjusted Vegetation Index (SAVI), calculated from ETM+/Landsat-7 data. The results showed LAI values ranging from 0.47 to 4.48. LAI-SVIs relationships were similar for all vegetation types, and the potential model gave the best fit. It was observed that LAI-NDVI correlation (coeficient of determination $(R 2)=0.72$ ) was not statistically different from LAI-SR correlation $(\mathrm{R} 2=0.70)$. The worst correlation was obtained by LAI-SAVI $(\mathrm{R} 2=0.56)$.

\subsection{Introdução}

Desde que Watson (1947) propôs a variável biofísica Índice de Área Foliar (IAF= área foliar por área de superfície do solo), vários trabalhos vêm associando-a, por meio de modelos, à produtividade e à evapotranspiração (Larcher, 1975; Running \& Coughlan, 1988; Tiktak \& Grinsven, 1995). Para o cálculo da evapotranspiração e da produtividade, em nível regional, um dos instrumentos importantes são os dados de sensoriamento remoto, utilizados, por exemplo, para caracterizar o dossel (Running \& Coughlan, 1988). Vários trabalhos, visando aos cálculos de evapotranspiração e produtividade em menores escalas, utilizaram técnicas de sensoriamento remoto para estimar o IAF (Running et al., 1989; Moran et al., 1995; Franklin et al., 1997). 
Uma das maneiras de caracterizar o dossel, por meio de dados de sensoriamento remoto, é utilizando índices de vegetação (IVs) (Goel, 1989). Os IVs são dados obtidos de medidas radiométricas de vegetação, sendo utilizados para: avaliar variações temporais e espaciais de dados biofísicos, como o IAF (Best \& Harlan, 1985; Friedl et al., 1994; Curran \& Williamson 1995); calcular a fração da radiação fotossinteticamente ativa absorvida pelo dossel (Asrar et al., 1984; Wiegand et al., 1990; Epiphanio \& Huete, 1995); a percentagem ou fração de cobertura verde (Carlson \& Ripley, 1997; Purevdorj et al., 1998; McGwire et al., 2000); e a biomassa (Tucker, 1979; Cusack et al., 1999). A base física dos IVs é atribuída à alta absorção da radiação pelos pigmentos e ao seu espalhamento pelas folhas, nas regiões espectrais do vermelho e do infravermelho próximo, respectivamente (Gates et al., 1965; Liu \& Huete, 1995).

O IV Razão Simples (SR), baseado em estudo de Jordan (1969) para estimar o IAF, é um dos mais utilizados. O SR é calculado pela razão entre a reflectância nas regiões do infravermelho próximo (iVP, $\lambda \sim 0,8 \mu \mathrm{m}$ ) e vermelho (ver, $\lambda \sim 0,6 \mu \mathrm{m})$, ou seja, $\mathrm{SR}=i V P / v e r$. Outro importante IV é o "Normalized Difference Vegetation Index", ou seja, Índice de Vegetação da Diferença Normalizada, dado por: NDVI=(iVPver $) /($ iVP+ver $)$. Em áreas onde há considerável variação de brilho devida a diferenças de umidade, variações de rugosidade, sombra ou diferentes teores de matéria orgânica no solo, podem ocorrer mudanças no IV (Huete, 1988; Jackson \& Huete, 1991). Com a finalidade de minimizar tais problemas, Huete (1988) propôs um novo IV, chamando-o de "Soil-Adjusted Vegetation Index" (SAVI), ou seja, Índice de Vegetação Ajustado para Influência do Solo, dado por: $\mathrm{SAVI}=(1+\mathrm{L})(i V P-v e r) /(i V P+v e r+\mathrm{L})$, sendo $\mathrm{L}$ uma constante que varia com a quantidade de vegetação. Todavia, $\mathrm{L}=0,5$ seria um valor ótimo para um grande intervalo de condições da vegetação (Huete, 1988).

A estimativa do IAF, em campo, para as condições de clima subtropical, é escassa na bibliografia. Entender a dinâmica do IAF é o primeiro passo para aplicar modelos, em menor escala, para calcular a evapotranspiração e a produtividade. Não é possível desenvolver um algoritmo simples para estimar o IAF com acurácia e que seja 
válido para todos os locais (Gobron et al., 1997), pois ele depende das condições de solo e do tipo de vegetação, assim como a geometria sol-sensor.

O objetivo deste trabalho é avaliar a relação entre IAF e IVs, baseado em dados do sensor ETM+ do Landsat-7, em uma microbacia rural em região subtropical, onde o IAF, para diferentes usos e coberturas do solo, foi determinado com auxílio do equipamento LAI-2000.

\subsection{Material e métodos}

\subsection{1 Área de estudo}

A área de estudo foi a microbacia hidrográfica do Ribeirão dos Marins (Figura 2), com aproximadamente $5973 \mathrm{ha}$, situada entre as coordenadas $22^{\circ} 41^{\prime} \mathrm{S}$ e $22^{\circ} 51^{\prime} \mathrm{S}$, e $47^{\circ} 40^{\prime}$ W e $47^{\circ} 45^{\prime}$ W, no Município de Piracicaba, Estado de São Paulo. Esta bacia faz parte da Rede Hidrológica do Estado de São Paulo, operada pelo Departamento de Águas e Energia Elétrica e Centro Tecnológico de Hidráulica da Universidade de São Paulo. Nela estão instalados vários instrumentos para estudos hidrológicos, como estações pluviométricas e estação limnimétrica. $\mathrm{O}$ clima é Cwa, subtropical úmido, conforme classificação de Koeppen, com verão chuvoso e inverno seco, sendo de 1278 $\mathrm{mm}$ a precipitação média anual. As temperaturas médias mensais variam de $24,9^{\circ} \mathrm{C}$ no verão a $17,1^{\circ} \mathrm{C}$ no inverno, com média anual de $21,4^{\circ} \mathrm{C}$ (Sentelhas et al., 1.998). Os solos da região são representados por: Agrissolo Vermelho Amarelo, Agrissolo Vermelho, Latossolo Vermelho, Latossolo Vermelho-Amarelo, Neossolo e Nitossolo (Oliveira, 1999; EMBRAPA, 1999). O relevo varia de ondulado a fortemente ondulado (Teramoto, 1995). 


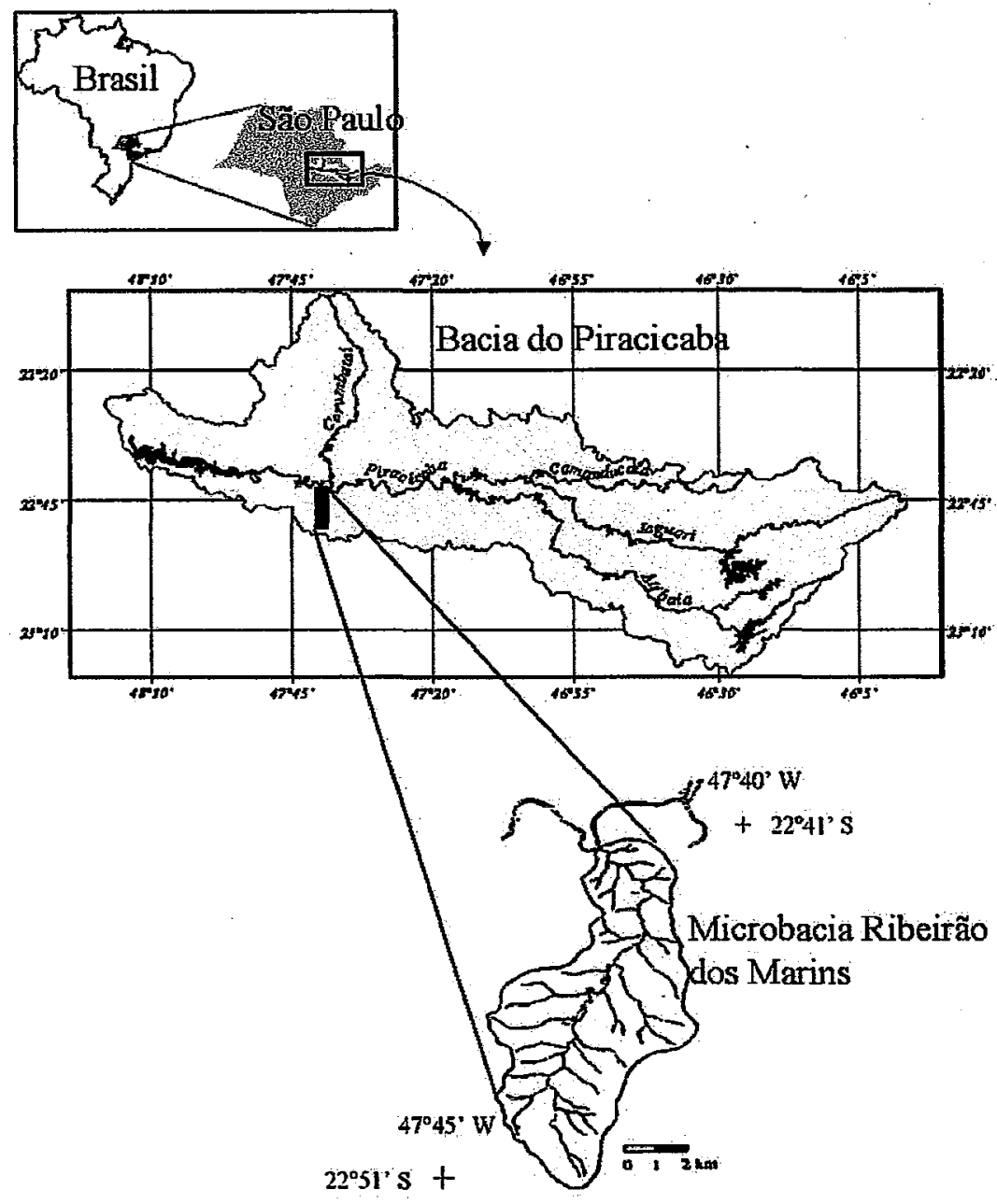

Figura 2 - Localização da área de estudo.

Adaptado: Projeto Piracena (2001).

O uso do solo na bacia é representado em grande parte por cana-de-açúcar (Saccharum spp.) e pastagens, apresentando também remanescentes de florestas, plantações de eucalipto (Eucalyptus spp.) e pequenas áreas com culturas anuais e horticultura (Figura 3). A cana-de-açúcar é cultivada na região em regime de sequeiro, tendo um ciclo que varia entre 12 e 18 meses, dependendo do manejo e época de plantio. Desta forma, para uma mesma época, pode-se encontrar a cana-de-açúcar em diferentes estádios de desenvolvimento, apresentando valores distintos de IAF. As áreas florestais são em sua grande parte remanescentes de floresta estacional semidecidual e floresta 
ripária (Rodrigues, 1999). Na microbacia em estudo, a floresta se limita quase que totalmente à floresta ripária, ocorrendo nas margens de cursos d'água, circundada ou pela cultura de cana-de-açúcar ou por pastagem. As espécies mais típicas presentes nas áreas de floresta ripária da região são: figueiras (Ficus spp.), louveira (Cylolobium vecchii A. Samp.), guanandi (Colophyllum brasiliensis Camb.), ingá (Inga affinis DC. Hook et Am), canela-do-brejo (Endlicheria paniculata (Spreng.) Macbr.) entre outras (Rodrigues, 1999). As plantações de eucalipto totalizam uma pequena área, de aproximadamente 15 ha, localizadas principalmente na porção superior da bacia.

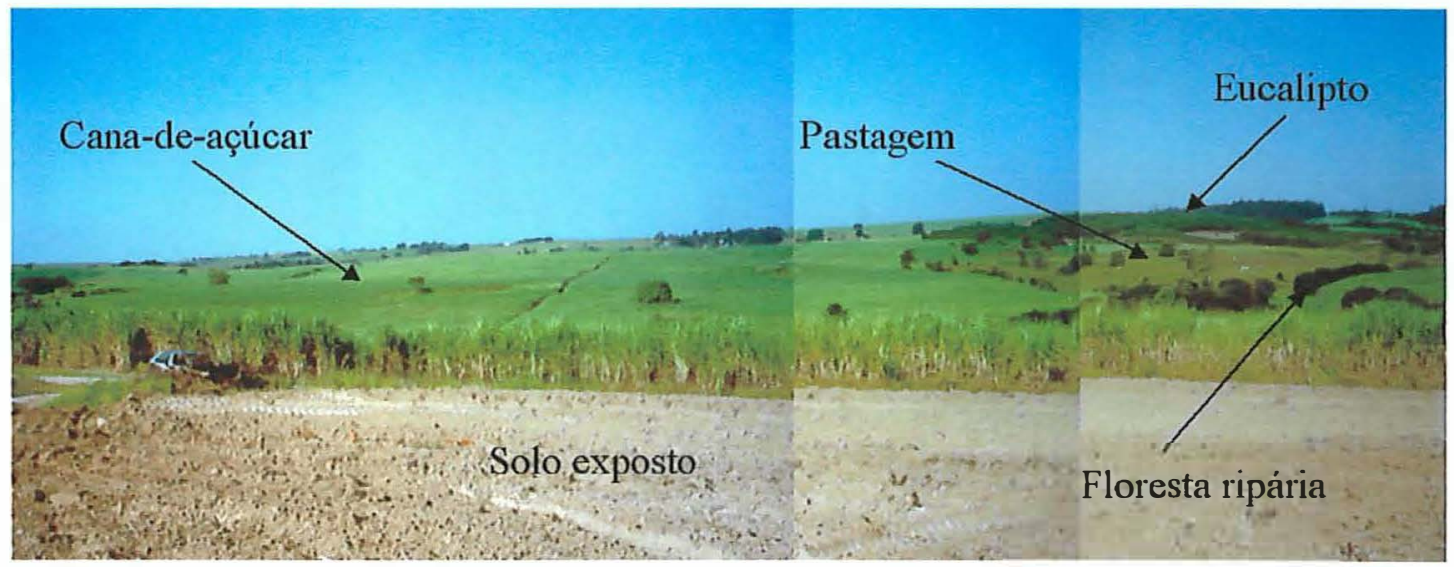

Figura 3 - Visão panorâmica da área de estudo, apresentando os diferentes usos e coberturas do solo.

As áreas para avaliação do IAF foram selecionadas de acordo com os seguintes critérios: representar os diversos usos e coberturas do solo existentes na bacia; apresentar características homogêneas, como vigor, altura e distribuição das plantas; ter tamanho compatível com a resolução espacial da imagem; e selecionar um número maior de amostras da cultura de cana-de-açúcar, pois esta apresenta a maior área de ocorrência e uma grande variabilidade nos valores de IAF para um mesmo período, devido às características próprias da cultura. 


\subsubsection{Estimativa do Índice de Área Foliar}

No presente estudo, utilizou-se o equipamento LAI-2000 (LI-COR, 1992) para determinar o IAF no campo. No cálculo da estrutura do dossel, o LAI-2000 faz uso da fração de abertura. A fração de abertura de um dossel é a fração de visão do céu em algumas direções abaixo do dossel. Medições da fração de abertura para uma certa gama de ângulos fornecem informação estrutural, como IAF e ângulo foliar (Welles, 1990).

O LAI-2000 utiliza um sensor de luz que mede a radiação difusa, simultaneamente, em 5 bandas angulares distintas $\left(0-13^{\circ}, 16-28^{\circ}, 32-43^{\circ}, 47-58^{\circ}\right.$ e $61-$ $\left.74^{\circ}\right)$. O sensor é constituído de cinco fotodiodos, cujas superfícies ativas estão arranjadas em anéis concêntricos. A imagem desta visão, quase-hemisférica, é projetada dentro destes anéis (Figura 4), permitindo, para cada intervalo angular, a medição da radiação na banda e no ângulo zenital conhecido. Um filtro óptico restringe a transmissão radiativa para comprimentos de onda menores que $490 \mathrm{~nm}$ (LI-COR, 1992).

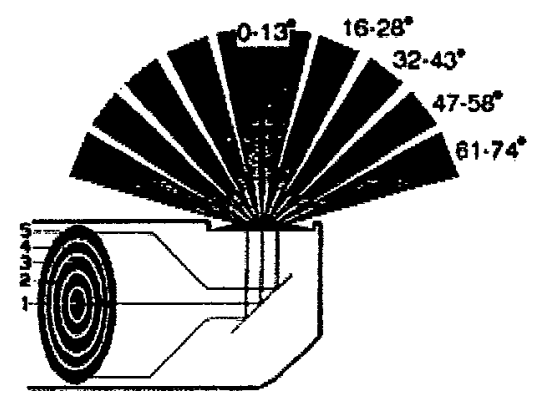

Figura 4 - Ângulos de visada e arranjo dos cinco detetores do LAI-2000.

FONTE: LI-COR (1992), p. 2-1.

Uma particularidade do LAI-2000 é a necessidade de se fazer uma leitura de referência externa ao dossel. Existe uma possibilidade de que as condições de iluminação do céu mudem entre a leitura de referência e a leitura abaixo do dossel, se o intervalo de tempo entre as medições for considerável. No entanto, podem-se utilizar dois equipamentos simultaneamente, um fora e outro no interior do dossel, eliminando este tipo de problema. Na prática, a fração de abertura em 5 ângulos zenitais pode ser 
medida realizando uma medição de referência externa ao dossel e uma ou mais leituras abaixo do dossel. A razão entre as leituras obtidas abaixo do dossel e as obtidas fora do dossel é usada para se obter uma estimativa da fração de abertura nos cinco ângulos.

A fração da radiação incidente, proveniente de uma fonte difusa, que passa através do dossel vegetal de espessura $S$, para cada ângulo de visada, pode ser expressa por:

$\frac{\text { Intensidade de radiação difusa abaixo do dossel no ângulo de visada } \theta}{\text { Intensidade de radiação difusa acima do dossel no ângulo de visada } \theta}=T(\theta)$

sendo $T(\theta)$ a probabilidade da não interceptação da radiação difusa para um dado ângulo de visada.

Quando um feixe de luz penetra num dossel, há uma chance de que este seja interceptado pela folhagem. A probabilidade da interceptação é proporcional ao comprimento do caminho percorrido, à densidade da folhagem, e está também relacionada com a orientação da folhagem. Se, no caminho de um feixe, os elementos foliares estiverem distribuídos de forma aleatória e forem pequenos quando comparados com a dimensão total do dossel, então um feixe na direção $(\theta, \phi)$ (descrita pelo ângulo zenital $\theta$ e ângulo azimutal $\phi$ ) tem a probabilidade de não interceptação de $T(\theta, \phi)$ dada pela Lei de Beer-Lambert:

$$
T(\theta, \phi)=\exp [-G(\theta, \phi) \mu S(\theta, \phi)]
$$

sendo: $G(\theta, \phi)$ a fração da folhagem projetada na direção $(\theta, \phi) ; \mu$ a densidade da folhagem (metro quadrado por metro cúbico); e $S(\theta, \phi)$ o comprimento do caminho (metros) de um extremo a outro do dossel na direção $(\theta, \phi)$. O sensor óptico LAI-2000 calcula a média sobre azimute. Pode-se reescrever a Equação (7) como: 


$$
G(\theta) \mu=-\frac{\ln (T(\theta))}{S(\theta)}=K(\theta)
$$

sendo $K(\theta)$ a freqüência de contatos entre os elementos foliares e a radiação, equivalente à probabilidade média do número de contatos por unidade de comprimento da trajetória do raio de luz no ângulo zenital $\theta$ (Welles, 1990; Welles \& Norman, 1991). O equipamento LAI-2000 assume que a função de distribuição angular é do tipo esférica, sendo $G(\theta)$ uma constante igual a $1 / 2$ nesta condição (Campbell \& Norman, 1989), logo:

$$
\mu=2 \int_{0}^{\pi / 2} \frac{-\ln (T(\theta))}{S(\theta)} \operatorname{sen} \theta d \theta
$$

A densidade foliar em todo dossel homogêneo está relacionada com a razão entre o IAF e a altura do dossel (z), enquanto que o comprimento do caminho $S$ é dado pela razão entre a altura do dossel e o ângulo zenital $\theta$, como mostram as Equações (10) e (11) abaixo:

$$
\begin{gathered}
\mathrm{IAF}=\mu z ; \\
S(\theta)=\frac{z}{\cos \theta} .
\end{gathered}
$$

Substituindo as Equações (9) e (11) em (10) temos:

$$
\mathrm{IAF}=2 \int_{0}^{\pi / 2}-\ln (T(\theta)) \cos \theta \operatorname{sen} \theta d \theta
$$

O LAI-2000 resolve a Equação (12) numericamente, desde que sempre se tenham fixado cinco ângulos zenitais, a qual toma a forma: 


$$
\mathrm{IAF}=2 \sum_{i=1}^{5} \frac{-\ln \left(T_{i}\right)_{1}}{S_{i}} W_{i}
$$

sendo: $T_{i}$ as 5 frações de abertura; $W_{i}$ os $\operatorname{sen} \theta d \theta$ para os cinco ângulos de visada do LAI-2000; e $S_{i}=1 / \cos \theta$.

O LAI-2000, como outros instrumentos de medição indireta, poderá superestimar o IAF de dosséis que contenham grande número de galhos mortos ou desfolhados. Este dado pode ser corrigido utilizando-se um fator de correlação entre o IAF calculado pelo LAI-2000 e o IAF calculado por um método direto (Gower \& Norman, 1991). Alguns estudos mostram que o equipamento LAI-2000, quando utilizado em áreas florestais, subestima o IAF, sendo sugerida a calibração do equipamento para as condições de uso local (Chen et al., 1991; Chason et al., 1991; Fassnacht et al., 1994; Hingston et al., 1998; Battaglia et al., 1998). A violação de algumas preposições para a utilização do equipamento LAI-2000 seria a causa desta subestimativa, como por exemplo, a não distribuição aleatória das folhas e/ou a sobreposição destas (Chen et al., 1991; Chason et al., 1991).

Para evitar subestimativa nas medidas de IAF, buscou-se realizar as medições em dias nublados e, quando isto não foi possível, as medições foram realizadas quando o ângulo de elevação solar era menor, ou seja, antes das 9 horas e depois das 16 horas, mantendo o sensor sempre sombreado. O número de repetições para cada tipo de uso do solo foi calculado pela metodologia da LI-COR (1992), sendo estabelecido para áreas de cana-de-açúcar, milho e pastagem o número de 16 repetições dentro e duas acima do dossel, enquanto que para floresta nativa e plantações de eucalipto foram 10 repetições abaixo e uma acima do dossel. Quanto à distribuição das medições de IAF sob dossel, em cana-de-açúcar e milho foram realizadas medições dentro do dossel variando a posição entre as linhas de plantio. A altura de medição nestas culturas variou de acordo com a presença de folhas senescentes, buscando-se evitá-las, elevando o sensor sempre acima destas. Nas plantações de eucalipto e em floresta nativa foram realizadas 10 
leituras espaçadas preferencialmente de $5 \mathrm{~m}$, uma de outra, a uma altura de aproximadamente $0,5 \mathrm{~m}$ do solo.

\subsubsection{Processamento da imagem}

A imagem utilizada foi do satélite Landsat-7, sensor ETM+ (base 220, ponto 76) gravada em 18 de janeiro de 2001, na mesma época da campanha de campo. A resolução da imagem foi reamostrada de $30 \mathrm{~m}$ para $25 \mathrm{~m}$. Nesta imagem foi realizada a correção geométrica no software SPRING (INPE, 1999), por meio de interpolador de primeiro grau de alocação de vizinho mais próximo, que atribui ao valor de nível de cinza (NC) do pixel da imagem corrigida, o mesmo valor do $\mathrm{NC}$ do pixel que se encontra mais próximo da posição a ser ocupada (Campbell, 1996; INPE, 1999). A projeção final do projeto foi UTM/SAD69. O erro final da correção foi de 0,5 pixel, ou seja, aproximadamente $12,5 \mathrm{~m}$.

As condições da atmosfera têm importância nas aplicações das técnicas do sensoriamento remoto, pois a informação refletida pelos alvos pode ser modificada quando percorre a atmosfera, podendo ser absorvida, refletida e espalhada, sendo que predomina na faixa do visível o espalhamento da luz (Slater et al., 1983). Logo, a atenuação dos efeitos atmosféricos é importante quando se realizam combinações lineares entre bandas (Myneni \& Asrar, 1994; Myneni et al., 1995), visto que o espalhamento atmosférico é uma função do comprimento de onda e há necessidade de se recuperar a resposta espectral do alvo. Portanto, os índices de vegetação SR, NDVI e SAVI, foram calculados a partir dos dados de valores de reflectância de superfície das bandas 3 e 4, gerados pelo modelo 6S (Vermote et al., 1997). O modelo 6S permite corrigir os efeitos atmosféricos de sensores em aeronaves e em satélites, levando em consideração a altura do alvo e do sensor e, realizando a correção: dos efeitos atmosféricos devido aos espalhamentos tipo Rayleigh e Mie, assim como a interação entre estes; e devido à absorção de gases $\left(\mathrm{O}_{2} ; \mathrm{O}_{3} ; \mathrm{H}_{2} \mathrm{O} ; \mathrm{CO}_{2} ; \mathrm{CH}_{4} ;\right.$ e $\left.\mathrm{N}_{2} \mathrm{O}\right)$. Os parâmetros de entrada utilizados no modelo $6 \mathrm{~S}$ foram: modelo de atmosfera tropical, modelo continental de aerossóis e visibilidade horizontal de $15 \mathrm{~km}$. Para cada um dos 32 
pontos onde se realizou a coleta de IAF em campo, foi adquirida a média de reflectância de uma janela de $2 \times 2$ ou $3 \times 3$ pixels de cada banda, de acordo com a forma e tamanho da área.

\subsubsection{Avaliação estatística das relações IVs-IAF}

Os modelos utilizados para estudar a relação entre IAF e IV ou reflectância de superfície das bandas individuais, neste trabalho, foram:

Linear: $\quad \quad \mathrm{Y}=a \mathrm{IAF}+b$

Potencial: $\quad \mathrm{Y}=a \mathrm{IAF}^{b}$

sendo, Y=IV (SR, NDVI e SAVI) ou reflectância de superfície das bandas individuais e, $a$ e $b$ são os parâmetros das equações. Esses modelos já foram utilizados em diversos trabalhos (Holben et al., 1980; Wiegand et al., 1990; Chen et al., 1996; Fassacht et al., 1997). A equação do tipo potência foi utilizada devido à natureza assintótica que as relações IAF-IV podem apresentar (Spanner et al., 1990; Nemani et al., 1993; Turner et al., 1999). Os modelos polinomial quadrático e cúbico não foram utilizados pois na análise preliminar dos dados não foi observada diminuição do NDVI com o aumento do IAF. Foi utilizada a análise de resíduo para identificar violação do modelo. A análise da melhor relação IAF-IV foi feita por meio do coeficiente de determinação (R2), $P$ (nível observado de significância) e do erro padrão (se).

\subsection{Resultados e discussão}

\subsubsection{Campanha de campo}

Os dados de IAF foram coletados entre os dias 15 e 20 de janeiro de 2001, sendo selecionadas 32 áreas, das quais $22 \mathrm{em}$ cana-de-açúcar, $3 \mathrm{em}$ pasto, $3 \mathrm{em}$ eucalipto, $2 \mathrm{em}$ milho e 2 em floresta ripária. Na Figura 5 é apresentado o resultado geral destas 
medições. $\mathrm{O}$ menor e o maior valores de IAF medidos em campo foram de 0,47 e 4,48 (Tabela 1), em áreas de cana-de-açúcar e floresta ripária, respectivamente.

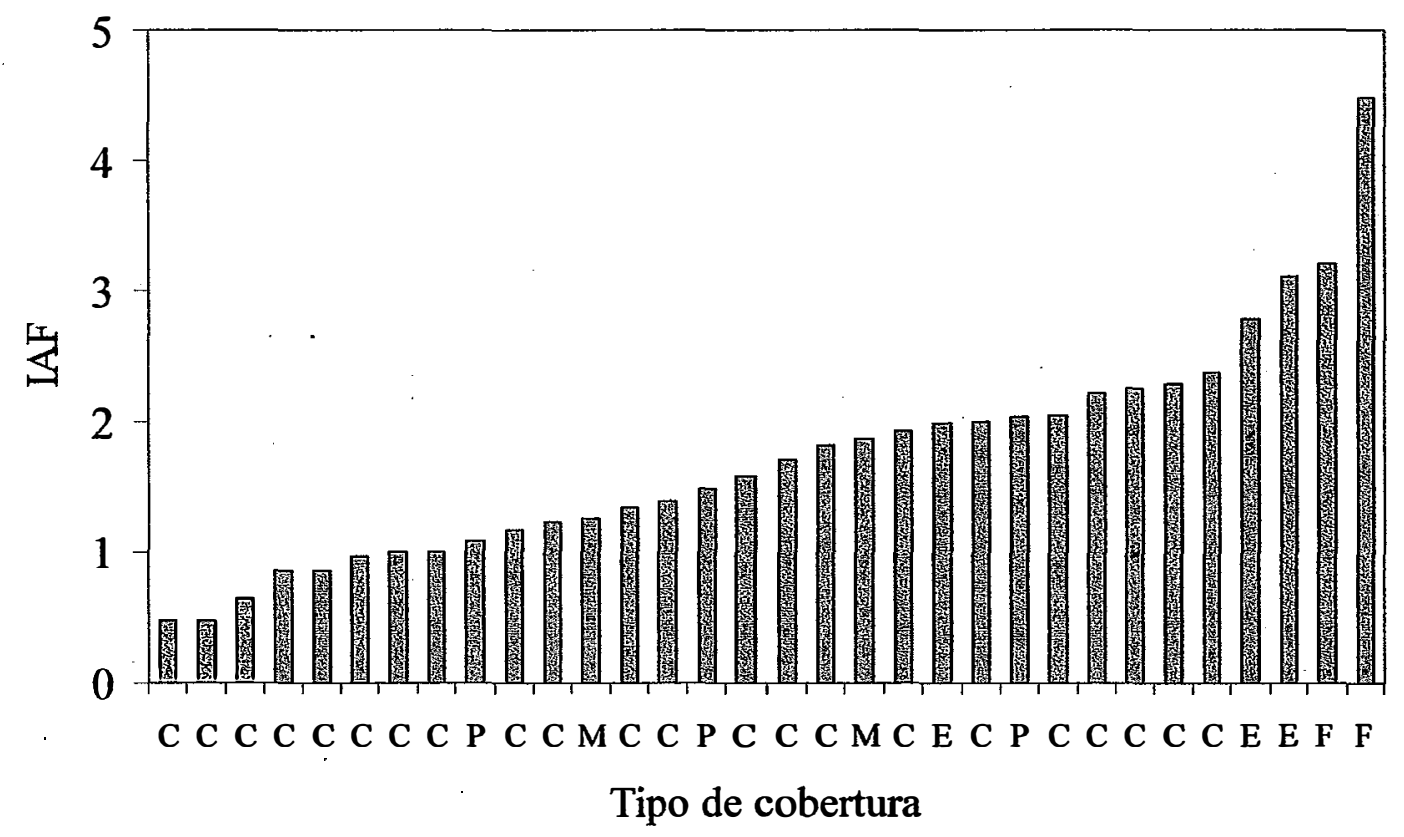

Figura 5 - Valores de IAF medidos em campo, sendo: C, cana-de-açúcar; P, pastagem; $\mathrm{M}$, milho; E, eucalipto; e F, floresta ripária. 
Tabela 1. Dados de: IAF, reflectância de superfície (ver e $i V P$ ) e índices de vegetação SR, NDVI e SAVI, para os diferentes tipos de cobertura do solo onde foi realizada a campanha de campo.

\begin{tabular}{lcccccc}
\hline Uso do solo & IAF & ver & $i V P$ & SR & NDVI & SAVI \\
\hline Cana-de-açúcar & 0,47 & 0,081 & 0,348 & 4,272 & 0,621 & 0,430 \\
Cana-de-açúcar & 0,47 & 0,064 & 0,292 & 4,605 & 0,643 & 0,401 \\
Cana-de-açúcar & 0,64 & 0,071 & 0,301 & 4,265 & 0,620 & 0,397 \\
Cana-de-açúcar & 0,86 & 0,084 & 0,351 & 4,180 & 0,614 & 0,429 \\
Cana-de-açúcar & 0,86 & 0,081 & 0,310 & 3,829 & 0,586 & 0,385 \\
Cana-de-açúcar & 0,97 & 0,066 & 0,334 & 5,102 & 0,672 & 0,448 \\
Cana-de-açúcar & 1,01 & 0,055 & 0,351 & 6,359 & 0,728 & 0,489 \\
Cana-de-açúcar & 1,01 & 0,061 & 0,352 & 5,749 & 0,704 & 0,478 \\
Cana-de-açúcar & 1,18 & 0,050 & 0,302 & 6,072 & 0,717 & 0,445 \\
Cana-de-açúcar & 1,24 & 0,069 & 0,342 & 4,960 & 0,664 & 0,449 \\
Cana-de-açúcar & 1,34 & 0,045 & 0,322 & 7,195 & 0,756 & 0,480 \\
Cana-de-açúcar & 1,39 & 0,077 & 0,368 & 4,788 & 0,654 & 0,462 \\
Cana-de-açúcar & 1,58 & 0,062 & 0,353 & 5,722 & 0,702 & 0,478 \\
Cana-de-açúcar & 1,71 & 0,037 & 0,368 & 9,904 & 0,817 & 0,548 \\
Cana-de-açúcar & 1,82 & 0,055 & 0,369 & 6,742 & 0,742 & 0,511 \\
Cana-de-açúcar & 1,93 & 0,050 & 0,369 & 7,412 & 0,762 & 0,521 \\
Cana-de-açúcar & 2,00 & 0,041 & 0,345 & 8,443 & 0,788 & 0,515 \\
Cana-de-açúcar & 2,05 & 0,046 & 0,347 & 7,469 & 0,764 & 0,505 \\
Cana-de-açúcar & 2,22 & 0,032 & 0,358 & 11,364 & 0,838 & 0,551 \\
Cana-de-açúcar & 2,25 & 0,035 & 0,359 & 10,308 & 0,823 & 0,544 \\
Cana-de-açúcar & 2,29 & 0,055 & 0,373 & 6,833 & 0,745 & 0,515 \\
Cana-de-açúcar & 2,37 & 0,052 & 0,376 & 7,230 & 0,757 & 0,523 \\
Pastagem & 1,09 & 0,044 & 0,358 & 8,150 & 0,781 & 0,523 \\
Pastagem & 1,49 & 0,046 & 0,383 & 8,333 & 0,786 & 0,544 \\
Pastagem & 2,03 & 0,044 & 0,340 & 7,756 & 0,772 & 0,503 \\
Milho & 1,26 & 0,066 & 0,353 & 5,381 & 0,687 & 0,469 \\
Milho & 1,86 & 0,042 & 0,370 & 8,779 & 0,795 & 0,539 \\
Floresta ripária & 3,21 & 0,028 & 0,339 & 11,964 & 0,846 & 0,538 \\
Floresta ripária & 4,48 & 0,019 & 0,333 & 17,772 & 0,893 & 0,553 \\
Eucalipto & 3,11 & 0,024 & 0,258 & 10,810 & 0,831 & 0,449 \\
Eucalipto & 1,99 & 0,027 & 0,280 & 10,290 & 0,823 & 0,470 \\
Eucalipto & 2,78 & 0,016 & 0,304 & 19,527 & 0,903 & 0,528 \\
\hline & & & & & & \\
& & & & & & \\
& & 0.753 &
\end{tabular}




\subsubsection{Relação entre IAF e bandas individuais (ver e $i V P$ )}

$\mathrm{Na}$ Figura 6 é apresentada a relação IAF-ver para todas as amostras, sendo esta relação estatisticamente significativa. As reflectâncias das áreas onde foram coletados dados de IAF variaram de 0,016 a 0,084 (Tabela 1). A relação foi do tipo linear inversa (ver $=-0,0169 \mathrm{IAF}+0,0796, \mathrm{R} 2=0,64, P<0,01 ; s e=0,01)$, devendo-se à absorção da radiação pelos pigmentos das folhas. A explicação da variável ver pelo IAF em outros trabalhos é variável. Peterson et al. (1987) encontraram alta correlação ( $R 2=0,89$, modelo potencial, dados de radiância) em florestas de coníferas; Holben et al. (1980) encontraram R2=0,57 (modelo linear, em soja); enquanto Epiphanio et al. (1997), em cultura de trigo, encontraram $\mathrm{R} 2=0,29$ (modelo linear). Neste trabalho não foi observada saturação de ver em relação ao IAF.

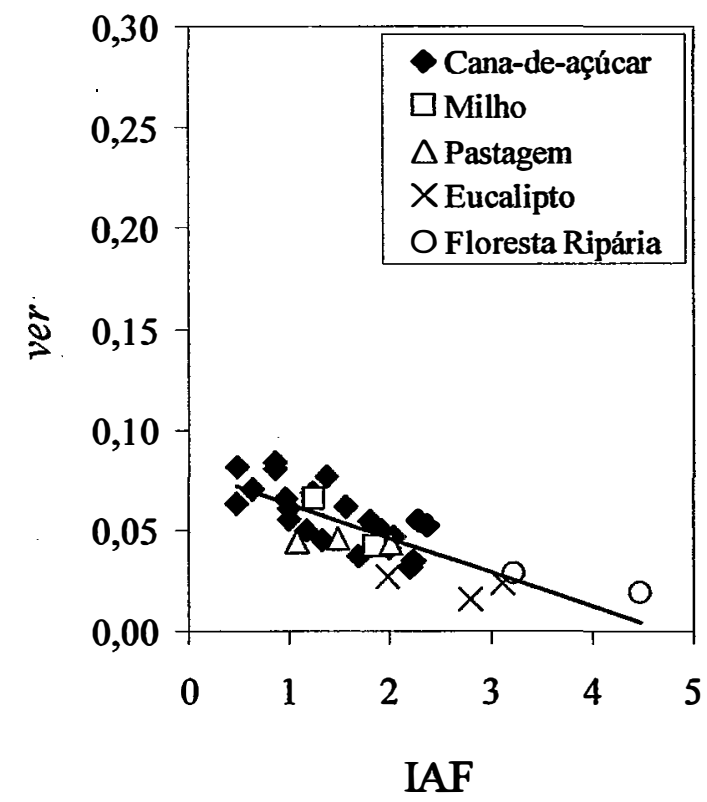

Figura 6 - Relação entre IAF de todas as amostras e a reflectância de superfície da banda do ver (TM3).

A relação IAF-iVP para todas as amostras é mostrada na Figura 7. Os valores de reflectância de superfície estiveram entre 0,258 e 0,383, apresentando uma amplitude de 
valores um pouco maior que a amplitude de encontrada para ver; todavia, não foi observada relação significativa entre IAF e $i V P$. A resposta espectral de $i V P$ nas áreas florestais (floresta ripária e eucalipto), tende a ser menor quando comparada às espécies não florestais (cana-de-açúcar, pastagem e milho), para os valores de IAF estimados. Sabe-se que a estrutura do dossel (IAF, altura, tamanho das folhas, distribuição do ângulo foliar etc.) afeta as propriedades espectrais do alvo (Asrar et al., 1985; Bouman, 1992; Myneni et al. 1995; Myneni et al., 1997). Desta forma, duas são as possibilidades de explicação sugeridas neste trabalho para os menores valores de iVP nas áreas florestais: i) folhas com comportamentos espectrais distintos neste comprimento de onda; e ii) maior possibilidade de sombreamento no dossel devido à sua estrutura. Realizando a separação entre áreas florestais e não florestais, a relação IAF-iVP foi não significativa nas áreas florestais e significativa, embora com baixo R2 (R2 $=0,36$, $P<0,01$, $s e=0,02$ ), nas áreas não florestais. Baixo R2 entre IAF e iVP também foi observado em outros trabalhos, por exemplo, Peterson et al. (1987), R2=0,04, em florestas de coníferas, e Nemani et al. (1993), R2=0,40, em área florestal, ambos com dados de radiância. Peterson et al. (1987) sugerem que a baixa relação pode ser explicada pela organização espacial do dossel e a forma característica das acículas das coníferas. 


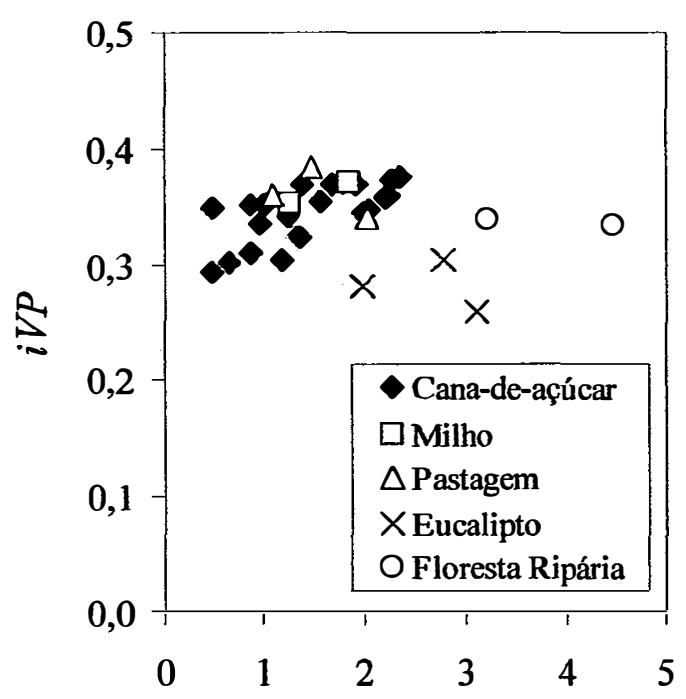

$\mathrm{IAF}$

Figura 7 - Relação entre IAF de todas as amostras e a reflectância de superfície da banda do $i V P$ (TM4).

\subsubsection{Relação entre IAF e IVs (SR, NDVI e SAVI)}

As Figuras 8a, 8b e 8c, mostram a relação entre o IAF e os IVs: SR; NDVI; e SAVI, respectivamente. $O$ padrão geral das curvas foi similar. $O$ modelo potencial apresentou ajuste mais adequado às relações IAF-IVs (Tabela 2). Observa-se, principalmente nas relações IAF-NDVI e IAF-SAVI, que o NDVI e SAVI aumentam mais rapidamente para menores valores de IAF e tendem a se estabilizar para maiores valores deste índice. Tal comportamento, nesta faixa de variação de IAF, tambẻm foi observado por outros autores para as relações: IAF-SR (Peterson et al., 1987); IAFNDVI (Holben et al., 1980); e IAF com SR, NDVI e SAVI (Turner et al., 1999). Os

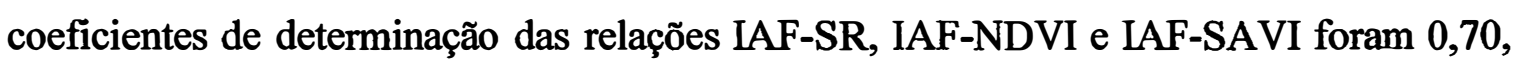
0,72 e 0,56 (Tabela 2), respectivamente. Estes resultados mostram que o NDVI, por exemplo, pode estimar o IAF com um se de aproximadamente $0,56 \mathrm{~m}^{2} / \mathrm{m}^{2}$. Epiphanio \& Huete (1995) observaram que a introdução do fator L no NDVI, faz com que o SAVI se torne menos sensível a alterações do ver e mais sensível a alterações do iVP. Como não houve relação IAF-iVP e, tendo o ver relação significativa com o IAF, seria de se 
esperar uma menor relação do IAF com SAVI e uma maior relação com o NDVI, conforme apresentado neste trabalho. $O$ índice de vegetação SR pode ser calculado como uma simples função do NDVI, sem informação adicional (Perry \& Lautenshlager, 1984), isto é, $\mathrm{SR}=f(\mathrm{NDVI})=(1+\mathrm{NDVI}) /(1-\mathrm{NDVI})$, assim, espera-se uma forte relação entre estes. Tal fato foi verificado neste trabalho, onde não houve diferença significativa entre os R2 das relações IAF-SR e IAF-NDVI. Logo, a mesma acurácia para estimar o IAF é esperada nestas relações.

O maior valor de IAF estimado neste trabalho foi de 4,63, não sendo observada saturação dos IVs, embora as relações tendam a ser assintóticas a partir de IAF $>3,00$, fato consistente com outras observações. Para Chen \& Cihlar (1996), por exemplo, a saturação dos IVs em culturas agrícolas e florestais ocorreria, aproximadamente, em IAF de 2,50 e de 5,00, respectivamente. Já Turner et al. (1999) observaram que a saturação ocorreu em IAF entre 3,00 e 5,00, em vegetação de clima temperado. 


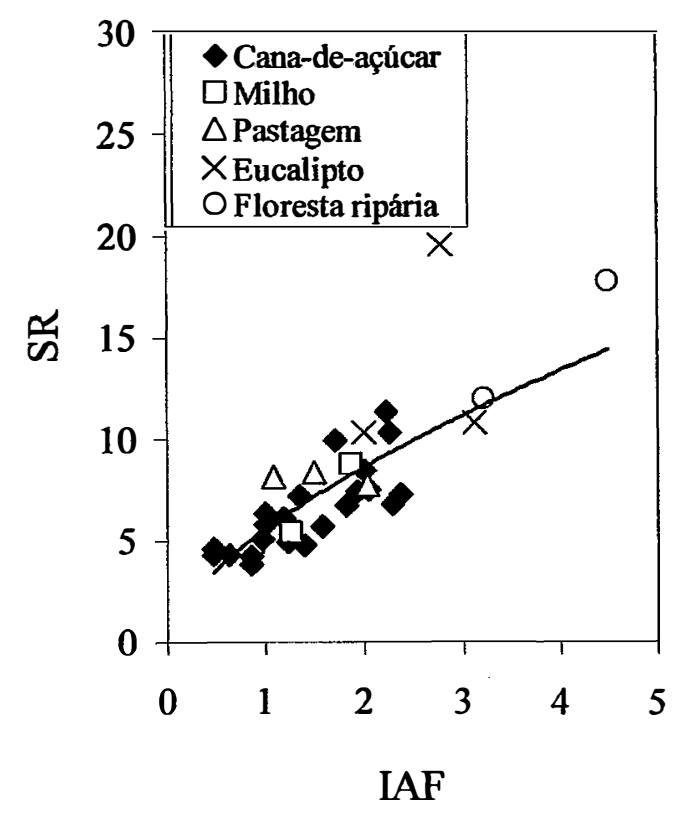

(a)

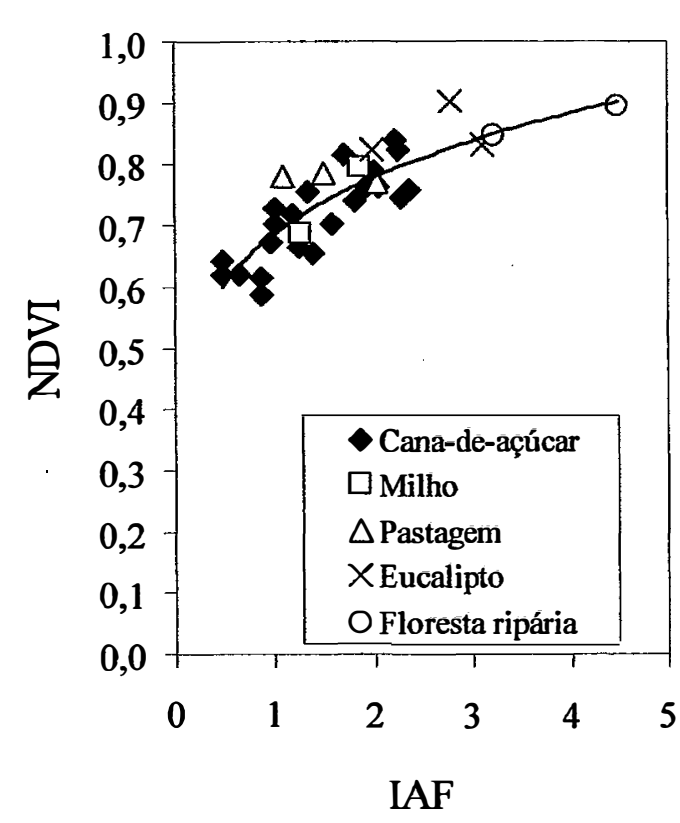

(b)

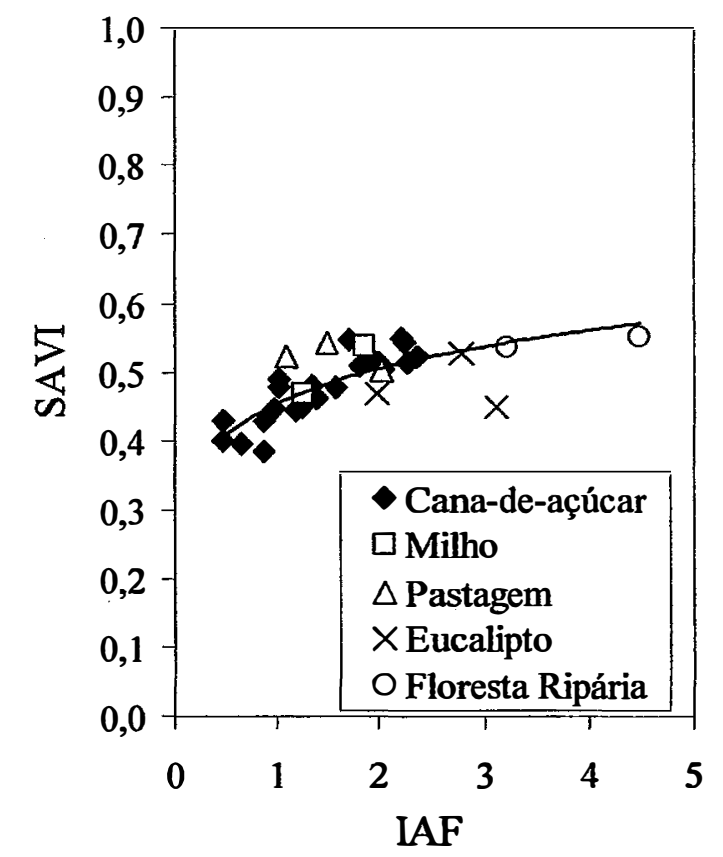

(c)

Figura 8 - Diagramas de dispersão de todos os dados de IAF e: SR (a); NDVI (b); e SAVI (c). 
Tabela 2. Modelos para as relações IAF e índices de vegetação.

$\begin{array}{llccc}\text { Fig. } & \text { Modelo } & \mathrm{R} 2 & P & s e \\ \text { 8(a) } & \mathrm{SR}=5,5622 \mathrm{IAF}^{0,6328} & 0,70 & <0,01 & 0,22 \\ \text { 8(b) } & \mathrm{NDVI}=0,6869 \mathrm{IAF}^{0,1809} & 0,72 & <0,01 & 0,06 \\ \text { 8(c) } & \mathrm{SAVI}=5,5622 \mathrm{IAF}^{0,6328} & 0,56 & <0,01 & 0,07\end{array}$

\subsection{Conclusões}

A conclusão geral deste trabalho foi que os índices de vegetação obtidos a partir de imagens Landsat podem ser utilizados com sucesso na determinação do IAF para diferentes usos e coberturas do solo na área de estudo. Como conclusões específicas têm-se:

i) a banda ver apresentou relação significativa $(\mathrm{R} 2=0,64)$ com o IAF, enquanto $i V P$ não apresentou relação com todos os dados de IAF, exceto se forem consideradas separadamente áreas não florestais $(\mathrm{R} 2=0,22)$. Assim, o ver tem maior influência sobre os IVs para explicar o IAF;

ii) o IV que apresentou melhor relação com o IAF foi o NDVI, sendo que SR não diferiu significativamente do NDVI, e o SAVI, por ser mais sensível ao $i V P$, apresentou a pior relação. 


\section{RELAÇÃo do ÍNDICE DE ÁREA FOLIAR COM AS FRAÇÕES DE COMPONENTES PUROS E COM O NDVI}

\section{Resumo}

O objetivo deste trabalho foi analisar a relação do Índice de Área Foliar (IAF) com o Índice de Vegetação da Diferença Normalizada (NDVI) e com frações de componentes puros estimados pelo Modelo Linear de Mistura Espectral (MLME). A área de estudo foi a microbacia do Ribeirão dos Marins, em Piracicaba, SP. O IAF foi medido em 32 pontos no campo, para diferentes coberturas do solo. O NDVI e os componentes puros foram obtidos de imagem Landsat/ETM+, corrigida para os efeitos atmosféricos por meio do modelo $6 \mathrm{~S}$. Três componentes puros foram considerados na imagem: vegetação, solo e sombra. A relação IAF-NDVI apresentou maior coeficiente de determinação ( 0,72 contra 0,56 da fração do componente puro solo). As relações entre IAF de cana-de-açúcar e frações de componente puro vegetação e solo mostraram melhores ajustes, contudo, similares à relação IAF de cana-de-açúcar e NDVI. Estes resultados indicam que a fisionomia vegetal teve grande influência no MLME e a estratificação pela fisionomia vegetal é sugerida para melhorar a estimativa do IAF. A relação do IAF com fração de componente puro sombra não foi significativa. 


\section{Summary}

The objective of this work was to analyze the relationship between Leaf Area Index (LAI) and Normalized Difference Vegetation Index (NDVI) and endmember fractions estimated through the Linear Spectral Mixture Modelling (LSMM). The study area was an agricultural watershed in Piracicaba, State of São Paulo, Brazil. LAI was measured in 32 plots in the field with different land covers. The NDVI and the endmember fractions were obtained from a Landsat/ETM+ image, corrected for the atmospheric effects through the $6 \mathrm{~S}$ model. Three endmembers were considered in the LSMM: vegetation, soil, and shadow. LAI-NDVI relationship showed the best R2 ( 0.72 against 0.56 from soil fraction). The relationship between only sugar-cane LAI and $\mathrm{F}_{\mathrm{VG}}$ and $F_{\text {SO }}$ showed a better fit, although similar to the relationship sugar-cane LAI and NDVI. Those results indicated that vegetation physiognomy has greater influence on the LSMM and the stratification by vegetation physiognomy is suggested in order to improve the LAI estimation. Relationship between LAI and shadow fraction was not statistically significant.

\subsection{Introdução}

Nestas últimas décadas o meio ambiente tornou-se motivo de grande preocupação para a humanidade, uma vez que as interferências antrópicas têm provocado sérias alterações nos ecossistemas. Como exemplo, as alterações no uso do solo e/ou a sua utilização inadequada em uma bacia hidrográfica (p.ex.: ausência de terraceamento e de proteção das margens de rios) podem provocar o assoreamento dos rios, pois promovem mudanças em suas propriedades hidrológicas, fazendo com que ela fique mais susceptível a fenômenos como enchentes e desertificação, além de causar um desequilíbrio para as espécies de animais e vegetais que ali vivem.

Os recursos naturais, como a água e o solo, também encontram-se ameaçados em sua sustentabilidade em várias regiões do planeta. A água em particular, tem-se tornado um recurso cada vez mais escasso, tanto para áreas urbanas quanto rurais, daí a 
necessidade de técnicas cada vez mais aprimoradas para avaliar sua circulação e ocorrência (p.ex.: água infiltrada, escoamento superficial e evapotranspiração). No ciclo hidrológico, a perda de água por evapotranspiração tem grande importância, tomemos como exemplo ilustrativo o continente norte-americano, onde aproximadamente $30 \%$ da água é drenada superficialmente ou percolada para o subsolo, enquanto os outros $70 \%$ retornam para a atmosfera, na forma direta de evaporação e transpiração (Rosenberg et al., 1983).

A variável biofísica Índice de Área Foliar (IAF), total de área foliar por área de superfície (Watson, 1947), está diretamente relacionada com a evapotranspiração (Rosenberg et al., 1983; Lang \& McMurtrie, 1992), sendo a principal variável de entrada descritora da vegetação em modelos para este cálculo (Running \& Coughlan, 1988; Tiktak \& Grinsven, 1995). O IAF também está relacionado com a capacidade de interceptação da chuva pelo dossel, sendo que esta freqüentemente aumenta com maiores valores de IAF (Kergoat, 1998; Dijk \& Bruijnzeel, 2001).

Plummer (2000) fez uma revisão sobre a perspectiva da combinação de modelos de processos ecológicos e dados de sensoriamento remoto, onde estes dados poderiam ser utilizados para guiar os modelos ecológicos. Os dados derivados de sensores remotos seriam, por exemplo, variáveis metereológicas e aqueles relacionados com a vegetação (p.ex.: IAF; fração de cobertura; altura etc.). Pode-se citar como exemplo Running et al. (1989) que, para calcular a evapotranspiração e a produtividade, utilizou dados de sensoriamento remoto para estimar o IAF.

Técnicas de sensoriamento remoto têm se mostrado um instrumento viável para se obter o IAF de maneira rápida e em escala regional, com nível aceitável de exatidão. Uma das formas mas simples de relacionar dados de sensoriamento remoto e IAF é por meio de índices de vegetação (Best \& Harlan, 1985; Running et al., 1986; Tumer et al., 1999). A base física destes índices é atribuída à alta absorção da radiação pelpelos pigmentos e ao seu espalhamento pelas folhas, nas regiões do vermelho (ver) e do infravermelho próximo (iVP), respectivamente (Gates et al., 1965). Um dos índices de 
vegetação que é amplamente utilizado é o NDVI, porém este índice é sensível às variações do substrato (Huete, 1998). Frações de componentes puros (FCPs), oriundos de modelo linear de mistura espectral (MLME), mostraram ser menos sensíveis a variações de substrato que o NDVI para estimar o IAF (García-Haro et al., 1996), assim como apresenta menor dependência do ângulo zenital solar (Hall et al., 1995a), podendo desta forma ser um método mais eficaz de estimativa desta variável.

Quando fótons interagem com um simples componente dentro do campo de visada do sensor, a mistura pode ser modelada como a soma de cada componente, mas quando fótons são espalhados e interagem com múltiplos componentes, como espalhamento pelas folhas da radiação no comprimento de onda $i V P$, a mistura tem um potencial de tornar-se não linear (Roberts et al., 1993; Borel \& Gerstl, 1994), sendo que modelos não lineares podem ser utilizados para estimar a fração de cada componente do alvo (Ray \& Murray, 1996). Considerando o espalhamento múltiplo desprezível (Roberts et al., 1998), pode-se aplicar o MLME, onde uma relação linear é usada para representar a mistura espectral de alvos dentro do elemento de resolução da imagem (pixel) do sensor remoto. As imagens fração de componentes puros considerados no MLME vêm sendo utilizadas para: identificar diferentes fases de plantios de eucalipto e diferentes espécies de pinheiros (Hlavka \& Spanner, 1995; Shimabukuro \& Smith, 1995); correlacioná-las a variáveis biofísicas (Hall et al., 1995a; Bernardes, 1996); identificar e mapear feições de degradação da terra relacionadas com processo de erosão do solo (Metternicht \& Fermat, 1998); classificar imagens (Novo \& Shimabukuro, 1997; Adams et al., 1995; CasalsCarrasco et al., 2000); mapear desflorestamento (Shimabukuro et al., 1994); estimar abundância de vegetação em área urbana (Small, 2001); e interpretar dados geológicos (Adams et al., 1986).

Neste trabalho, uma missão de coleta de dados de IAF foi realizada em uma microbacia rural, para diferentes usos e coberturas do solo, e esses dados foram analisados e relacionados com frações de componentes puros do MLME e com o NDVI, gerados a partir de dados do sensor ETM+ do satélite Landsat-7, da mesma época da campanha de campo. 


\subsection{Material e métodos}

\subsection{1 Área de estudo e dados de IAF}

A área de estudo foi a microbacia do Ribeirão dos Marins (item 3.2.1) e a metodologia para a determinação do IAF apresentada no item 3.2.2.

\subsubsection{Processamento da imagem}

A imagem utilizada foi do satélite Landsat-7, sensor ETM+ (base 220, ponto 76) gravada em 18 de janeiro de 2001, na mesma época da campanha de campo. Foi feita a correção geométrica da imagem, e a reflectância de superfície foi estimada a partir do modelo 6S (Vermote et al. (1997), ver item 3.2.3). Para cada um dos 32 pontos onde se realizou a coleta de dados de IAF em campo, foi adquirida a média de valores de reflectância de superfície (ver e iVP) e das FCPs de uma janela de $2 \times 2$ ou $3 \times 3$ pixels, de acordo com a forma e o tamanho da área.

\subsubsection{Geração do NDVI}

O NDVI foi obtido por meio dos valores médios para as janelas de reflectância de superfície das bandas TM3 (ver) e TM4 (iVP), sendo este índice dado por:

$$
\mathrm{NDVI}=(i V P-v e r) /(i V P+v e r)
$$

\subsubsection{Geração das frações dos componentes puros}

A resposta de cada pixel em qualquer comprimento de onda pode ser considerada como uma combinação linear das respostas de cada componente da mistura. Deste modo, cada pixel contém informações sobre a fração e a resposta espectral de cada componente dentro da resolução unitária do terreno (Shimabukuro \& Smith, 1991), podendo desta forma aplicar-se o MLME, conforme: 


$$
r_{i}=\sum_{j=1}^{n}\left(a_{i j} x_{j}\right)+e_{i}
$$

sendo: $r_{i}$ a reflectância de superfície de um pixel, para a $i$-ésima banda espectral; $a_{i j}$ a reflectância do $j$-ésimo componente puro do pixel para a i-ésima banda espectral; $x_{j}$ a fração do j-ésimo componente puro no pixel; $e_{i}$ o resíduo da modelagem para a i-ésima banda espectral; $j=1,2,3, \ldots, n$ (índice de componentes); $i=1,2,3, \ldots, m$ (índice de bandas espectrais consideradas).

Cada um dos valores, $\boldsymbol{r}_{i}$ e $a_{i j}$, são admitidos como conhecidos. O termo $x_{j}=0$ determina a ausência deste componente e o valor $x_{j}=1$ indica que o pixel contém apenas o componente puro considerado. Para estimar a FCP $\left(x_{j}\right)$ do MLME, utilizam-se vários métodos, tais como: método dos mínimos quadrados com restrições e dos mínimos quadrados ponderados (Shimabukuro, 1991), e componentes principais (Adams et al., 1986). Neste trabalho, a estimativa das FCPs foi feita pela metodologia dos mínimos quadrados com restrições, baseada na minimização da função $\mathrm{F}=\sum_{i=1}^{m} e_{i}^{2}$, sendo que $m$ corresponde ao número de bandas espectrais do sensor ETM+. Maiores detalhes desta solução podem ser encontrados em Shimabukuro \& Smith (1991).

Segundo Shimabukuro \& Smith (1995), após estimadas as frações por um dos métodos citados anteriormente, é possível calcular o erro médio das estimativas para cada pixel (Equação 18) e o erro médio da imagem (Equação 19). O erro médio da imagem indica quão bem a variabilidade espectral foi explicada com os componentes puros selecionados, sendo utilizado para avaliar a acurácia do mapeamento da superfície.

$$
\text { Erro médio }=\sum\left|e_{i}\right| / m
$$

sendo: $m$ o número de bandas espectrais; $k$ o k-ésimo pixel; e $e_{i}=r_{i}-\sum_{j=1}^{n}\left(a_{i j} x_{j}\right)$. Desta forma o erro médio da imagem é dado por: 
Erro médio da imagem $=\sum_{k=1}^{n}$ Erro $_{\text {médio }} / n$,

em que $n$ é o número total de pixels.

Os valores de reflectância atribuídos aos componentes puros (CPs) podem ser provenientes de bibliotecas espectrais (Smith et al., 1991) e, mais freqüentemente, podem ser selecionados diretamente de pixels que compõem a própria cena por meio de composições coloridas (Adams et al., 1995) ou pelo método baseado em componentes principais (Metternicht \& Fermont, 1998). García-Haro et al. (1999) propõem mais três métodos: a) método que consiste na dedução da melhor rotação possível do eixo do fator abstrato para alinhá-lo na direção real do componente puro; b) método baseado na posição de todos os dados num espaço reduzido; e c) método baseado em redes neurais, cuja arquitetura implementa os princípios do MLME.

Neste trabalho, a seleção dos CPs foi realizada com o auxílio do diagrama de dispersão entre componentes principais (PC) (Sharma, 1996; Johnson \& Wichern, 1998) 1 e 2 (PC1 e PC2) gerados com as 6 bandas de reflectância de superfície. Os dois primeiros $\mathrm{PC}$ 's, $\mathrm{PCl}$ e PC2, explicaram $97 \%$ da variação total da imagem. Os CPs foram selecionados nos vértices do diagrama de dispersão (Figura 9) e as suas referências espectrais (Figura 10) adquiridas em consulta às bandas originais da imagem para $o$ pixel selecionado. Desta forma, obtiveram-se $3 \mathrm{CPs}$ referentes à vegetação, ao solo e à sombra. Por meio da inspeção na imagem dos CPs selecionados e do padrão das suas respectivas curvas espectrais, observaram-se: a) o CP sombra correspondeu à área de água, localizada no rio Piracicaba, e o padrão da resposta espectral foi de baixos valores de reflectância tanto na faixa espectral do visível como na do infravermelho; b) o CP solo foi localizado em área de solo exposto, sendo sua resposta espectral a maior, na faixa do visível, quando comparada aos demais $\mathrm{CPs}$; e c) o $\mathrm{CP}$ vegetação correspondeu à área de cana-de-açúcar verde e sadia com baixos valores de reflectância de superfície na faixa do visível, devido à absorção da radiação pelos pigmentos nesta faixa e alto valor de reflectância na faixa do $i V P$, devido ao espalhamento múltiplo da radiação pelas folhas do dossel. 


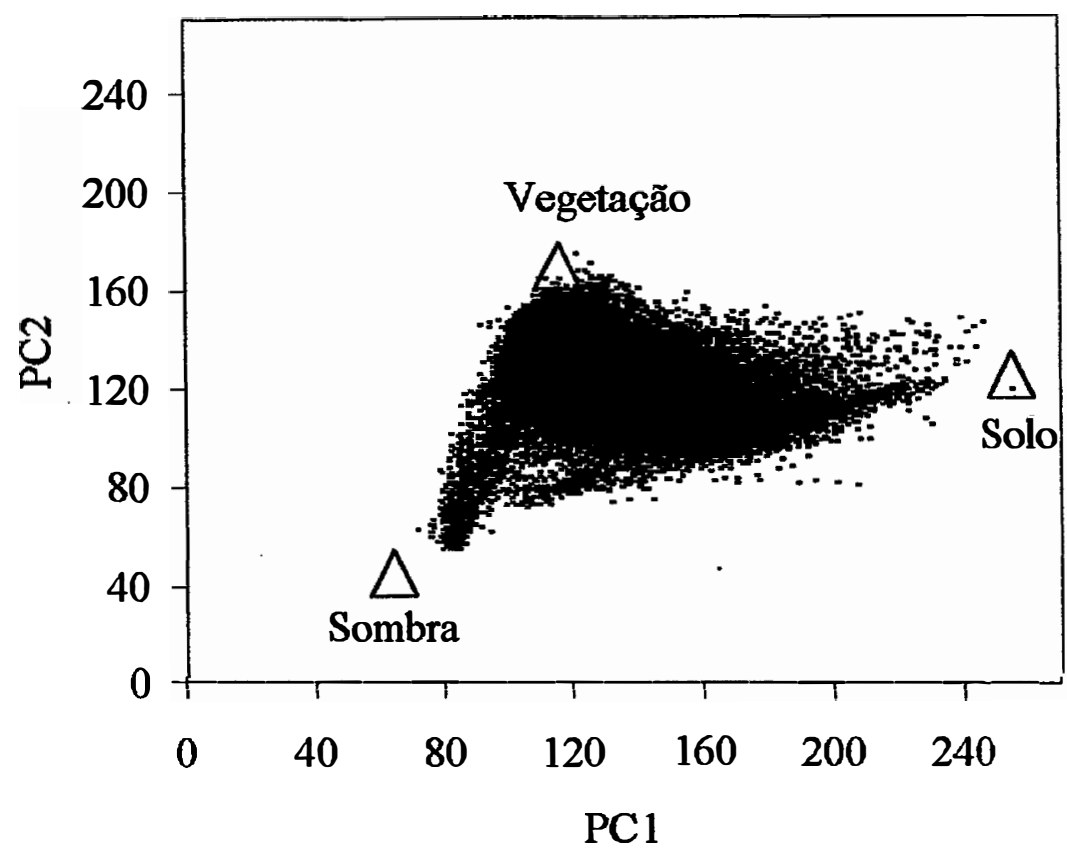

Figura 9 - Diagrama de dispersão dos componentes principais 1 e 2 (com 64000 pixels), sendo $\Delta$ os componentes puros localizados nos vértices deste.

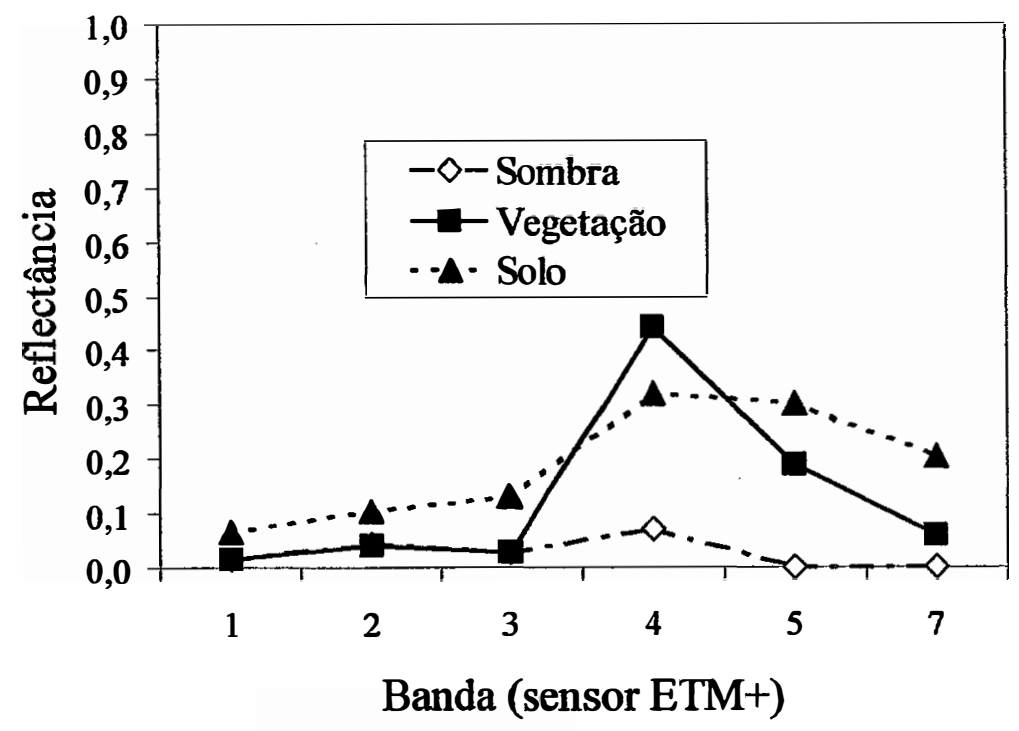

Figura 10 - Curvas de reflectância de superfície referentes aos componentes puros vegetação, solo e sombra, selecionados a partir do diagrama dos componentes principais 1 e 2 . 


\subsubsection{Avaliação estatistica das relações: frações de componentes puros-IAF e NDVI-IAF}

As relações entre o IAF e as FCPs (vegetação $\left(\mathrm{F}_{\mathrm{VEG}}\right)$, solo $\left(\mathrm{F}_{\mathrm{SOL}}\right)$ e sombra $\left(\mathrm{F}_{\mathrm{SOM}}\right)$ ) e o NDVI foram realizadas primeiramente de maneira individual, tendo sido aplicados aos dados os modelos de regressão do tipo linear e potencial:

Modelo linear: $\quad \mathrm{Y}=a \mathrm{IAF}+b$;

Modelo potencial: $\quad \mathrm{Y}=a \mathrm{IAF}^{b}$,

sendo: $\mathrm{Y}$ as FCPs (FEG, $\mathrm{F}_{\mathrm{SOL}}, \mathrm{F}_{\mathrm{SOM}}$ ) e o NDVI; e $a$ e $b$ os parâmetros dos modelos. Foi utilizada a análise de resíduos para identificar violação dos modelos. Também foi realizada, para avaliação das FCPs com o IAF, uma outra abordagem com o intuito de verificar se as frações combinadas poderiam apresentar uma melhora na estimativa deste dado biofísico. Para tanto, utilizou-se um modelo cúbico completo, relacionando as FCPs com o IAF:

$$
\mathrm{IAF}=a_{0}+\sum_{i=1}^{n} a_{i} x_{i}+\sum \sum_{i<j}^{n} a_{i j} x_{i} x_{j}+\sum \sum_{i<j}^{n} b_{i j} x_{i} x_{j}\left(x_{i}-x_{j}\right)+\sum \sum_{i<j<k}^{n} \sum a_{i k j} x_{i} x_{j} x_{k}
$$

sendo: $a_{0} \mathrm{o}$ intercepto; a e $b$ os parâmetros do modelo; e $x$ a FCP; $i, j$ e $k, 1,2,3, \ldots . . n$, em que $n$ é índice da FCP utilizado no modelo. Este modelo é proposto para análise de dados de mistura devido à restrição $\Sigma x_{i}=1$. A porção $\sum_{i=1}^{n} a_{i} x_{i}$ é chamada porção linear da mistura. Quando há o surgimento de uma curvatura não linear de mistura entre os pares de componentes, os parâmetros $a_{i j}$ representam a mistura antagônica. Os termos de alta ordem são freqüentemente necessários em modelos de mistura, pois o fenômeno em estudo pode ser complexo e a região experimental pode ser extensa, portanto requerendo um modelo mais elaborado (Montgomery, 2001). Para o caso em estudo, com $x$ sendo $\mathrm{F}_{\text {VEG }}$ ou $\mathrm{F}_{\mathrm{SOL}}$ ou $\mathrm{F}_{\text {SOM, }}$ a Equação 22 passa a ser escrita como: 


$$
\begin{aligned}
\mathrm{IAF}= & a_{0}+a_{1} \mathrm{~F}_{\mathrm{VEG}}+a_{2} \mathrm{~F}_{\mathrm{SOL}}+a_{3} \mathrm{~F}_{\mathrm{SOM}}+a_{12} \mathrm{~F}_{\mathrm{VEG}} \mathrm{F}_{\mathrm{SOL}}+ \\
& a_{13} \mathrm{~F}_{\mathrm{VEG}} \mathrm{F}_{\mathrm{SOM}}+a_{23} \mathrm{~F}_{\mathrm{SOL}} \mathrm{F}_{\mathrm{SOM}}+b_{12} \mathrm{~F}_{\mathrm{VEG}}\left(\mathrm{F}_{\mathrm{VEG}}-\mathrm{F}_{\mathrm{SOL}}\right)+ \\
& +b_{13} \mathrm{~F}_{\mathrm{VEG}}\left(\mathrm{F}_{\mathrm{VEG}}-\mathrm{F}_{\mathrm{SOM}}\right)+b_{23} \mathrm{~F}_{\mathrm{SOL}}\left(\mathrm{F}_{\mathrm{SOL}}-\mathrm{F}_{\mathrm{SOM}}\right)+a_{123} \mathrm{~F}_{\mathrm{VEG}} \mathrm{F}_{\mathrm{SOL}} \mathrm{F}_{\mathrm{SOM}}
\end{aligned}
$$

A avaliação estatística dos parâmetros da equação do modelo completo, foi realizada no SAS (SAS Institute Inc., 1990), por meio do procedimento "stepwise". Este procedimento considera primeiramente um modelo de regressão linear simples, utilizando como variável auxiliar aquela de maior coeficiente de correlação observado com a variável de resposta. Etapas se sucedem quando uma variável a mais é incorporada ao modelo. Para cada etapa de incorporação tem-se uma etapa em que uma das variáveis já selecionada pode ser descartada quando não melhora o desempenho do modelo (Chamet et al., 1999). A análise da melhor relação IAF-IV foi feita por meio do coeficiente de determinação (R2) , $P$ e do $s e$ (erro padrão).

\subsection{Resultados e discussão}

\subsubsection{IAF estimado}

Os valores de IAF em campo foram coletados com o equipamento LAI-2000 (LICOR, 1992), entre os dias 15 e 20 de janeiro de 2001. Foram selecionados 32 pontos de coleta, dos quais: 22 em cana-de-açúcar; 3 em eucalipto; 3 em pastagem; 2 em milho; e 2 floresta ripária (item 3.3.1). Os valores de IAF variaram de 0,47 a 4,48 para áreas de cana-de-açúcar e floresta ripária, respectivamente.

\subsubsection{Relação IAF-NDVI}

A Figura 11 mostra a relação entre o IAF e o NDVI. O modelo potencial apresentou ajuste mais adequado a esta relação. Observa-se que o NDVI aumenta mais 
rapidamente para menores valores de IAF e tende a se estabilizar para maiores valores de IAF, o que neste trabalho ocorreu em torno de 3,00. Tal comportamento também foi observado por outros autores para esta faixa de IAF (Holben et al., 1980; Turner et al., 1999). Turner et al. (1999) observaram que a saturação ocorreu entre IAF de 3,00 a 5,00. O coeficiente de determinação foi de 0,72 . Quando foram considerados apenas dados de IAF de coberturas não florestais (cana-de-açúcar, milho e pastagem) houve uma diminuição da variação de NDVI explicada (Tabela 3), todavia não diferindo significativamente ( $1 \%$ de probabilidade) da relação IAF-NDVI anterior, com todos os dados de IAF. O mesmo pode ser observado na relação com apenas os dados de IAF de cana-de-açúcar. Os resultados mostraram que o IAF total pode ser estimado por meio do NDVI com um se de aproximadamente $0,47 \mathrm{~m}^{2} / \mathrm{m}^{2}$.

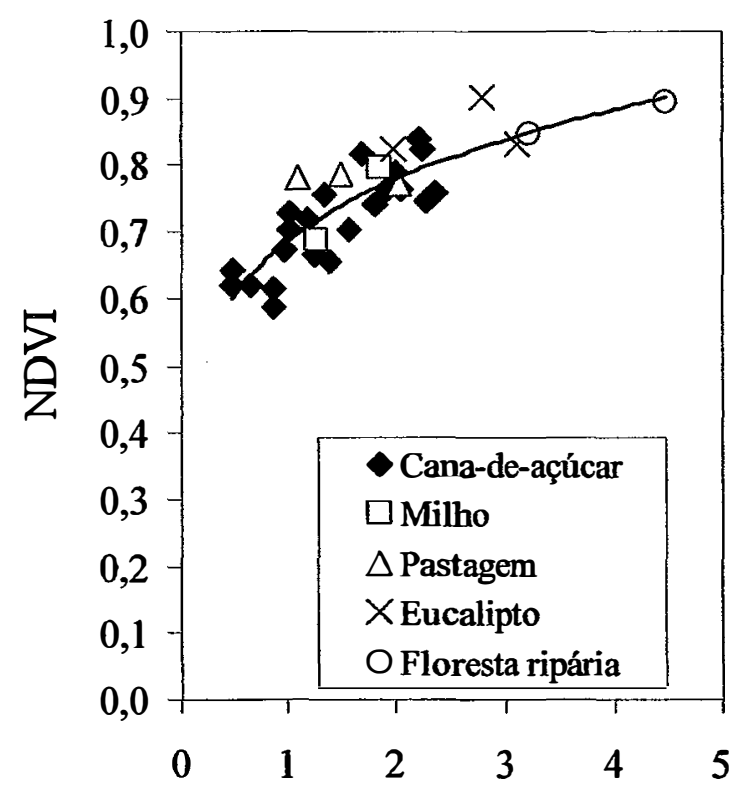

IAF

Figura 11 - Diagrama de dispersão de todos os dados de IAF "versus" NDVI. 
Tabela 3. Resumo dos resultados da análise de regressão simples da relação entre IAF e NDVI.

\begin{tabular}{llcccc}
\hline IAF considerado & Modelo & $N$ & $\mathrm{R} 2$ & $s e$ & $P$ \\
\hline Total $^{\mathrm{a}}$ & $\mathrm{NDVI}=0,6869 \mathrm{IAF}^{0,1809}$ & 32 & 0,72 & 0,06 & $<0,01$ \\
Não florestais $^{\mathrm{b}}$ & $\mathrm{NDVI}=0,6861 \mathrm{IAF}^{0,1698}$ & 27 & 0,62 & 0,06 & $<0,01$ \\
Cana-de-açúcar $^{\mathrm{c}}$ & $\mathrm{NDVI}=0,098 \mathrm{IAF}+0,5734$ & 22 & 0,69 & 0,04 & $<0,01$ \\
\hline
\end{tabular}

${ }^{a}$ Considerados todos os dados de IAF das diferentes coberturas do solo.

${ }^{\mathrm{b}}$ Considerados os dados de IAF de cana-de-açúcar, pastagem e milho.

' Considerados apenas os dados de IAF's da cana-de-açúcar.

\subsubsection{Relações IAF-FCPs}

$\mathrm{O}$ erro médio da imagem das estimativas das FCPs pelo método dos mínimos quadrados com restrição, utilizando os componentes puros, vegetação, solo e sombra, foi de 2\%. Um exame visual das imagens das FCPs mostrou um resultado consistente com as observações de campo. As imagens das FCPs (Figura 12) podem ser utilizadas como um importante descritor das condições de cobertura vegetal em uma classificação, não sendo considerada a quantificação dos dados do uso do solo, mas na qualificação destes por meio de uma interpretação visual. As imagens $\mathrm{F}_{\mathrm{VEG}}$ e $\mathrm{F}_{\mathrm{SOL}}$ se apresentam com maior contraste, onde áreas de vegetação e sem vegetação são facilmente identificadas. Já a imagem $\mathrm{F}_{\mathrm{SOM}}$ apresenta a menor variância, dificultando a sua análise no reconhecimento do uso da terra. 


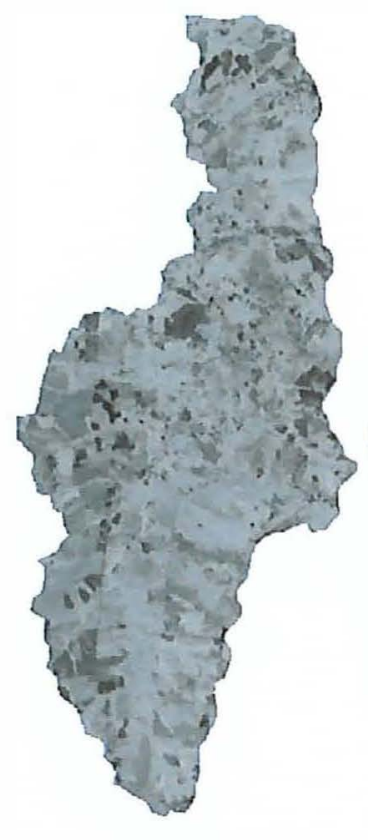

(a)

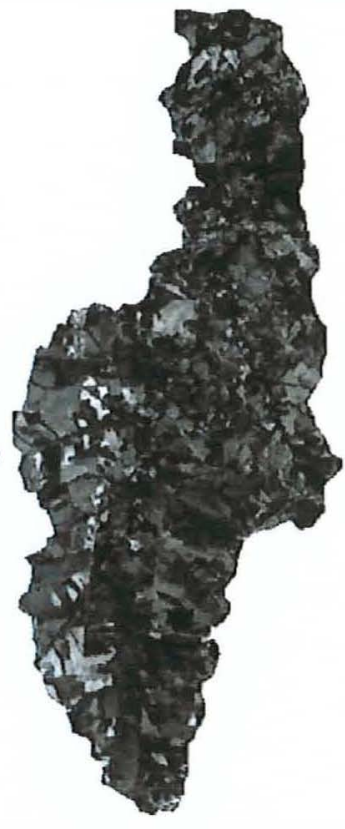

(b)

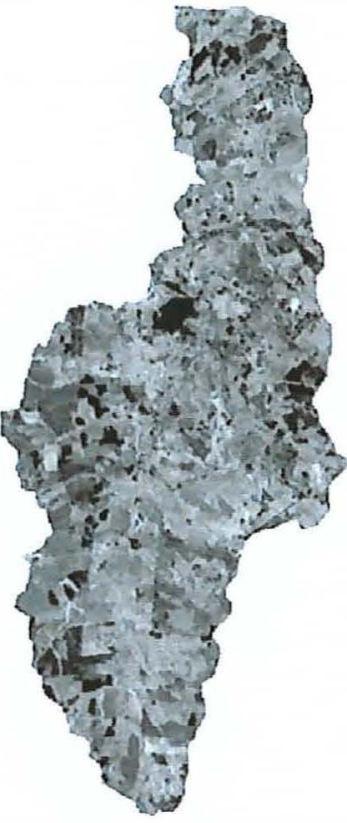

(c)

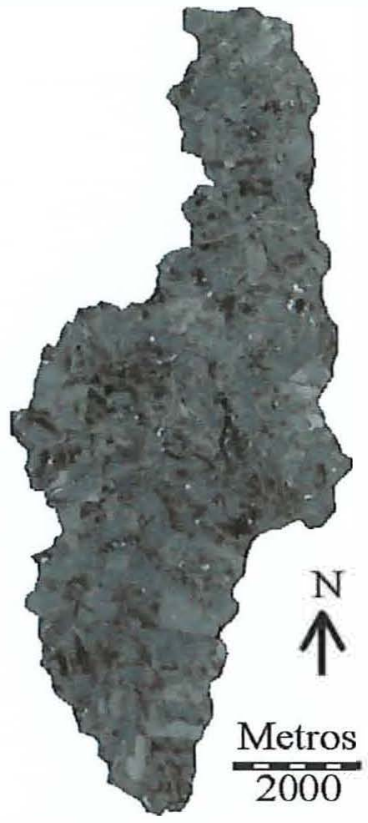

(d)

Figura 12 - Imagens dos índices estudados: a) NDVI; b) F FOL; c) F $F_{V E G}$ e d) F FOM.

Na Figura 13 é apresentada a relação IAF-FVEG. Esta relação foi do tipo potencial, com $\mathrm{R} 2=0,52$, onde para maiores valores de IAF houve aumento, não linear, das $\mathrm{F}_{\mathrm{VEG}}$. $\mathrm{O}$ valor máximo das $\mathrm{F}_{\mathrm{VEG}}$ nas amostras estudadas foi de $80 \%$ (Tabela 4), em área de milho $(\mathrm{IAF}=1,86)$. Considerando-se apenas os dados de IAF de espécies não florestais (IAF $\leq 2,37$ ) a relação foi do tipo linear positiva (Tabela 5) com variação explicada pelo modelo de $62 \%$. Tal comportamento de linearidade para menores valores de IAF também foi observado por García-Haro et al. (1996), que utilizaram valores de

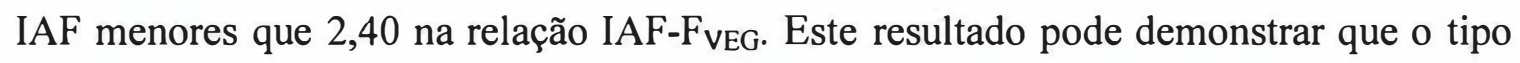
de cobertura afeta o comportamento das frações deste componente puro ou, mais ainda, que para maiores valores de IAF haveria tendência de saturação da F $_{\mathrm{VEG}}$, fazendo com que a relação também possa saturar a partir de determinado valor de IAF, assim como o NDVI. 


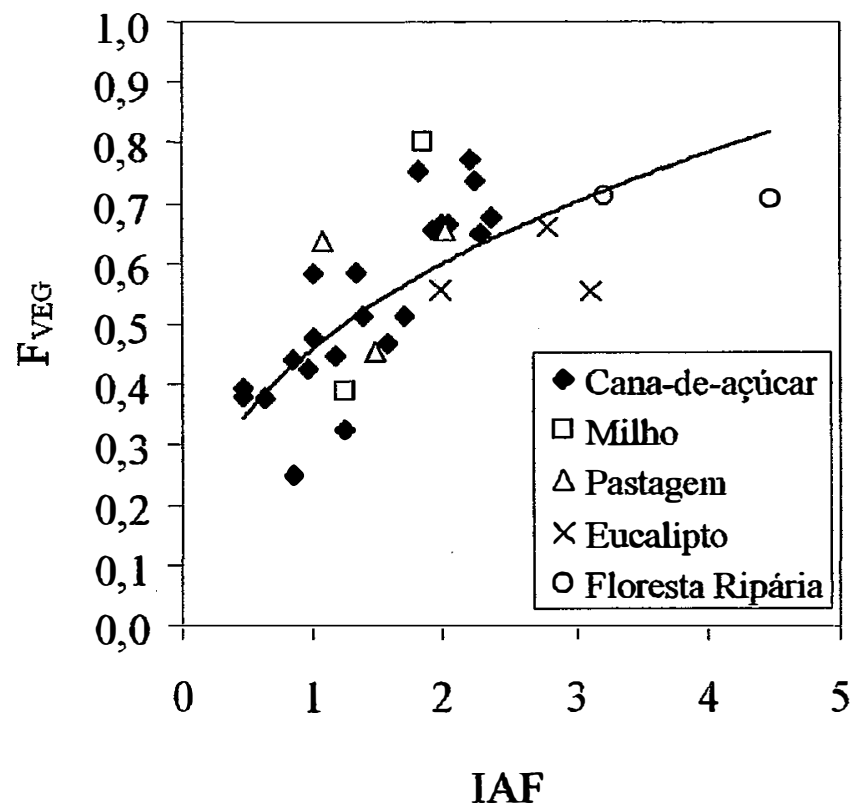

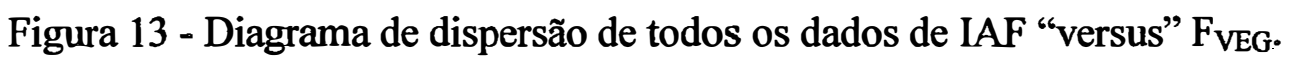


Tabela 4. Valores de NDVI e frações dos três componentes puros derivados pelo método de mínimos quadrados com restrição: vegetação, solo e sombra.

\begin{tabular}{|c|c|c|c|c|c|}
\hline Uso do solo & LAI & NDVI & $F_{\text {VEG }}$ & $\mathrm{F}_{\mathrm{SOL}}$ & $\mathrm{F}_{\mathrm{SOM}}$ \\
\hline Cana-de-açúcar & 0,97 & 0,621 & 0,425 & 0,453 & 0,115 \\
\hline Cana-de-açúcar & 2,25 & 0,643 & 0,738 & 0,036 & 0,221 \\
\hline Cana-de-açúcar & 0,47 & 0,620 & 0,393 & 0,404 & 0,197 \\
\hline Cana-de-açúcar & 1,01 & 0,614 & 0,478 & 0,316 & 0,199 \\
\hline Cana-de-açúcar & 1,24 & 0,586 & 0,323 & 0,473 & 0,198 \\
\hline Cana-de-açúcar & 1,58 & 0,672 & 0,469 & 0,335 & 0,191 \\
\hline Cana-de-açúcar & 2,05 & 0,728 & 0,664 & 0,176 & 0,153 \\
\hline Cana-de-açúcar & 2,29 & 0,704 & 0,649 & 0,235 & 0,109 \\
\hline Cana-de-açúcar & 1,93 & 0,717 & 0,656 & 0,283 & 0,056 \\
\hline Cana-de-açúcar & 0,86 & 0,664 & 0,441 & 0,453 & 0,101 \\
\hline Cana-de-açúcar & 1,01 & 0,756 & 0,584 & 0,329 & 0,081 \\
\hline Cana-de-açúcar & 2,37 & 0,654 & 0,677 & 0,267 & 0,051 \\
\hline Cana-de-açúcar & 1,82 & 0,702 & 0,753 & 0,171 & 0,070 \\
\hline Cana-de-açúcar & 1,39 & 0,817 & 0,514 & 0,402 & 0,078 \\
\hline Cana-de-açúcar & 2,00 & 0,742 & 0,664 & 0,188 & 0,142 \\
\hline Cana-de-açúcar & 2,22 & 0,762 & 0,771 & 0,112 & 0,110 \\
\hline Cana-de-açúcar & 1,71 & 0,788 & 0,514 & 0,271 & 0,209 \\
\hline Cana-de-açúcar & 0,64 & 0,764 & 0,377 & 0,492 & 0,125 \\
\hline Cana-de-açúcar & 1,18 & 0,838 & 0,447 & 0,325 & 0,222 \\
\hline Cana-de-açúcar & 0,86 & 0,823 & 0,250 & 0,400 & 0,350 \\
\hline Cana-de-açúcar & 1,34 & 0,745 & 0,586 & 0,252 & 0,156 \\
\hline Cana-de-açúcar & 0,47 & 0,757 & 0,381 & 0,447 & 0,167 \\
\hline Pastagem & 1,49 & 0,781 & 0,454 & 0,491 & 0,049 \\
\hline Pastagem & 2,03 & 0,786 & 0,653 & 0,281 & 0,061 \\
\hline Pastagem & 1,09 & 0,772 & 0,637 & 0,192 & 0,166 \\
\hline Milho & 1,86 & 0,687 & 0,802 & 0,107 & 0,086 \\
\hline Milho & 1,26 & 0,795 & 0,389 & 0,560 & 0,045 \\
\hline Floresta Ripária & 3,21 & 0,846 & 0,712 & 0,143 & 0,139 \\
\hline Floresta Ripária & 4,48 & 0,893 & 0,709 & 0,092 & 0,192 \\
\hline Eucalipto & 2,78 & 0,831 & 0,660 & 0,032 & 0,307 \\
\hline Eucalipto & 1,99 & 0,823 & 0,557 & 0,234 & 0,203 \\
\hline Eucalipto & 3,11 & 0,903 & 0,554 & 0,050 & 0,390 \\
\hline
\end{tabular}




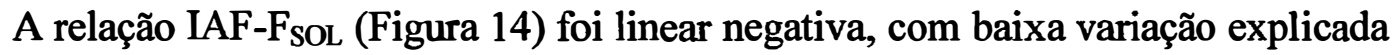
pelo modelo $(\mathrm{R} 2=0,56)$. $\mathrm{O}$ menor valor das $\mathrm{F}_{\mathrm{SOL}}$ para os dados analisados foi de $3 \%$, em plantação adulta de eucalipto (IAF $=2,78$ ). À medida em que o IAF aumenta, diminui a área de solo exposto, acarretando numa diminuição da $\mathrm{F}_{\text {SOL }}$. A estratificação dos dados de IAF para a cana-de-açúcar na relação com $\mathrm{F}_{\text {SOL }}$ apresentou melhor ajuste (Tabela 5), com R2 $=0,68$ e erro padrão para a estimativa do IAF de aproximadamente $0,32 \mathrm{~m}^{2} / \mathrm{m}^{2}$. A fisionomia vegetal pode ter influenciado as relações com o IAF considerando $\mathrm{F}_{\mathrm{VEG}}$ e $\mathrm{F}_{\mathrm{SOL}} \mathrm{e}$, nestes casos, talvez trabalhar com dados estratificados pelo tipo de cobertura pode melhorar o desempenho destas relações.

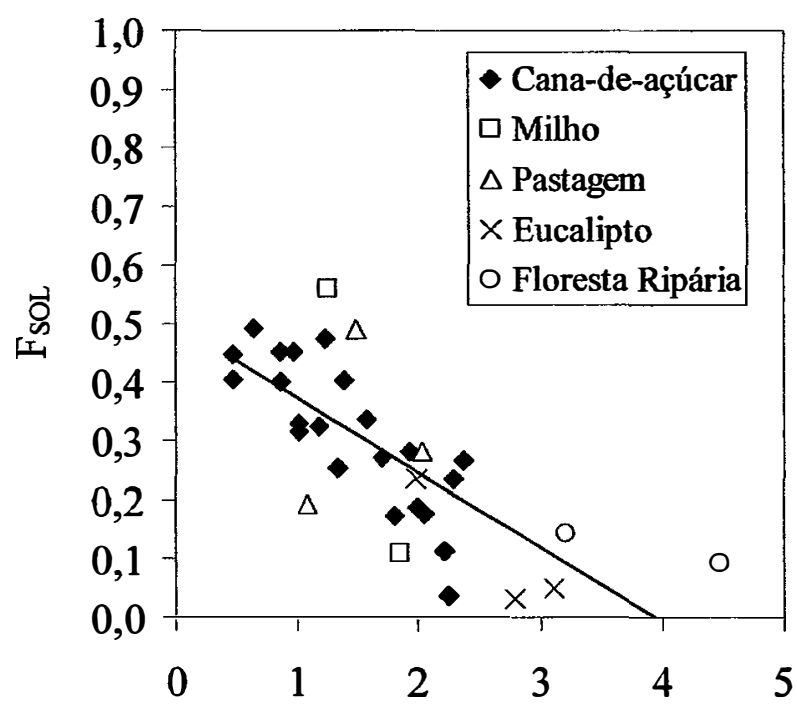

IAF

Figura 14 - Diagrama de dispersão de todos os dados de IAF "versus" FSOL.

A relação IAF-FSom não foi significativa. Tal resultado também foi observado por García-Haro et al. (1996) na relação IAF-F ${ }_{S O M}$ sob condições de solo exposto. Todavia, quando o solo em seu estudo foi submetido a diferentes teores de carvão, passou a haver um aumento deste até aproximadamente IAF de 1 e para maiores valores não foi observada diminuição significativa. Relação significativa entre IAF e $F_{S O M}$ também foi observada por Hall et al. (1995a), que obtiveram a melhor relação do IAF de 
Picea mariana e Populus tremuloides justamente com esta FCP. Os autores justificam que, em parte, este resultado poderia ser explicado pela maior extensão das $\mathrm{F}_{\mathrm{SOM}} \mathrm{em}$ relação às demais frações. Percebe-se (Figura 15) que as plantações de eucalipto apresentam valores mais elevados de $\mathrm{F}_{\mathrm{SOM}}(0,30 \mathrm{em}$ média), o que as difere significativamente da média geral $(0,15$ em média). $O$ fato das plantações de eucalipto apresentarem maiores valores de $\mathrm{F}_{\text {SOM }}$ pode ser explicado pala estrutura do seu dossel. Estas plantações encontram-se na fase adulta, como descrito anteriormente, sendo o espaçamento entre árvores de aproximadamente $3 \mathrm{~m}$, apresentando grandes aberturas no dossel, o que poderia aumentar a quantidade de sombras na área. As áreas de floresta ripária não apresentaram esta tendência de alta na $\mathrm{F}_{\text {SOM }}$ no presente trabalho. Tal fato pode ser explicado devido a este tipo de cobertura não apresentar tantas aberturas como as plantações de eucalipto, embora seja uma cobertura que se apresenta na imagem com textura rugosa. Em estudos anteriores, $\mathrm{F}_{\mathrm{SOM}}$ foi relacionada com a estrutura de dosséis. Adams et al. (1995), por exemplo, observaram que áreas de florestas densas têm mais sombra que áreas de pastagem e/ou regeneração.

Tabela 5. Resumo dos resultados da análise de regressão simples das relações entre IAF e as frações dos componentes puros de vegetação, solo e sombra.

\begin{tabular}{llcccc}
\hline IAF & Modelo & $N$ & R2 & se & $P$ \\
\hline Todos os dados & $\mathrm{F}_{\mathrm{VEG}}=0,4592 \mathrm{IAF}^{0,3863}$ & 32 & 0,52 & 0,10 & $<0,01$ \\
Não florestais & $\mathrm{F}_{\mathrm{VEG}}=3,0292 \mathrm{IAF}-0,1891$ & 27 & 0,62 & 0,10 & $<0,01$ \\
Cana-de-açúcar & $\mathrm{F}_{\mathrm{VEG}}=0,2027 \mathrm{IAF}+0,2426$ & 22 & 0,70 & 0,08 & $<0,01$ \\
Todos os dados & $\mathrm{F}_{\mathrm{SOL}}=-0,1269 \mathrm{IAF}+0,4993$ & 32 & 0,56 & 0,10 & $<0,01$ \\
Não florestais & $\mathrm{F}_{\mathrm{SOL}}=-0,1653 \mathrm{IAF}+0,5541$ & 27 & 0,49 & 0,10 & $<0,01$ \\
Cana-de-açúcar & $\mathrm{F}_{\mathrm{SOL}}=-0,1668 \mathrm{IAF}+0,5501$ & 22 & 0,68 & 0,07 & $<0,01$ \\
\hline
\end{tabular}




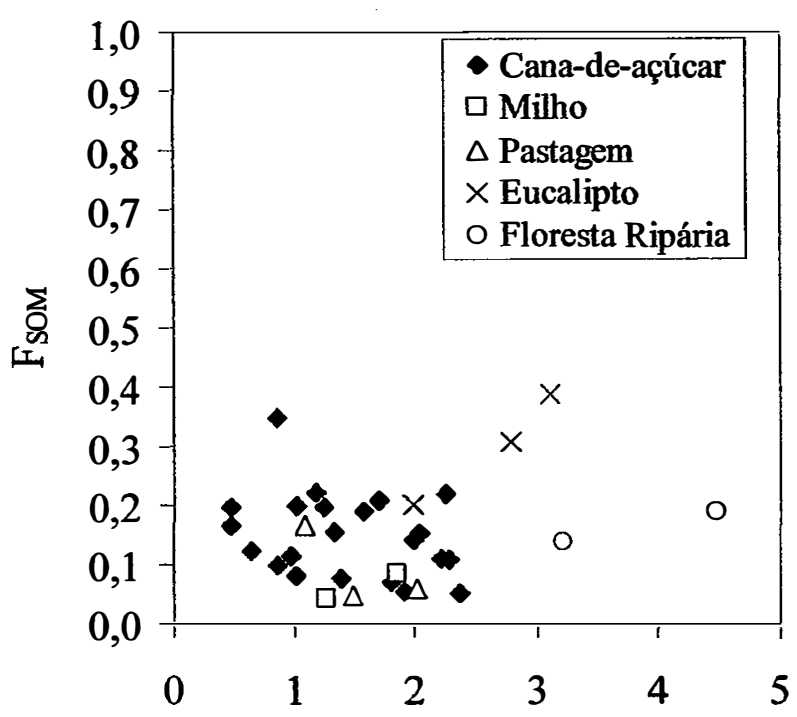

IAF

Figura 15 - Diagrama de dispersão de IAF "versus" FSOM.

O modelo completo de mistura (Equação 23) foi aplicado aos dados e seu resultado é apresentado na Figura 16. O coeficiente de determinação foi de 0,61 (R2 sem “outlier" foi de 0,68 , Tabela 6), não diferindo significativamente dos $R 2$ das relações $\mathrm{F}_{\mathrm{VEG}}-\mathrm{IAF}$ e $\mathrm{F}_{\mathrm{SOL}}-\mathrm{IAF}$, ou seja, espera-se a mesma acurácia na determinação do IAF tanto com o modelo simples como com o modelo completo. Todavia, o modelo mostrou que houve uma mistura antagônica para a estimativa do IAF com as FCPs. Nota-se que a variação do IAF com respeito a $F_{V E G}$ depende da $F_{S O L} e$ vice-versa, pois, $\partial \mathrm{IAF} / \partial \mathrm{F}_{\mathrm{SOL}}=f\left(\mathrm{~F}_{\mathrm{SOL}}, \mathrm{F}_{\mathrm{SOM}}\right)$ e $\partial \mathrm{IAF} / \partial \mathrm{F}_{\mathrm{SOM}}=f\left(\mathrm{~F}_{\mathrm{SOL}}, \mathrm{F}_{\mathrm{SOM}}\right)$. Análises futuras com um maior número de dados de IAF poderão ser realizadas utilizando modelo completo, esperando que a mistura antagônica de fato exista, e que tal modelo possa ser empregado de forma a melhorar a estimativa do IAF. 
Tabela 6. Resumo dos resultados da análise de regressão simples das relações entre IAF e as frações dos componentes puros de vegetação, solo e sombra.

\begin{tabular}{llcccc}
\hline IAF & Modelo & $N$ & $\mathrm{R} 2$ & se & \multicolumn{1}{c}{$\boldsymbol{P}$} \\
\hline Todos os dados & $\mathrm{IAF}=3,332-6,999 \mathrm{~F}_{\mathrm{SOL}}+5,825 \mathrm{~F}_{\mathrm{SOL}}\left(\mathrm{F}_{\mathrm{SOL}}-\mathrm{F}_{\mathrm{SOM}}\right)$ & 32 & 0,61 & 0,55 & $<0,01$ \\
Todos os dados* & $\mathrm{IAF}=2,994-3,004 \mathrm{~F}_{\mathrm{SO}}-6,807 \mathrm{~F}_{\mathrm{SOL}} \mathrm{F}_{\mathrm{SOM}} \mathrm{F}_{\mathrm{VEG}}$ & 31 & 0,68 & 0,42 & $<0,01$ \\
Não florestais & $\mathrm{IAF}=-0,18912+3,029217 \mathrm{~F}_{\mathrm{VEG}}$ & 27 & 0,62 & 0,36 & $<0,01$ \\
Cana-de-açúcarar & $\mathrm{IAF}=-0,41461+3,469584 \mathrm{~F}_{\mathrm{VEG}}$ & 22 & 0,70 & 0,34 & $<0,01$
\end{tabular}

*Regressão sem "outlier" (erro residual padrão maior que +2 ) referente à medida em floresta ripária $(\mathrm{IAF}=4,48)$.

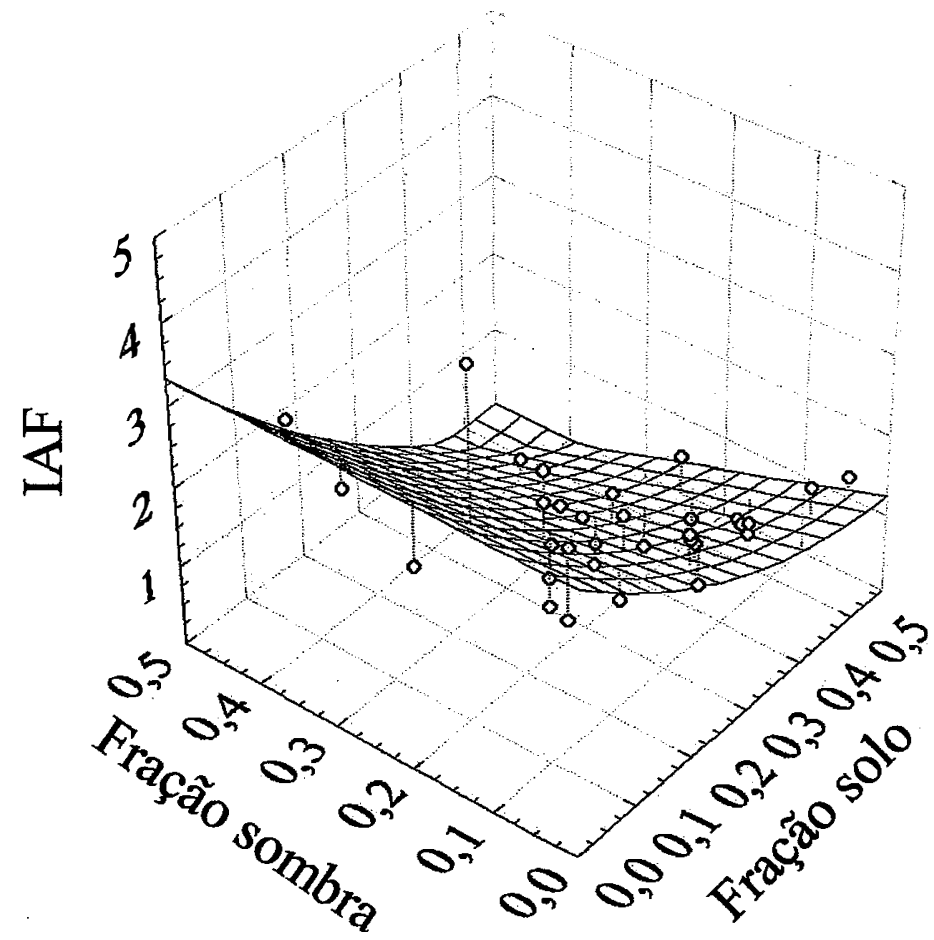

Figura 16 - Superficie de resposta para a estimativa do $\mathrm{IAF}$ por meio de $\mathrm{F}_{\mathrm{SOL}}$ e $\mathrm{F}_{\mathrm{SOM}}$. Modelo com todos os dados de IAF (Tabela 6).

A Tabela 7 mostra a correlação entre as imagens FCPs e NDVI. Observa-se a alta correlação que há entre o NDVI e $\mathrm{F}_{\mathrm{VEG}}$, e correlação média com $\mathrm{F}_{\text {SOL. Todavia o IAF }}$ 
explicou uma maior variação do NDVI. O NDVI neste trabalho demonstrou ser menos sensível às variações de estrutura da vegetação.

Tabela 7. Correlação entre valores de NDVI e as FCPs.

\begin{tabular}{lcccc}
\hline & NDVI & F VEG & F $_{\text {SOL }}$ & F $_{\text {SOM }}$ \\
\hline NDVI & 1,00 & & & \\
F $_{\text {VEG }}$ & 0,93 & 1,00 & & \\
F SOL $^{\text {F }}$ & $-0,85$ & $-0,91$ & 1,00 & \\
SOM & $-0,03$ & $-0,04$ & $-0,38$ & 1,00 \\
\hline
\end{tabular}

\subsection{Conclusões}

Neste trabalho foi realizada uma análise da relação do IAF de diferentes coberturas do solo com o NDVI e com FCPs, estas últimas obtidas pelo MLME. Na área de estudo, o IAF foi melhor relacionado com valores de NDVI. Quanto às FCPs, apenas a $F_{V E G}$ e a $F_{S O L}$ tiveram relação significativa com o IAF. Enquanto o NDVI é de fácil geração, pois é apenas uma relação linear entre bandas, necessitando apenas dos valores de reflectância de superfície, no MLME há um dispêndio de tempo na escolha de componentes puros e a sua solução matemática é mais sofisticada e também exigente computacionalmente. Por fim, sugere-se o índice de vegetação NDVI para posteriores trabalhos de estimativa do IAF na área em estudo. 


\section{ESTIMATIVA DO ÍNDICE DE ÁREA FOLIAR MENSAL EM UMA MICROBACIA HIDROGRÁFICA COM DADOS DE SENSORIAMENTO REMOTO}

\section{Resumo}

O objetivo deste trabalho foi avaliar a relação IAF-NDVI para diferentes épocas do ano e gerar mapas de IAF por meio desta relação para uma microbacia. Para isto, foi realizada uma campanha de campo de coleta de dados mensais de IAF com o equipamento LAI-2000, durante o ano de 2001, em áreas de cana-de-açúcar, pastagem, milho, eucalipto e floresta ripária, na microbacia do Ribeirão dos Marins, SP. Foram adquiridas 4 imagens em 2001 (janeiro, março, agosto e novembro), do Landsat/ETM+, posteriormente corrigidas para os efeitos amosféricos com o modelo $6 \mathrm{~S}$. O IAF máximo observado na microbacia em campanha de campo foi de 4,90 (floresta ripária). O IAF da cana-de-açúcar apresentou a maior variabilidade durante o ano, devido ao tipo de manejo empregado para esta cultura na área em estudo e características intrínsecas da cultura. As respostas das bandas individuais do vermelho (ver) e do infravermelho próximo $(i V P)$, assim como a do NDVI, para as quatro datas, foram sensíveis, além do IAF, às variações do ângulo zenital solar (AZS), ao brilho do solo e à arquitetura do dossel. O NDVI de eucalipto mostrou-se com maiores valores devido aos baixos valores de ver, como possível resultado da maior quantidade de sombras desta cobertura. O IAF explicou de $57 \%$ a $72 \%$ da variação do NDVI para as quatro datas estudadas. O IAF médio na microbacia para as quatro datas, estimado pelo modelo relacional IAF-NDVI, variou de 0,97 a 1,59 , apresentando alta correlação $(0,99)$ com a precipitação acumulada 
de três meses anteriores às estimativas do IAF médio. Os resultados deste trabalho representam um pequeno passo para o entendimento da dinâmica do IAF na área de estudo e similares, assim como sua relação com o NDVI.

\section{Summary}

The objective of this work was to assess the relationship LAI-NDVI from different dates and generate LAI maps through this relation for a rural watershed. To accomplish this, the LAI was monthly collected in the field during 2001, with a LAI2000 equipment, in plots of sugar-cane, pasture, corn, eucalypt, and riparian forest in the Ribeirão dos Marins watershed, in Piracicaba, SP, Brazil. Four 2001 Landsat-7/ETM+ (from January, March, August, and November) images were acquired and corrected for the atmospheric effects through the $6 \mathrm{~S}$ model. The maximum LAI value observed during the field campaign in the watershed was 4.90 . The sugar-cane LAI presented the greater variation due to the management of this crop in the study area and the plant characteristics. The response from red and near infrared bands, as well as NDVI, for the four dates, were sensitive, besides the LAI, to the solar zenith angle, soil brightmess, and canopy architecture variations. The NDVI for eucalypt showed the greater values due to the low red reflectance values, as a possible result of greater amount of shadow of that type of land cover. The IAF explained $57 \%$ to $72 \%$ of the NDVI variation in the four dates studied. The mean LAI for the four dates, estimated by the relational model LAINDVI, varied from 0.97 to 1.59 , presenting high correlation $(0.99)$ with three-month accumulated precipitation previous to the mean LAI estimation. The result of this work represent a small step towards the understanding of LAI dynamics in the study area and similar areas, as well its relationship with the NDVI.

\subsection{Introdução}

Estudos recentes vêm alertando a comunidade mundial sobre a diminuição na oferta de água em algumas regiões, devido à demanda crescente por este recurso. Por exemplo, Vörösmarty et al. (2000), em estudo sobre vulnerabilidade dos recursos 
hídricos globais "versus" mudanças climáticas e crescimento populacional e econômico, observaram que estes últimos irão ditar a relação entre suprimento de água e demanda em um grau muito maior que as mudanças climáticas, nos próximos 23 anos. Jackson et al. (2001) relataram que nos próximos 29 anos será improvável que o "runoff" aumente mais que $10 \%$, todavia, estima-se que a população da Terra cresça em 1/3 e, a não ser que a eficiência no uso da água aumente, este desbalanço irá reduzir os ecossistemas de águas limpas e aumentar o número de espécies aquáticas extintas. Segundo os mesmos autores, já são utilizados nos dias de hoje, $50 \%$ da água dos rios para uso humano, contudo, 1 bilhão de pessoas sofrem com a falta de água para beber e 3 bilhões são carentes em serviços de saneamento. Logo, estudos referentes ao ciclo hidrológico em bacias hidrográficas podem ajudar a compreender melhor os efeitos que mudanças antrópicas dentro da bacia podem acarretar na circulação e distribuição da água e, desta forma, auxiliar nas tomadas de decisões, visando a minimizar os danos à natureza e melhorar a utilização da água.

O ciclo hidrológico, devido a sua complexidade, tem que ser tratado como um todo, requerendo desta forma planejamento e coordenação entre teoria, modelagem e observação (Chahine, 1992). Um dos componentes mais importantes no ciclo hidrológico é a evapotranspiração. Toma-se como exemplo ilustrativo o continente norte-americano, onde aproximadamente $30 \%$ da água é drenada superficialmente ou percolada para o subsolo, enquanto os outros $70 \%$ retornam para a atmosfera na forma direta de evapotranspiração (Rosenberg et al., 1983).

O IAF é uma das principais variáveis para o cálculo da evapotranspiração (Sellers et al., 1997). Em nível regional, a única maneira de estimar este índice é por meio de dados de sensoriamento remoto. Running et al. (1989) utilizaram dados de sensoriamento remoto (estimadores do IAF) para calcular a evapotranspiração e a fotossíntese líquida em região de floresta de coníferas. Moran et al. (1995) empregaram a combinação de modelagem e dados de sensoriamento remoto para estimar IAF e evapotranspiração em alfafa. Em trabalho recente, Matsushita \& Tamura (2002) descreveram uma metodologia para integrar dados de sensoriamento remoto com um 
modelo de ecossistema para estimar a produção líquida primária, sendo que o IAF é a principal variável para integrar estes dados com os modelos ecológicos.

Uma das maneiras convenientes de se estimar o IAF por meio de dados de sensoriamento remoto é utilizando Índices de Vegetação (IVs) (Myneni et al., 1995), sendo o NDVI (Índice de Vegetação da Diferença Normalizada) amplamente utilizado. Vários estudos vêm relacionando o NDVI, tanto com o IAF quanto com outras variáveis do dossel de diferentes coberturas vegetais, como por exemplo: IAF e concentração de nitrogênio de diferentes cultturas agrícolas (Boegh et al., 2002); fração de cobertura de vegetação, biomassa, altura e IAF de videiras (Montero et al., 1999); IAF e biomassa de soja (Holben et al., 1980); Fração de Radiação Fotossinteticamente Ativa Absorvida pelo Dossel (FAPAR) (Asrar et al, 1984); IAF de milho (Wiegand et al., 1990); biomassa de gramíneas (Tucker, 1979); percentagem de cobertura verde de gramíneas no Japão e na Mongólia (Purevdorj et al., 1998); IAF de mangue (Green et al., 1997); IAF e FAPAR de algodão, trigo e milho (Wiegand \& Richardson, 1990); FAPAR e capacidade fotossintética de pinheiros (Yoder \& Waring, 1994).

Como visto acima, vários estudos vêm sendo realizados para analisar a relação do NDVI com o IAF, todavia os resultados não têm sido consistentes devido a vários fatores que afetam o NDVI, particularmente o efeito combinado da estrutura do dossel com a geometria sol-sensor (Goetz, 1997). Por exemplo, aumento do NDVI com o aumento do Ângulo Zenital Solar (AZS) (Middleton, 1990; Deering et al., 1999). A dependência do NDVI à estrutura do dossel é apresentada em Turner et al. (1999) e Spanner et al. (1990). Logo, a correção dos IVs para as variações do alvo e da geometria sol-sensor torna-se de difícil implementação na prática, necessitando de ajuste com dados de campo durante a época de aquisição da imagem.

Estimar o IAF por meio de técnicas de sensoriamento remoto é um pequeno passo para a implementação de modelos que usem esta variável para cálculo da evapotranspiração em nível regional. Neste trabalho é apresentado um estudo da relação IAF-NDVI de diferentes coberturas vegetais, em uma microbacia hidrográfica, em 
diferentes épocas do ano. Posteriormente essas relações foram utilizadas para gerar mapas de IAF para a área em estudo.

\subsection{Material e métodos}

\subsection{1 Área de estudo e dados de IAF}

A área de estudo foi a microbacia hidrográfica do Ribeirão dos Marins, em Piracicaba, SP (ver item 3.2.1). Mensalmente, entre o $15^{\circ}$ e o $20^{\circ}$ dia de cada mês de 2001, 41 áreas foram visitadas e o IAF foi medido com o auxílio do equipamento LAI2000 (LI-COR, 1992), de acordo com presença de vegetação na área. A metodologia empregada para as medições em cada tipo de cobertura é mostrada no item 3.2.2. Em cada área foram obtidas as coordenadas locais com um receptor GPS, com um erro de posicionamento de aproximadamente $15 \mathrm{~m}$, para sua posterior localização na imagem.

\subsubsection{Processamento das imagens}

Neste trabalho foram utilizadas 4 imagens (Tabela 8) do Landsat-7, sensor ETM+ (base 220, ponto 76) para analisar a relação IAF-NDVI e para gerar mapas de IAF da área. Procurou-se selecionar as imagens com espaçamento de tempo igual durante o ano, ou seja, espaçadas de 3 meses uma da outra, para ter uma representatividade do IAF durante o ano. Todavia, devido à presença de nuvens nas épocas adequadas, o espaçamento entre as datas das imagens variou de 2 a 5 meses uma da outra. Nestas imagens a correção geométrica foi realizada por meio de interpolador de primeiro grau de alocação de vizinho mais próximo. A projeção final do projeto foi UTM/SAD69 e o erro final da correção nas imagens foi menor que 0,5 pixel. 
Tabela 8. Características das.imagens Landsat-7/ETM+ quanto ao Ângulo Zenital Solar (AZS), resolução espacial e visibilidade utilizada no modelo 6S.

\begin{tabular}{cccc}
\hline Data de gravação & Ângulo zenital solar & Resolução $(\mathrm{m})$ & Visibilidade $(\mathrm{km})$ \\
\hline $18 / 01 / 01$ & $32,7^{\circ}$ & 25 (reamostrada) & 15 \\
$23 / 03 / 01$ & $41,1^{\circ}$ & 30 & 35 \\
$14 / 08 / 01$ & $49,7^{\circ}$ & 30 & 25 \\
$02 / 11 / 01$ & $28,2^{\circ}$ & 25 (reamostrada) & 15 \\
\hline
\end{tabular}

O NDVI foi calculado a partir dos dados de valores de reflectância de superfície das bandas 3 (ver) e 4 (iVP) do sensor ETM+, calculados a partir do modelo 6S (Vermote et al., 1997, ver item 3.2.3). Os parâmetros de entrada utilizados no modelo 6S foram: modelo de atmosfera tropical, modelo continental de aerossóis e visibilidade horizontal variável para cada imagem (Tabela 8). Primeiramente foi assumido um valor de $15 \mathrm{~km}$ de visibilidade horizontal. Em seguida aumentava-se a visibilidade até que não houvesse modificação nos dados de reflectância. Verificou-se, por meio do arquivo de saída do modelo $6 \mathrm{~S}$, a presença de pixels em que a reflectância de superfície foi calculada com valor menor que zero; todavia, este número foi pequeno (máximo de 10 pixels em imagens compostas por 1.189 .390 pixels ou seja, $8,4.10^{-6} \%$ do número total de pixels). Para cada um dos pontos onde se realizou a coleta de IAF em campo, foi calculada a média de reflectância de uma janela de $2 \times 2$ ou $3 \times 3$ pixels de cada banda, de acordo com a forma e o tamanho da área (Figura 17). 


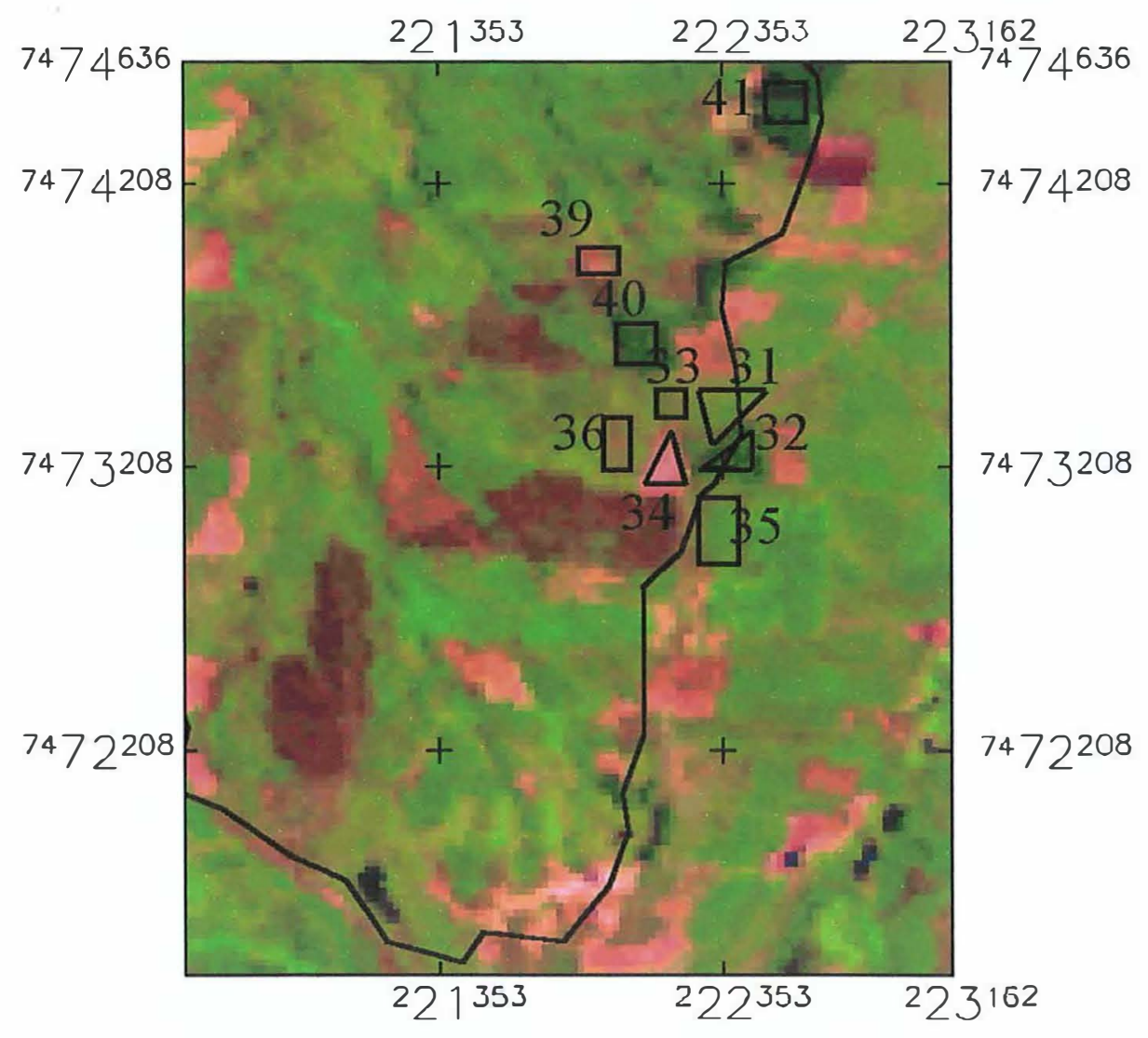

Figura 17 - Exemplo de áreas onde foram coletados dados de IAF em campo e as amostras de valores de ver e $i V P$ na imagem.

\subsubsection{Avaliação estatística}

Os modelos utilizados para estudar a relação IAF-NDVI das diferentes imagens foram do tipo linear e potencial. Os modelos polinomial quadrático e cúbico não foram utilizados pois, na análise preliminar dos dados, não foi observada diminuição do NDVI com o aumento do IAF, não justificando a utilização destes. Os modelos do tipo linear e potencial já foram utilizados em diversos trabalhos (Holben et al., 1980; Wiegand et al., 1990; Chen et al., 1996; Fassacht et al., 1997). A equação do tipo potencial foi utilizada devido à natureza assintótica que a relação IAF-NDVI pode apresentar (Spanner et al., 1990; Nemani et al., 1993; Turner et al., 1999). Foi utilizada a análise de resíduo para 
identificar violação do modelo. A análise da melhor relação IAF-NDVI foi feita por meio do coeficiente de determinação (R2), nível observado de significância $(P)$ e do erro padrão (se). Por fim, a melhor relação IAF-NDVI foi invertida e utilizada para gerar os mapas de IAF da área de estudo para as diferentes datas. A avaliação da relação entre IAF e reflectância das bandas individuais também foi realizada, numa primeira etapa da análise do NDVI.

\subsection{Resultados e discussão}

\subsubsection{Precipitação e temperatura (ano de 2001)}

Durante o ano da campanha de campo (2001), a temperatura média foi de $22,5^{\circ} \mathrm{C}$ (média anual $21,4^{\circ} \mathrm{C}$ ) com máxima mensal de $26,0^{\circ} \mathrm{C}$ (média máxima anual de $24,9^{\circ} \mathrm{C}$ ) e mínima mensal de $18,5^{\circ} \mathrm{C}$ (média mínima anual de $17,1^{\circ} \mathrm{C}$ ) nos meses de fevereiro no inverno e junho, respectivamente (Posto da ESALQ, DCE, 2002, Figura 18). A precipitação total anual foi de 1371,8 mm (DAEE, 2002) (média de 1278,0 mm), sendo que a precipitação acumulada dos meses entre abril e setembro correspondeu a apenas $18 \%$ da precipitação total e o restante desta (82\%) ocorreu nos demais meses do ano. $\mathrm{Na}$ Figura 19 é apresentada a relação entre temperatura e precipitação, observando-se uma alta correlação $(0,84)$ entre elas. 


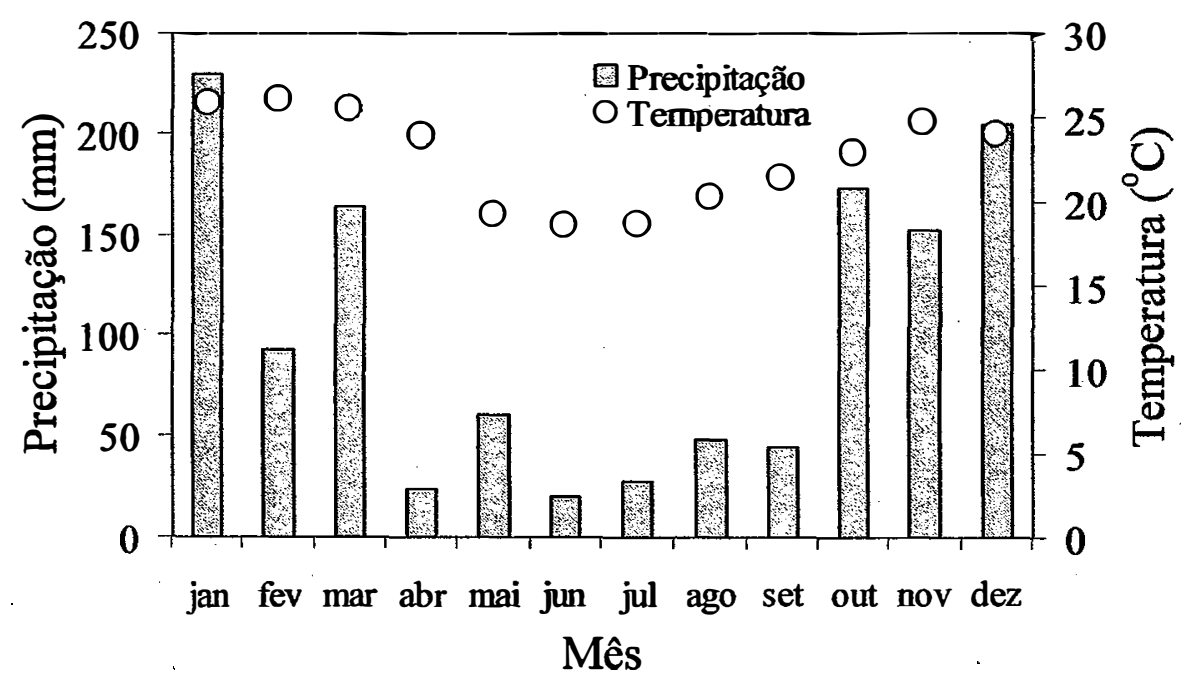

Figura 18 - Precipitação (DAEE, 2002) e temperatura média mensal (DCE, 2002) para o ano de 2001.

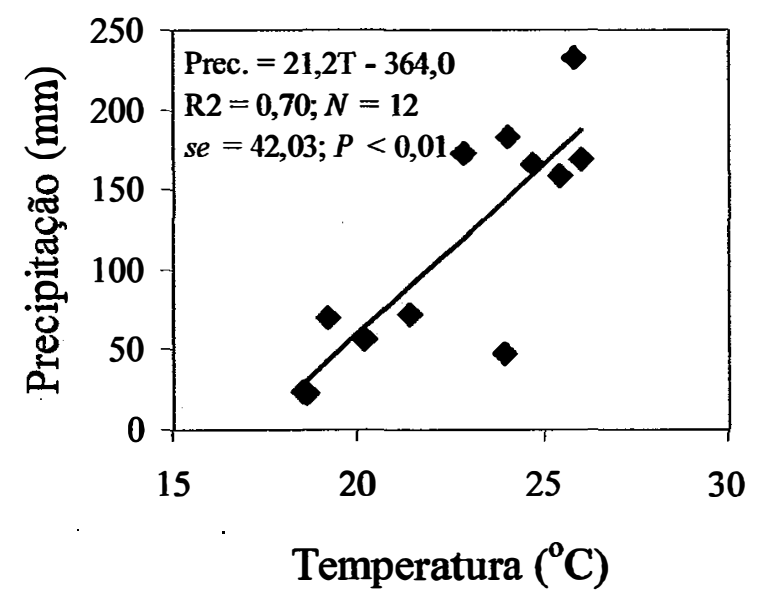

Figura 19 - Diagrama de dispersão entre a temperatura média mensal e a precipitação mensal do ano de 2001.

\subsubsection{Avaliação dos dados de IAF}

O IAF em campo foi medido em áreas de cana-de-açúcar, de pastagem, de milho, de eucalipto e de floresta ripária. A variação total do IAF medido durante a campanha de 
campo de 2001, na área em estudo, foi de 0,16 a 4,90, em áreas de cana-de-açúcar e de floresta ripária, respectivamente. Os dados mensais de IAF por área medida encontramse no Anexo. Segue uma avaliação da variação do IAF para os diferentes tipos de cobertura do solo encontradas na bacia durante a campanha de campo de 2001.

\section{Áreas florestais}

Já foi observado que a utilização do LAI-2000 para a determinação do IAF em áreas florestais pode subestimar este índice (Hingston et al., 1998; Battaglia et al., 1998), devido à violação de algumas pressuposições que a metodologia para cálculo do IAF com este equipamento requer e que em dosséis florestais podem não ocorrer. Como por exemplo temos a distribuição aleatória das folhas, uma vez que em dosséis florestais, geralmente, há presença de sobreposição das folhas (Chen et al., 1991; Chason et al., 1991). É mostrada na Figura 20 a variação do IAF ao longo do ano para as duas áreas de floresta ripária. O valor médio de IAF para floresta ripária foi de 3,14, com máximo de 4,90 (mês de fevereiro, área 11), ocorrido após meses chuvosos. O menor valor de IAF medido foi de 1,71 (área 10), ocorrido no último mês de estiagem (setembro). Medições de IAF em florestas tropicais no Brasil já foram realizadas, podendo-se citar: Roberts et al. (1996), que obtiveram valores de IAF entre 4,63 e 6,00 e Honzák et al. (1996), que estimaram IAF entre 2,97 e 6,18, com o auxílio de fotografia hemisférica, ambos em floresta amazônica.

Uma das causas da variação do IAF em floresta ripária neste trabalho, ao longo do ano, está relacionada às próprias características desta vegetação, que é semidecidual, ou seja, apresenta perda das folhas para parte das espécies durante um período do ano. Foi observada correlação positiva entre o IAF desta vegetação com a precipitação e a temperatura média mensal, de 0,56 e 0,57, respectivamente (Figura 21 ). 


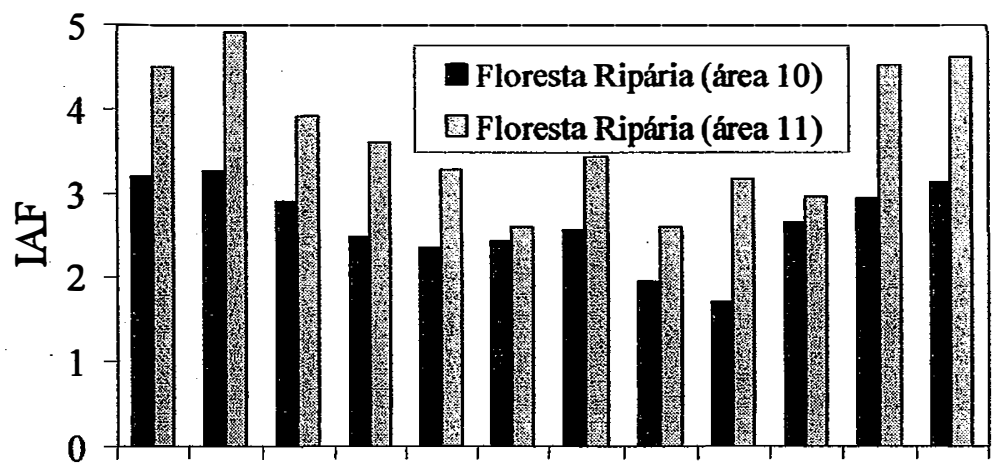

jan fev mar abr mai jun jul ago set out nov dez

Mês

Figura 20 - Variação do IAF ao longo do ano para floresta ripária.

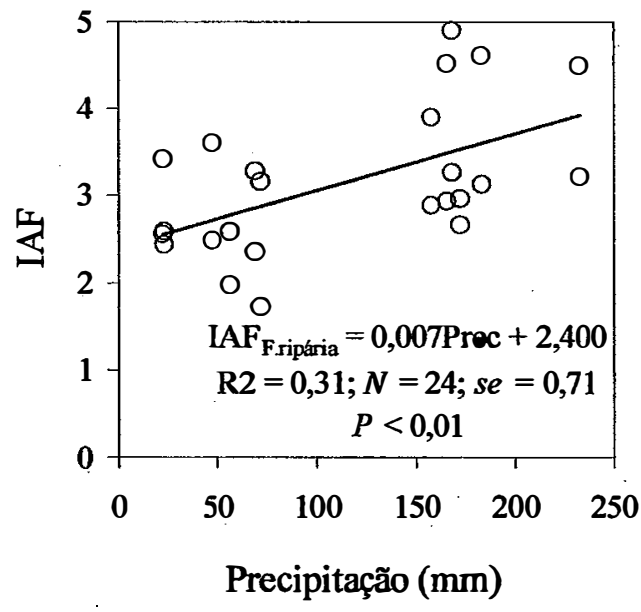

(a)

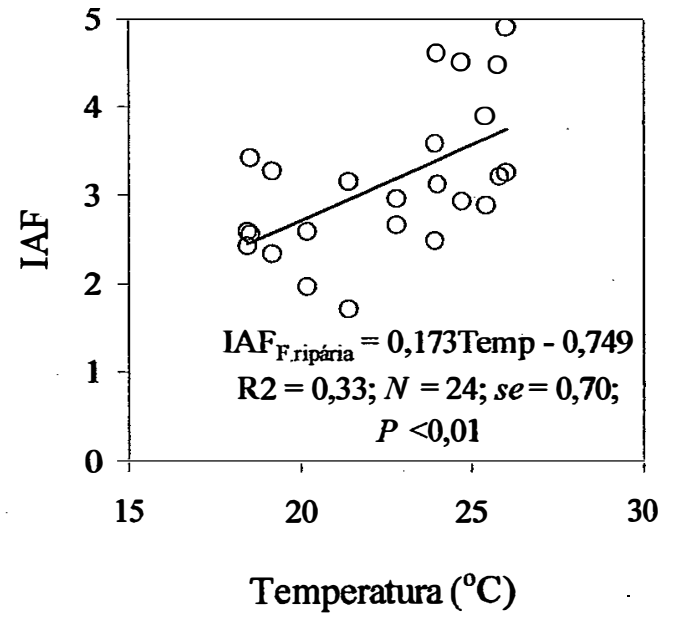

(b)

Figura 21 - Diagramas de dispersão do LAF mensal da floresta ripária com a respectiva precipitação (a) e temperatura média mensal (b).

A Figura 22 mostra a variação do IAF de eucalipto ao longo do ano, para as três áreas onde foram realizadas as medições desta variável. Os valores de IAF mínimo, máximo e médio destas áreas foram de 1,66 (área 40, mês de novembro), 3,13 (área 32, mês de março) e 2,36, respectivamente. No mês de dezembro, duas áreas com eucalipto foram derrubadas (áreas 40 e 41). O equipamento LAI-2000 vem sendo utilizado por diversos autores para estimar IAF de eucalipto (Hingston et al., 1998; Xavier, 1998; 
Ares \& Fownes, 2000). Além dos fatores climatológicos e edáficos que fazem o IAF variar, Xavier (1998) observou que o IAF foi distinto para diferentes materiais genéticos com a mesma idade, assim como o IAF ao longo de seu desenvolvimento pode ter dois comportamentos: estabilizar depois de um certo valor ou apresentar uma queda com a idade. Já Ares \& Fownes (2000) observaram que o IAF em plantações de eucalipto diminui com o aumento da altitude local. Xavier (1998), no Brasil, e Hingston (1998), na Austrália, encontraram IAF máximo de 4,31 e 4,03, respectivamente, medido com o LAI-2000. A variabilidade do IAF desta cultura é bastante alta, dependendo de vários fatores, como os já citados, de tal forma que os dados de IAF encontrados neste wabalho não destoam daqueles de outros estudos.

Não foi observada relação significativa do IAF com a precipitação mensal e a temperatura mensais (Figura 23). Contudo notou-se uma queda de $20 \%$ do IAF ao longo dos meses (IAF de janeiro em relação a novembro, Figura 22), de acordo com o observado por Xavier (1998) para algumas plantações de eucalipto em que o IAF diminuiu com a idade.

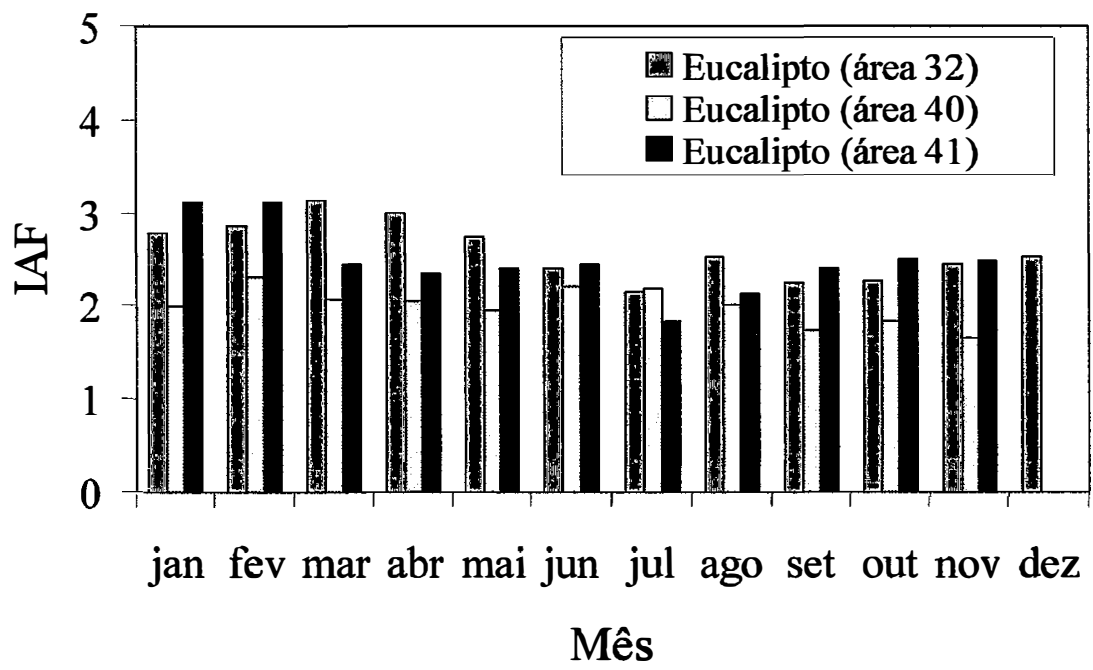

Figura 22 - Variação do IAF ao longo do ano para as plantações de eucalipto. 


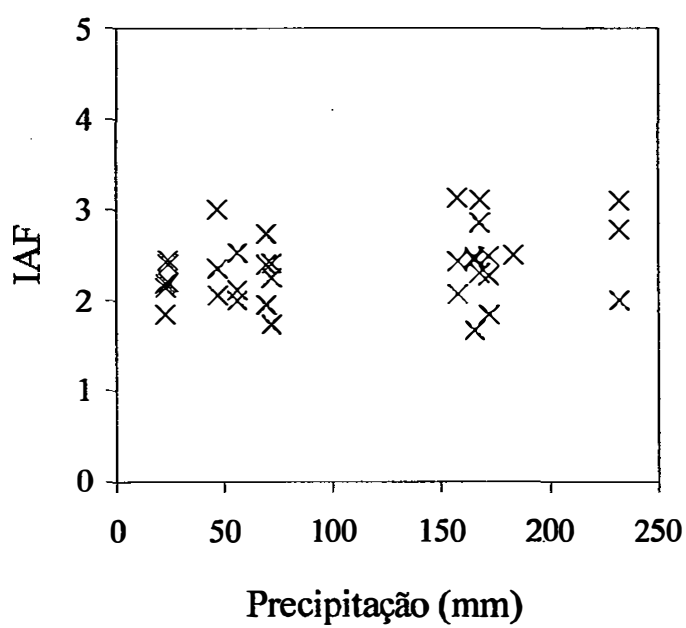

(a)

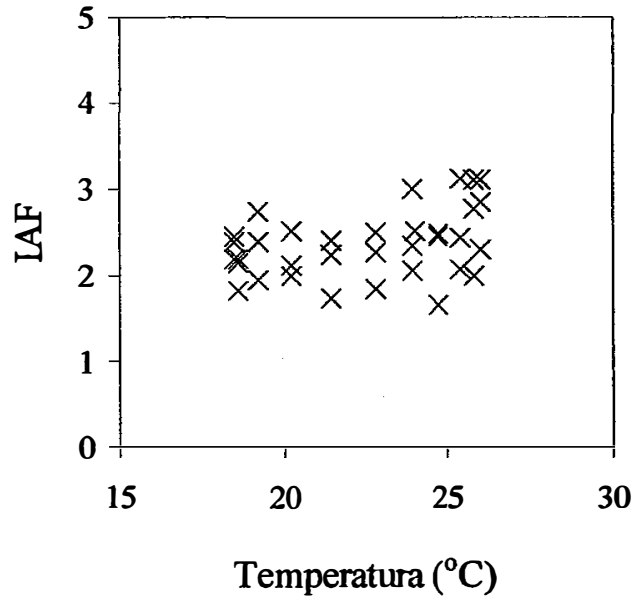

(b)

Figura 23 - Diagramas de dispersão do IAF mensal do eucalipto com a respectiva precipitação (a) e temperatura média mensal (b).

Pastagem

A estimativa de valores de IAF com o equipamento LAI-2000, em áreas de pastagem, tem restrição devido à altura do sensor (Welles \& Norman, 1991), que é de 3 $\mathrm{cm}$, podendo ocorrer subestimativa deste índice em pastagem baixa. No entanto, as pastagens na área em estudo apresentaram altura sempre superior a $10 \mathrm{~cm}$, com exceção do mês de agosto, em que três áreas não foram medidas por se apresentarem completamente secas, devido à estiagem e/ou alta intensidade de pastejo. Na Figura 24 são mostrados os valores de IAF das pastagens ao longo do ano de 2001. O maior valor, o menor e a média de IAF medidos nestas áreas foi 2,45 (área 26, junho), 0,66 (área 36, novembro) e 1,49, respectivamente. Valores de IAF medidos pelo método de pesagens (Daughtry, 1990), no Brasil, variaram de 0,49 a 3,90 (Roberts et al., 1996). Devido à grande dinâmica desta cobertura, relacionada ao pastejo pelo gado, não foi verificada relação significativa do IAF, tanto com a precipitação mensal como com a temperatura média (Figura 25). 


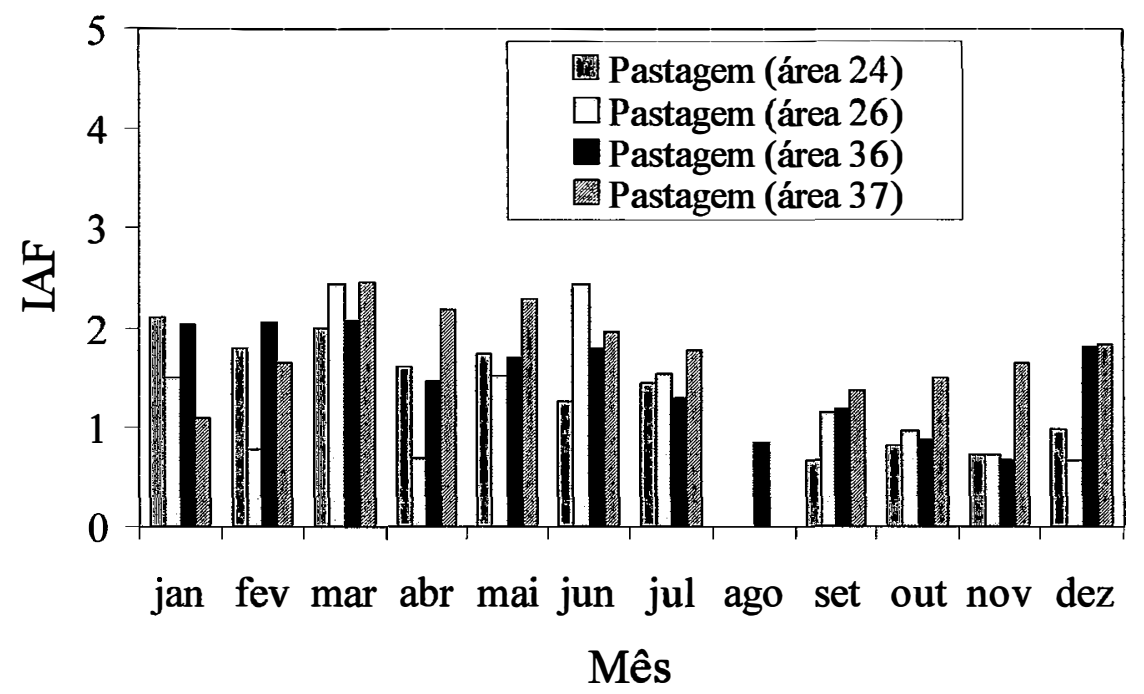

Figura 24 - Variação do IAF ao longo do ano para a pastagem.

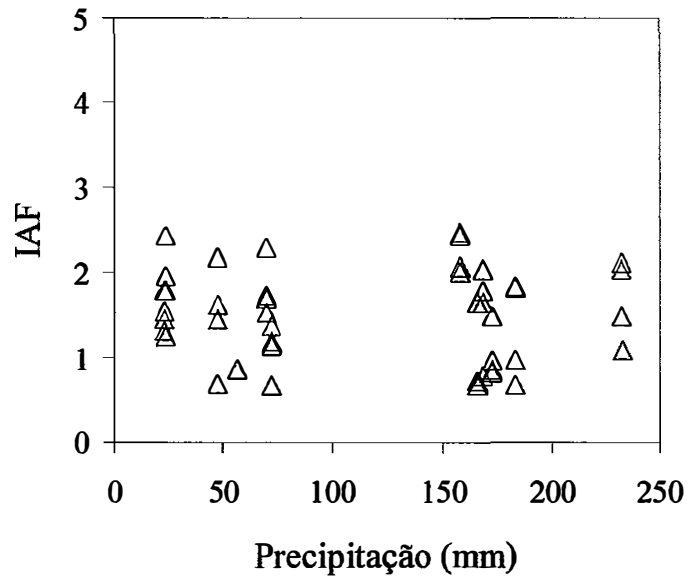

(a)

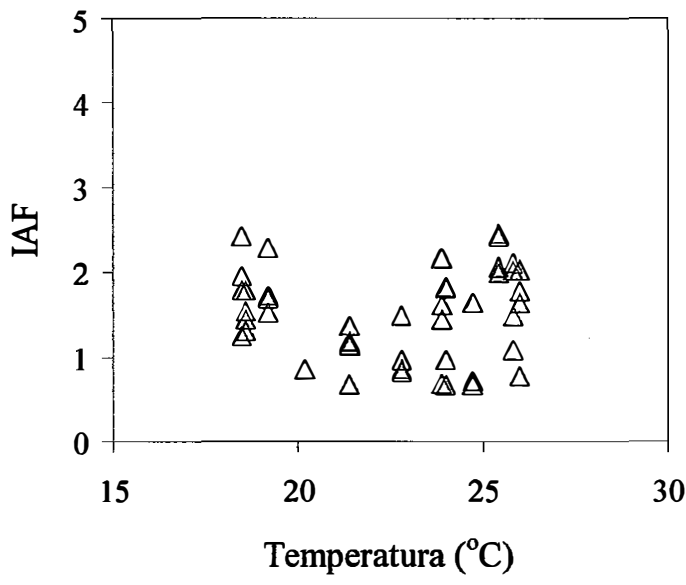

(b)

Figura 25 - Diagramas de dispersão do IAF mensal da pastagem com a respectiva precipitação (a) e temperatura média mensal (b). 
Cana-de-açúcar

O maior valor de IAF em cana-de-açúcar durante a campanha de campo foi de 3,34 (área 38, mês de julho), o qual é inferior aos encontrados em outros estudos (Robertson et al., 1996; Keating et al., 1999; Cheeroo-Nayamuth et al., 2000) e inferior, ainda, ao valor observado por Machado et al. (1982), na mesma região deste estudo (3,70, cana-de-açúcar de 300 dias). Os maiores valores de IAF devem estar associados ao material genético distinto e idade, assim como diferenças entre as técnicas de manejo empregadas na cultura (por exemplo: espaçamento entre plantas, adubação, irrigação etc.) nos diversos estudos.

$\mathrm{Na}$ área de estudo o plantio da cana é concentrado no início do primeiro semestre, permitindo a colheita após 18 meses (cana de ano-e-meio), ou no meio do segundo semestre, com colheita após 12 meses (cana de ano) (Koffler et al., 1979). Observa-se na Figura 26 a variabilidade temporal do plantio/rebrota e de desenvolvimento da cana-de-açúcar, que tiveram como início de plantio/rebrota os meses de junho e julho (Figura 26a) e estendendo-se até os meses de outubro e novembro (Figura 26c), época que coincide com o início das chuvas na região. Algumas áreas que foram acompanhadas encontraram-se em pousio até junho, quando então foi realizado o plantio (Figura 26e). Por fim, na Figura 26d são apresentadas as áreas onde não foi possível estabelecer a época de plantio. 


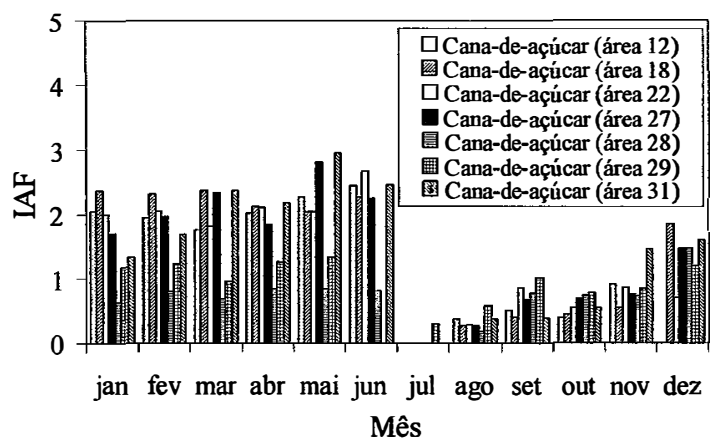

(a)

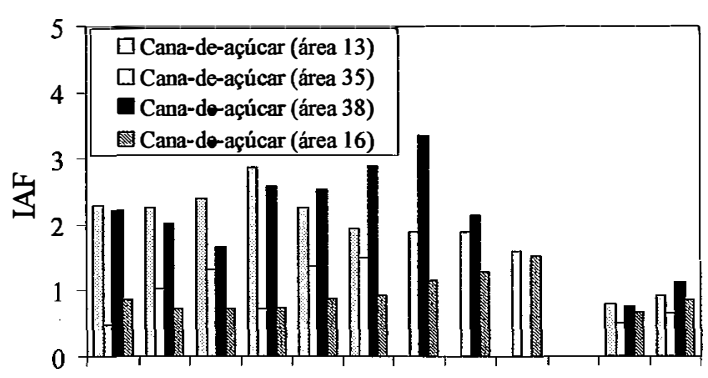

jan fev mar abr mai jun jul ago set out nov dez Mês

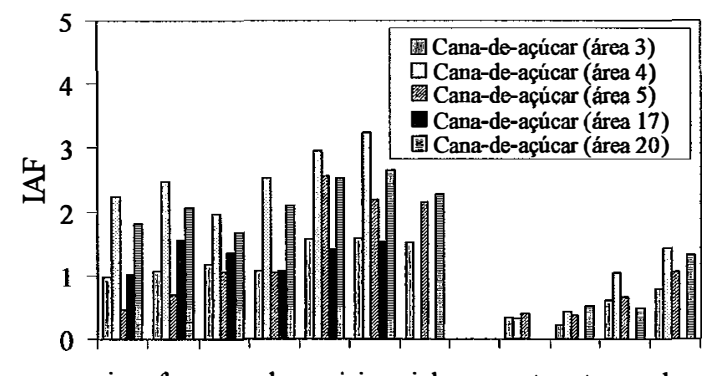

jan fev mar abr mai jun jul ago set out nov dez Mês

(b)

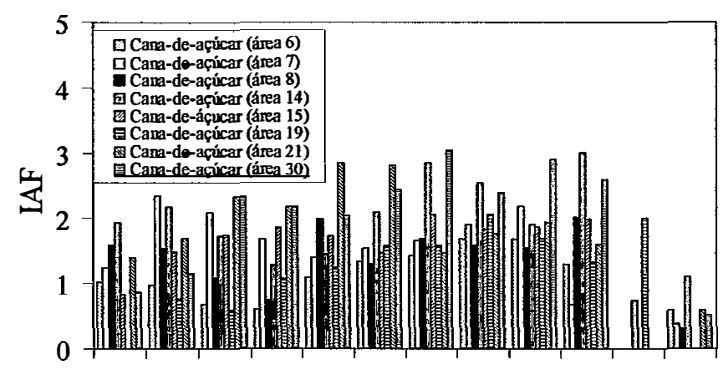

jan fev mar abr mai jun jul ago set out nov dez Mês

(c)

(d)

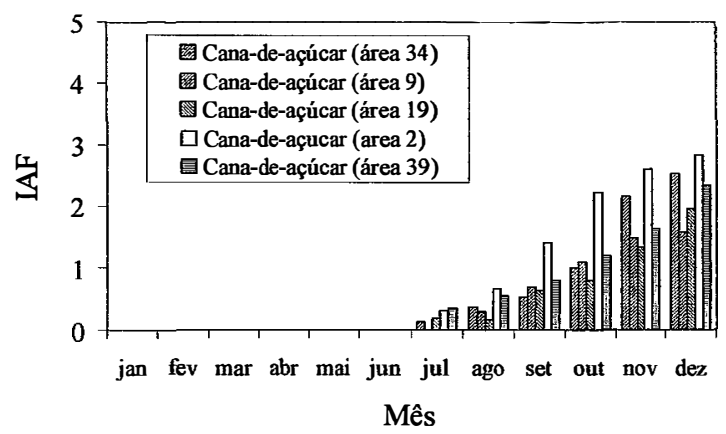

(e)

Figura 26 - Dinâmica do IAF da cultura de cana-de-açúcar na área de estudo, de acordo com o época de plantio ou corte: junho e julho (a); agosto e setembro (b); outubro e novembro (c); sem mês de plantio estabelecido (d); e área em pousio até o mês de maio e plantio em junho e julho (e). 
A Figura 27 apresenta a relação do IAF da cana-de-açúcar com o mês de plantio ou corte (Plantio) e a idade da cultura (Idade), para as amostras coletadas em campo, sendo considerados apenas os dados de IAF das Figuras 26a, 26b, 26c e 26e, pois nas amostras da Figura 26d não foi estabelecida a época do plantio. A variação total do IAF explicada pelo mês de plantio e idade da cultura foi de $47 \%(P<0,01)$. O IAF apresentou maiores valores após aproximadamente 10 meses do plantio, concordando com os resultados de Machado et al. (1982). Este resultado mostra que dificilmente podem-se gerar mapas de IAF em uma determinada época na bacia sem se conhecer bem o uso do solo, já que cada área de cana-de-açúcar tem sua respectiva época de plantio e idade, logo um desenvolvimento do IAF distinto para cada uma. $O$ erro médio na estimativa do IAF foi de 0,65 . O IAF= $f($ Idade, Plantio) foi dado por:

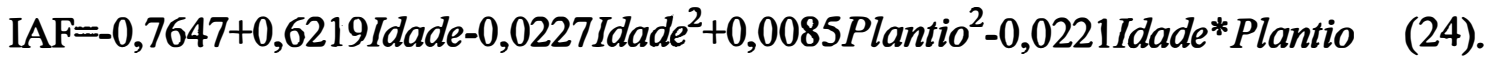

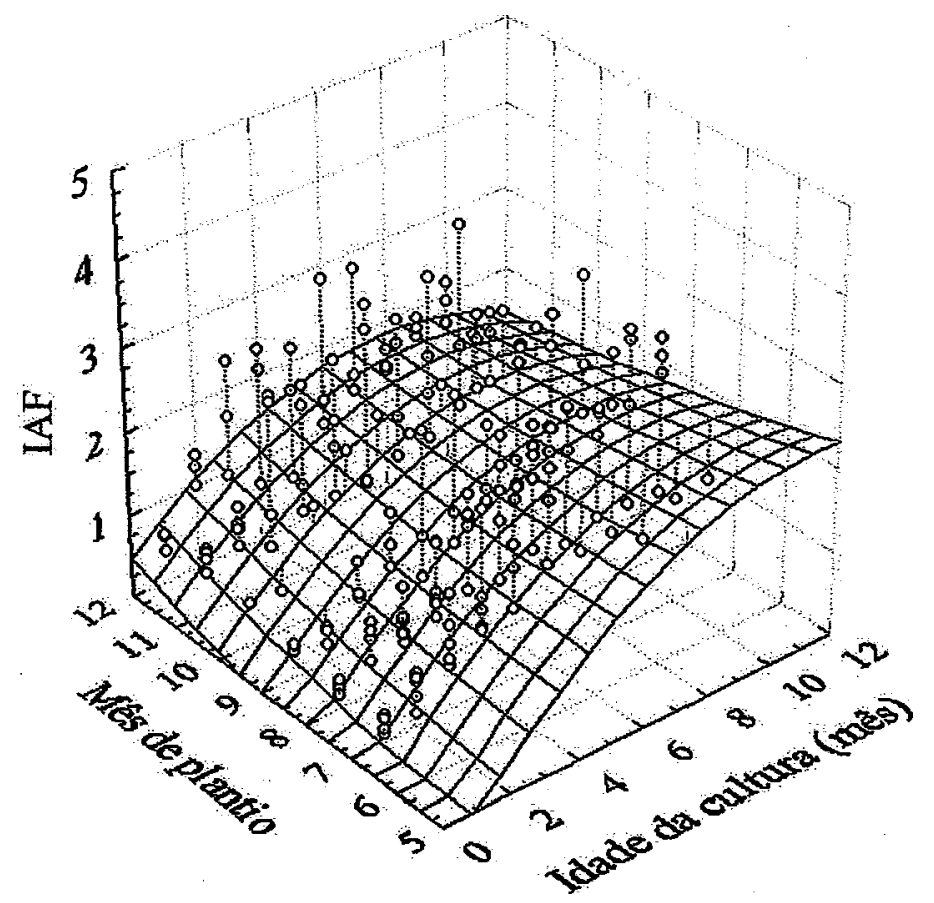

Figura 27 - Relação do IAF da cana-de-açúcar com a época de plantio ou corte e a idade da cultura. 
Milho

Foram observados dois talhões com a cultura do milho (Zea mays), com plantio em outubro, apresentando valor máximo de IAF de 3,07 (área 23, dezembro). Como referência pode-se citar Oliveira et al. (1993), que obtiveram um IAF máximo, em milho irrigado no Brasil, de 2,45. Mais uma vez, diferenças de material genético e manejo, entre os dois estudos, devem explicar esta diferença.

\subsubsection{Relação do IAF com as bandas individuais e com o NDVI}

Na Tabela 9 são apresentados os valores mínimos e máximos do IAF, medidos em campo, por tipo de cobertura do solo, nos meses em que as imagens foram adquiridas (janeiro, março, agosto e novembro). O IAF máximo medido nestas datas foi de 4,51 (floresta ripária, no mês de novembro), enquanto que o menor valor medido foi de 0,16 (cana-de-açúcar, no mês de agosto).

Tabela 9. Número de áreas $(N)$ onde o IAF foi medido, por tipo de cobertura do solo, nas diferentes épocas em que foram adquiridas as imagens. Entre parênteses a variação do IAF para cada tipo de cobertura do solo.

\begin{tabular}{lcccc}
\hline & \multicolumn{5}{c}{ Dados da campanha de campo, para os meses em que as imagens } \\
Cobertura do solo & janeiro & março & agosto & novembro \\
& $N$ e IAF & $N$ e IAF & $N$ e IAF & $N$ e IAF \\
& $($ mín;máx) & $($ mín;máx) & (mín;máx) & (mín;máx) \\
\hline Cana-de-açúcar & $22(0,47 ; 2,37)$ & $23(0,58 ; 2,39)$ & $24(0,16 ; 2,53)$ & $23(0,48 ; 2,60)$ \\
Milho & $2(1,26 ; 1,86)$ & - & - & $2(1,61 ; 2,16)$ \\
Pastagem & $3(1,09 ; 2,03)$ & $3(2,06 ; 2,45)$ & $1(0,85)$ & $4(0,72 ; 1,64)$ \\
Eucalipto & $3(1,99 ; 3,11)$ & $3(2,07 ; 3,13)$ & $3(2,00 ; 2,52)$ & $3(1,66 ; 2,45)$ \\
Floresta Ripária & $2(3,21 ; 4,48)$ & $2(2,89 ; 3,90)$ & $2(1,96 ; 2,59)$ & $2(2,93 ; 4,51)$ \\
Total & $\mathbf{3 2}(\mathbf{0 , 4 7 ; 4 , 4 8 )}$ & $\mathbf{3 1}(\mathbf{0 , 5 8 ;} \mathbf{3 , 9 0 )}$ & $\mathbf{3 0}(\mathbf{0 , 1 6 ; 2 , 5 9 )}$ & $\mathbf{3 4}(\mathbf{0 , 4 8 ; 4 , 5 1 )}$ \\
\hline
\end{tabular}


A Figura 28 mostra os "box-plots" das medidas de IAF nos meses em que as imagens foram adquiridas. Observa-se, com exceção de agosto, que os valores máximos e mínimos de IAF mensais são similares, embora para o mês de novembro a amplitude do $1^{\circ}$ e $3^{\circ}$ quartis foi mais estreita e com menores valores de IAF. Os menores valores de IAF coletados em agosto foram reflexos das condições meteorológicas, com menores precipitações e temperaturas, assim como grande parte da área de cana-de-açúcar, que representa o maior número de amostras, se apresentar em início de desenvolvimento, como mostrado no ítem anterior.

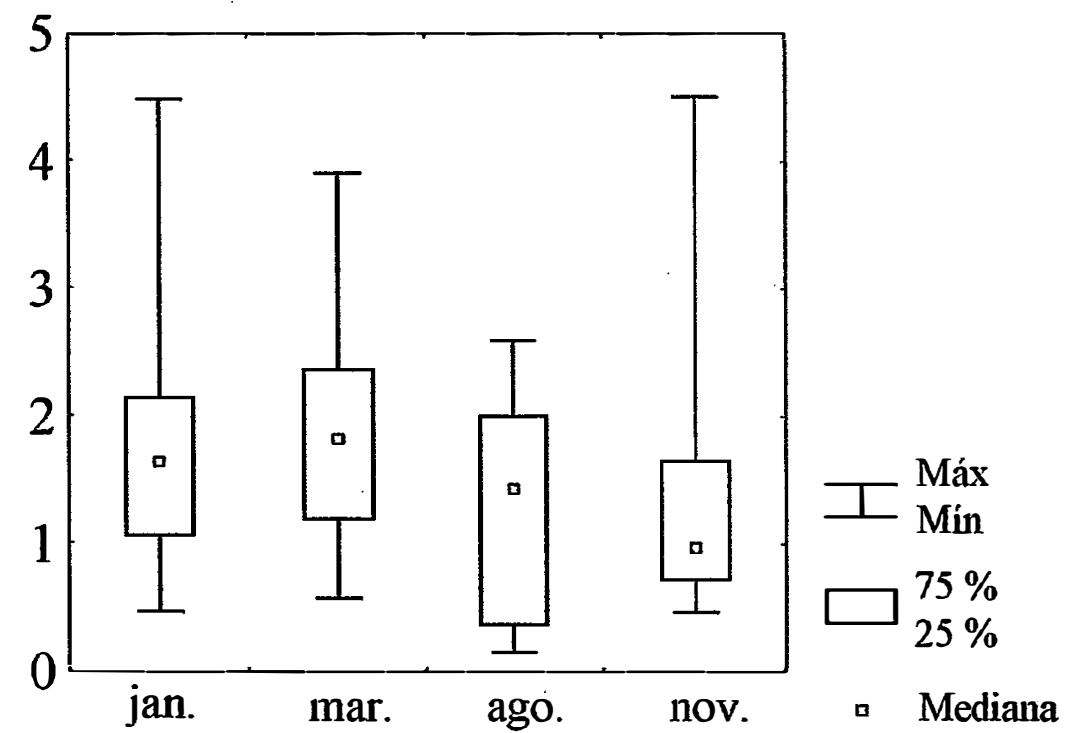

Figura 28 - "Box-plots" das amostras de IAF dos meses em que as imagens foram adquiridas.

Na Figura 29 são apresentados os dados de IAF por tipo de cobertura do solo nos meses em que as imagens foram adquiridas. Os dados de IAF nas datas de janeiro (Figura 29a) e março (Figura 29b) apresentaram uma variação crescente e contínua do IAF nas áreas medidas; enquanto que nos meses de agosto (Figura 29c) e novembro (Figura 29d) observam-se duas faixas distintas de IAF. A primeira delas com valores de IAF menores que 1 (cana-de-açúcar recém plantada ou brotada e pastagem) e a segunda 
com valores de IAF maiores que 1 (dados de IAF de: cana-de-açúcar em avançado estádio de desenvolvimento, floresta ripária e plantações de eucalipto).

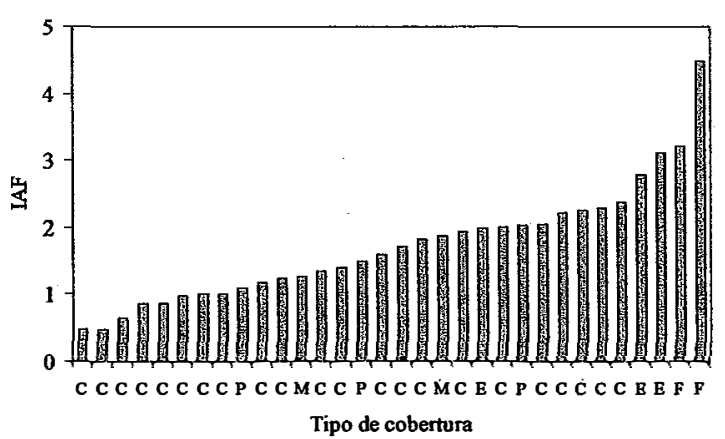

(a)

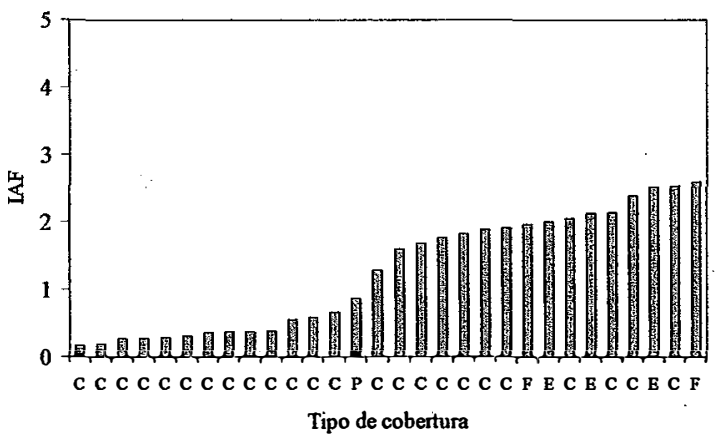

(c)

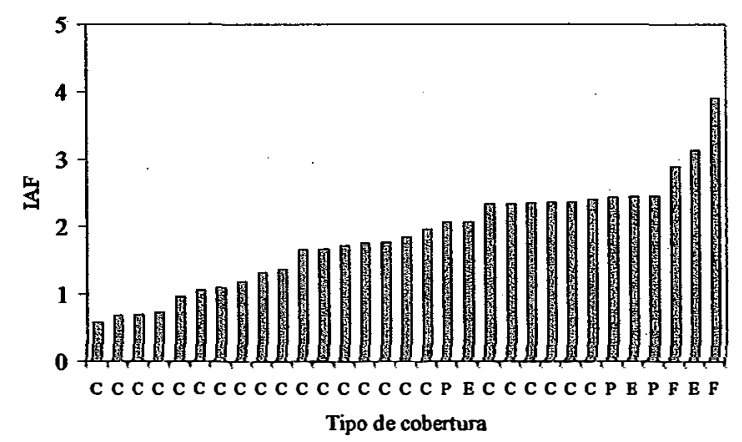

(b)

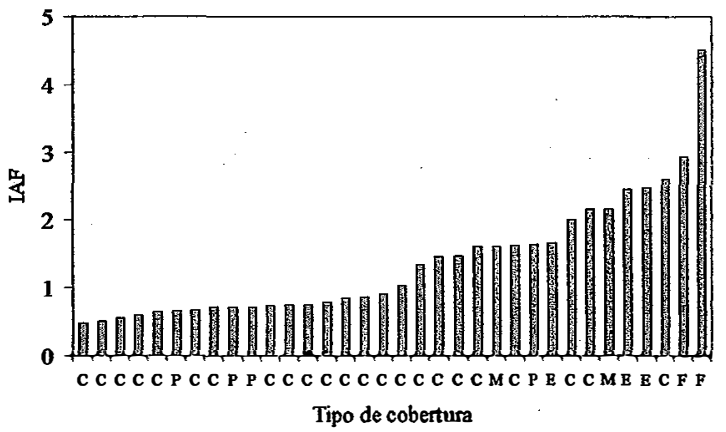

(d)

Figura 29 - Variação do IAF por tipo de cobertura do solo (C, cana-de-açúcar; P, pastagem; M, milho; E, eucalipto; e F, floresta ripária) nos meses em que as imagens foram adquiridas: janeiro (a), março (b), agosto (c) e novembro (d).

Relação do IAF com as bandas individuais (ver e iVP)

A relação IAF-ver é caracterizada pela absorção da radiação neste comprimento de onda pelas folhas, devido à presença de pigmentos nestas, enquanto a relação IAFiVP é caracterizada pelo espalhamento múltiplo da radiação pela vegetação, devido à estrutura celular das folhas e à maior transmissividade destas (Gates et al., 1965). Logo, 
espera-se uma relação negativa entre IAF-ver, ou seja, com o aumento do IAF haveria uma diminuição de ver, devido ao aumento da área foliar capaz de absorver a radiação neste comprimento de onda. Já a relação IAF-iVP é esperada ser positiva, devido ao aumento do espalhamento da radiação nesta faixa de comprimento de onda com o aumento do IAF. A variação de ver e iVP depende, além do IAF, de outros fatores, entre eles: i) estrutura do dossel como um todo (p.ex.: estrutura foliar, a altura da planta, a distribuição do ângulo foliar etc.) (Asrar et al., 1985; Myneni et al., 1997); ii) geometria sol-sensor-alvo (Middleton, 1991; Walter-Shea et al., 1997; Deering et al., 1999); iii) substrato (Huete, 1988); e iv) atmosfera (Myneni \& Asrar, 1994).

A relação IAF-ver para as diferentes datas estudadas (Figura 30) foi significativa $(P<0,01)$. O modelo que melhor se ajustou a esta relação nas diferentes datas foi do tipo linear negativo, com R2 variando de 0,50 a 0,68 (Tabela 10), consistente com a magnitude do R2 de outros estudos para esta relação (Holben et al., 1980, R2 = 0,57 para IAF de soja; Peterson et al., 1987, R2 = 0,89 para IAF de floresta de conífera; Spanner et al., 1990, R2 = 0,80 para IAF de floresta de conífera; e Gong et al., 1995, $\mathrm{R} 2=0,72$ para IAF de várias espécies florestais).

Pode-se observar que as plantações de eucalipto geralmente apresentaram menores valores de ver quando comparadas às demais coberturas com a mesma ordem de grandeza do IAF. Tal comportamento pode estar associado à maior quantidade de sombra nesta cultura, devido à estrutura do dossel. Estas plantações encontravam-se em fase adulta, com espaçamento entre plantas de aproximadamente $3 \mathrm{~m}$, apresentando várias aberturas no dossel, aumentando a quantidade de sombras, logo diminuindo ver. 


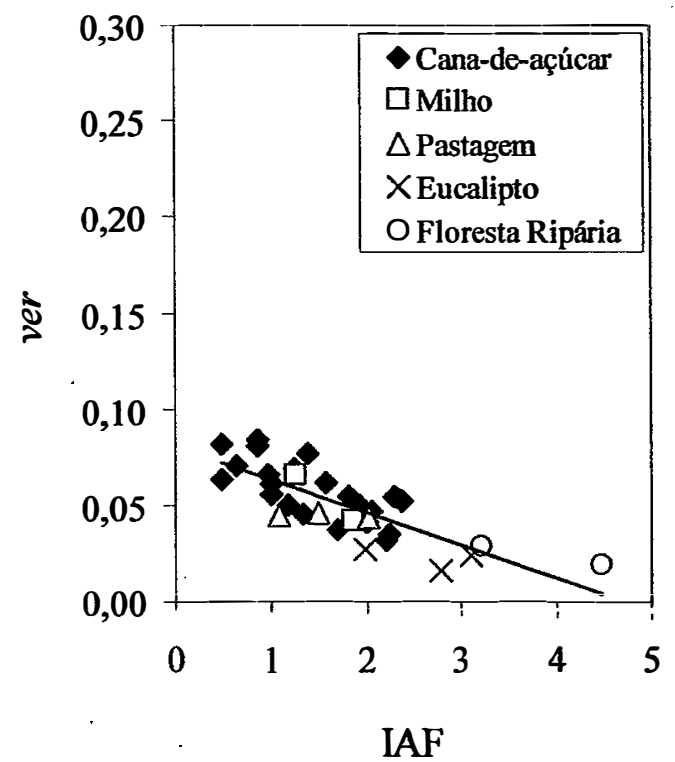

(a)

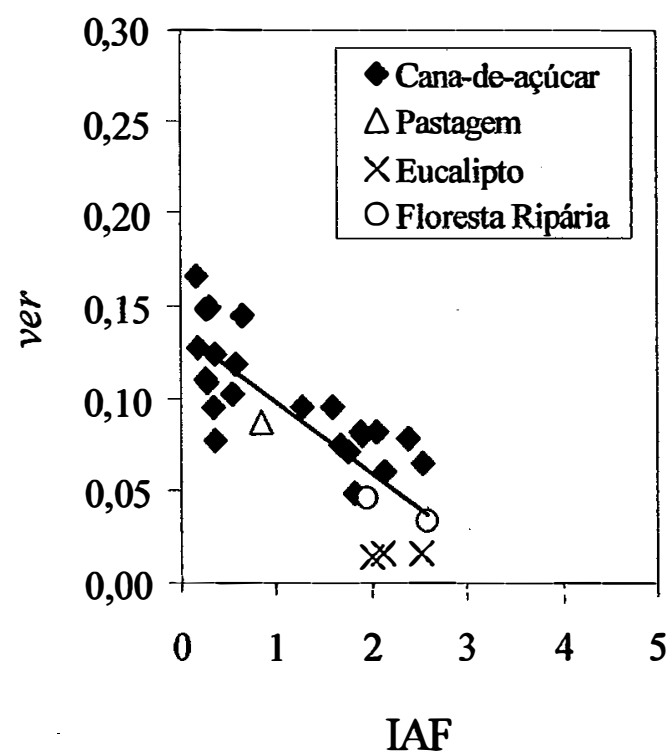

(c)

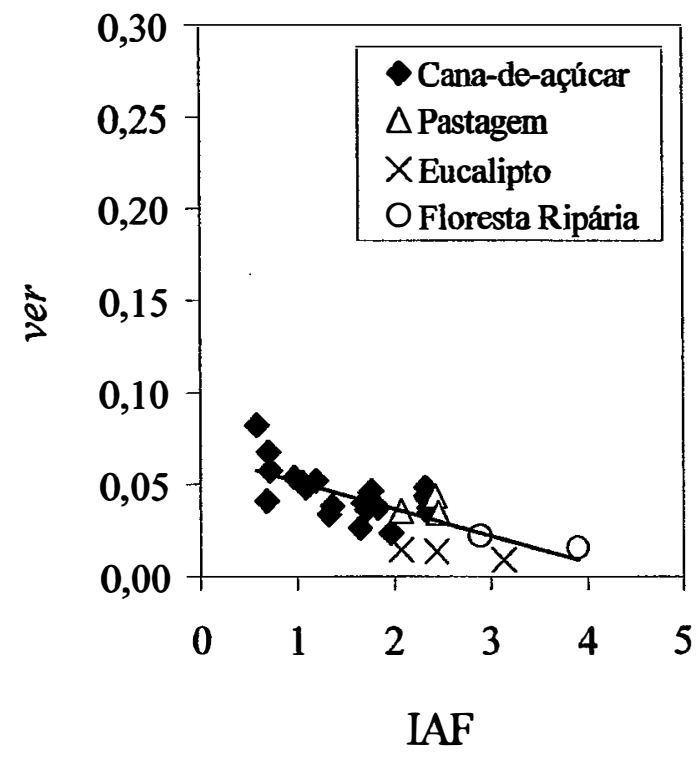

(b)

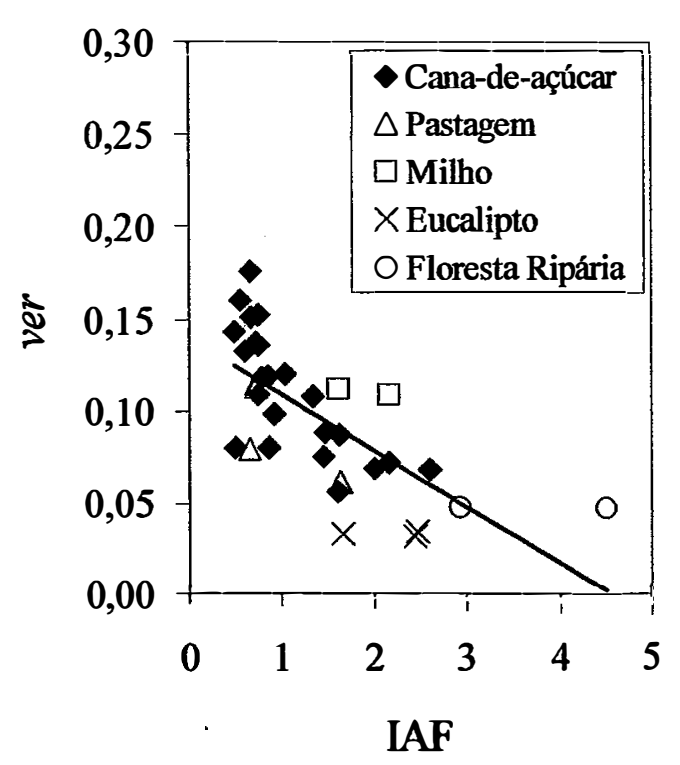

(d)

Figura 30 - Diagrama de dispersão entre IAF e ver para as amostras de janeiro (a), março (b), agosto (c) e novembro (d), com AZS de $32,7^{\circ}, 41,1^{\circ}, 49,7^{\circ}$ e $28,2^{\circ}$, respectivamente. 
Tabela 10. Modelos para a relação IAF-ver e seus coeficientes de determinação (R2), níveis de significância $(P)$ e erro padrão (se) para as 4 imagens adquiridas durante $o$ ano.

\begin{tabular}{ccclccccc}
\hline Fig. & Data & AZS & Modelo & $N$ & $\mathrm{R} 2$ & $P$ & se \\
\hline 30a & $18 / 01 / 01$ & $32,7^{\circ}$ & ver $=-0,0170 \mathrm{IAF}+0,0800$ & 32 & 0,64 & $<0,01$ & 0,01 \\
30b & $23 / 03 / 01$ & $41,1^{\mathrm{o}}$ & ver $=-0,0147 \mathrm{IAF}+0,0665$ & 31 & 0,53 & $<0,01$ & 0,01 \\
30c & $14 / 08 / 01$ & $49,7^{\mathrm{o}}$ & ver $=-0,0382 \mathrm{IAF}+0,1374$ & 30 & 0,68 & $<0,01$ & 0,02 \\
30d & $02 / 11 / 01$ & $28,2^{\circ}$ & ver $=-0,0306 \mathrm{IAF}+0,1397$ & 34 & 0,50 & $<0,01$ & 0,03 \\
\hline
\end{tabular}

As regressões LAF-ver de janeiro e março (Figura 30a e 30b) e agosto e novembro (Figura 30c e 30d), apresentaram interceptos e inclinações respectivas iguais ao nível de $5 \%$ de probabilidade. Uma das justificativas para a variação de ver em níveis similares de IAF nas diferentes datas é a influência do AZS, da reflectância do substrato e da biomassa. Considerou-se, para esta análise, que os efeitos atmosféricos foram corrigidos de forma adequada. Como alguns exemplos do comportamento AZS-ver têmse: i) diminuição do ver com aumento do AZS na cultura de trigo (Jackson et al., 1979); ii) Middleton (1991) observou diferentes comportamentos para esta relação em gramíneas, todavia, o mais freqüente foi a diminuição de ver com o aumento do AZS; iii) diminuição do ver com o aumento do AZS em duas espécies florestais (abeto negro $\mathrm{e}$ pinho do Canadá), em razão do aumento de sombras para maiores AZSs nestes dosséis florestais, e relação AZS-ver quase constante para as plantações de choupo, devido à absorção ser alta, pelo alto valor de IAF desta floresta, tanto para para áreas sob radiação direta como aquelas com sombra (Deering et al., 1999). Considerando, como apresentado nos estudos acima, que o ver diminui, ou no máximo permanece constante, com o aumento do AZS para uma determinada faixa de IAF, tem-se que: os valores de ver de novembro foram maiores ou iguais aos das demais datas, concordando com os estudos citados, uma vez que a imagem de novembro foi adquirida sob o menor AZS $\left(28,2^{\circ}\right)$. Já os valores de ver para o mês de agosto $\left(\mathrm{AZS}=49,7^{\circ}\right)$ contrariam os resultados obtidos em outros estudos, pois mostram-se maiores do que os valores de ver dos meses de janeiro e março, que apresentaram AZSs menores, $32,7^{\circ}$ e $41,1^{\circ}$, respectivamente 
(Figura 31). A justificativa para maiores valores de ver em agosto em relação aos de janeiro e março, deve estar associada: i) ao brilho do substrato em agosto ser maior do que em janeiro e março, devido ao solo apresentar-se mais seco e à presença de matéria seca, contribuindo para que os valores de ver daquela data fossem maiores; e ii) à menor quantidade de biomassa da cana-de-açúcar e da pastagem em agosto, o que tende a aumentar o ver (Tucker, 1979).

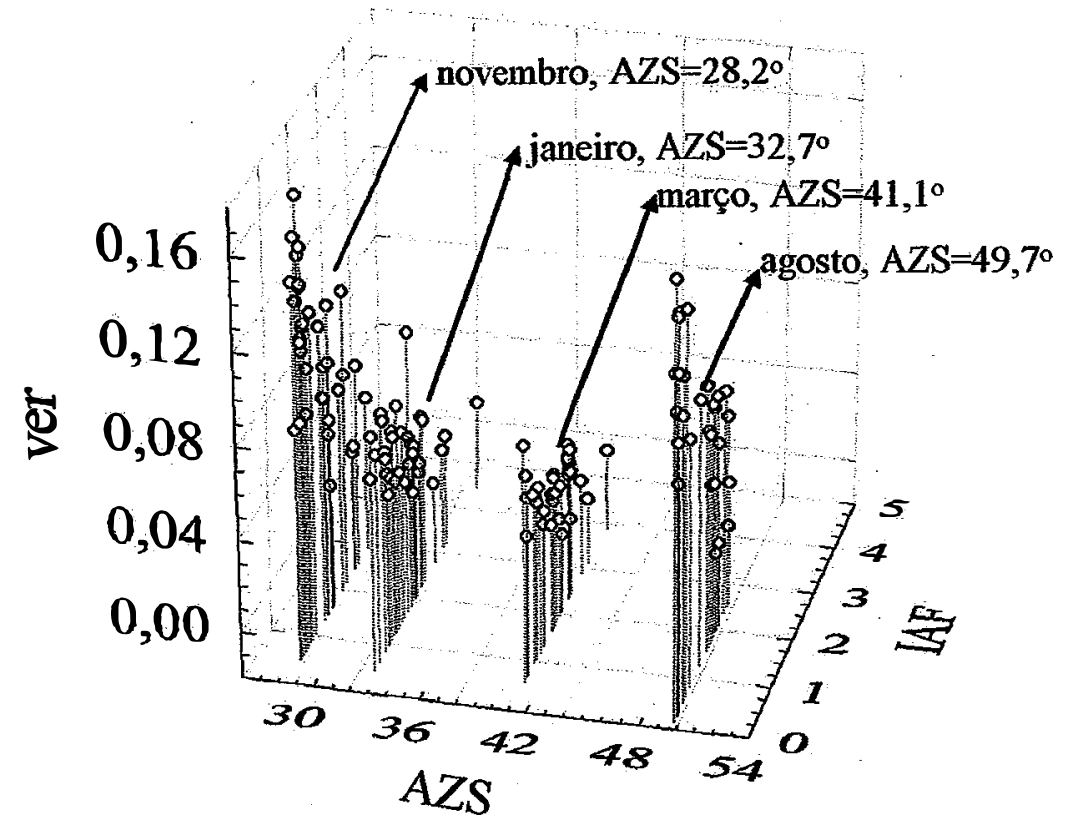

Figura 31 - Diagrama de dispersão IAF-AZS-ver.

Percebe-se que a cultura do eucalipto parece ser menos afetada pelas variações do AZS (Figura 30) e pelo brilho do solo, possivelmente devido à alta quantidade de sombras em diferentes AZSs, minimizando a influência que a reflectância ao nível do solo poderia acarretar na resposta espectral desta cobertura.

As relações IAF-iVP, nas diferentes datas (Figura 32), não foram significativas. Relações não significativas entre IAF e iVP também foram observadas em áreas florestais (Peterson et al., 1987; Spanner et al., 1990). Spanner et al. (1987) observaram que não houve relação significativa entre a radiância na região do infravermelho 
próximo e o IAF de diferentes espécies florestais, devido às diferenças de abertura do dossel, ao tipo de vegetação de sub-bosque e à reflectância ao nível do solo. Neste trabalho, considerando-se apenas os dados de IAF de espécies não-florestais (cana-deaçúcar, pastagem e milho), a relação IAF-iVP torna-se significativa $(P<0,05)$ nos meses de janeiro e março, embora com baixo R2 (0,36 e 0,26, respectivamente). Este resultado pode refletir a influência desta faixa de comprimento de ondas às variações de estrutura do dossel e de reflectância do solo.

Os dados de iVP da cultura de eucalipto, aparentemente, mostram-se com menores valores em relação aos dados de $i V P$ das demais coberturas vegetais, para uma faixa equivalente de valores de IAF. Esta observação pode refletir a maior quantidade de sombras nestas plantações, devido à estrutura do dossel, como discutido anteriormente. 


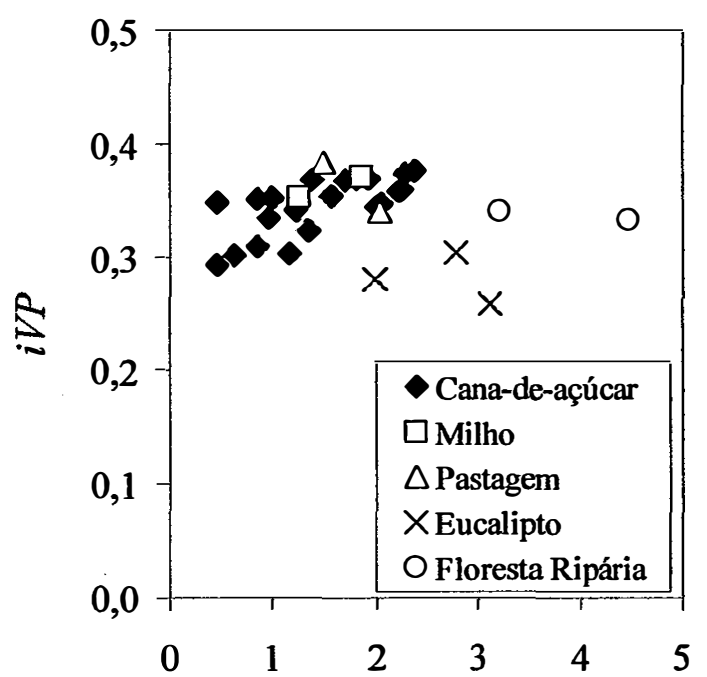

IAF

(a)

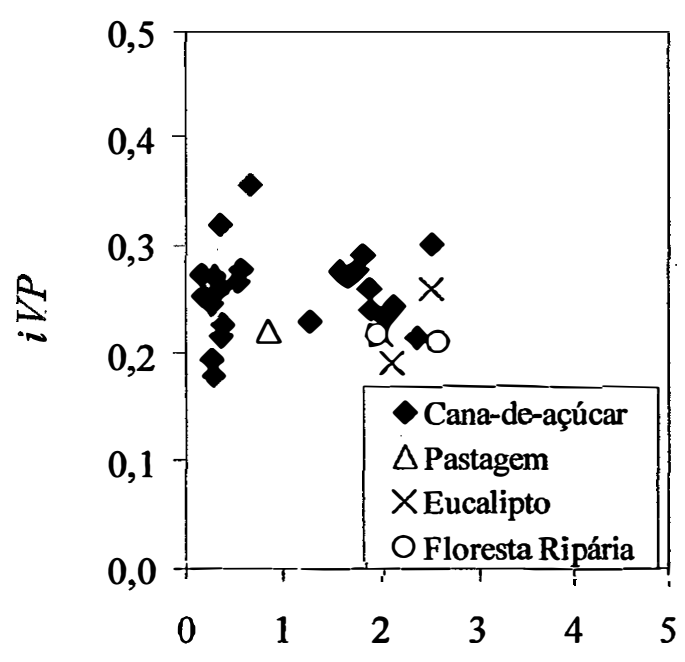

IAF

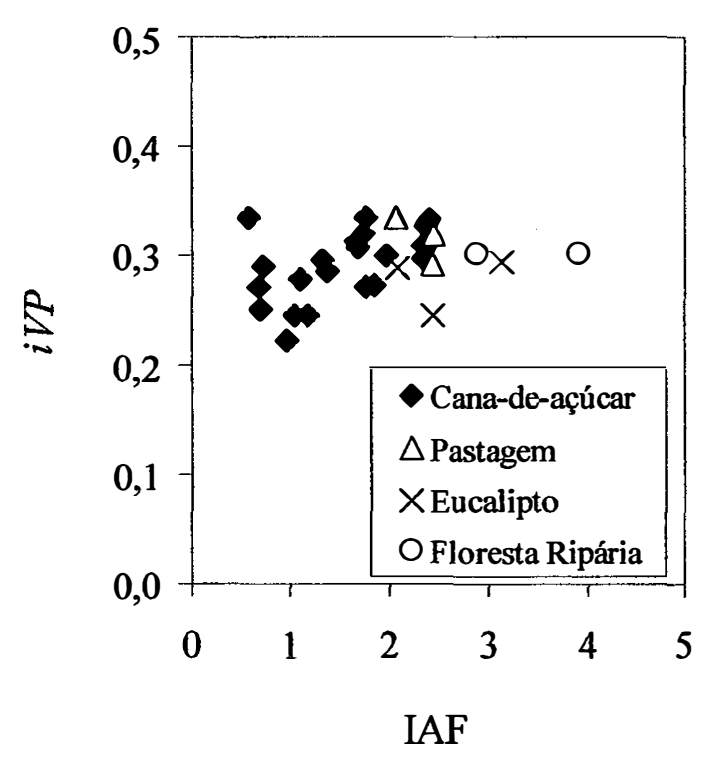

(b)

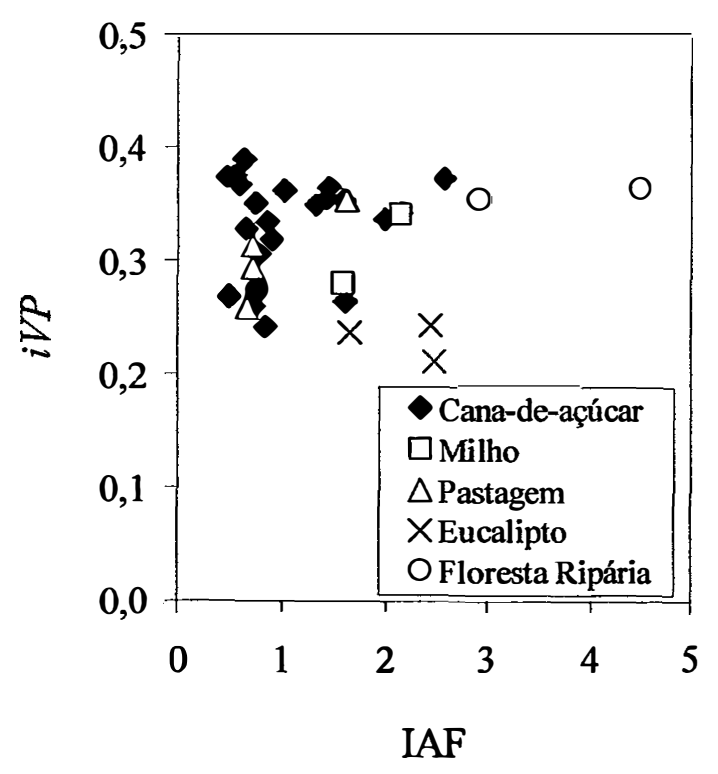

(d)

Figura 32 - Diagrama de dispersão entre IAF e $i V P$ para as amostras de janeiro (a), março (b), agosto (c) e novembro (d), com AZS de $32,7^{\circ}, 41,1^{\circ}, 49,7^{\circ}$ e $28,2^{\circ}$, respectivamente. 
Os valores médios ${ }^{1}$ de $i V P$ para os meses de janeiro, março, agosto e novembro, nas áreas onde o IAF foi medido, foram de $0,34^{\mathrm{a}}, 0,29^{\mathrm{b}}, 0,25^{\mathrm{c}}, 0,32^{\mathrm{ab}}$, respectivamente. Os valores das médias de $i V P$ para cada data são comparáveis, de acordo com a Figura 28. Na Figura 33 é apresentada a relação IAF-AZS-iVP nas diferentes épocas do ano, sendo que o IAF não foi significativo na estimativa do $i V P$ para a faixa de IAF analisada. O AZS conseguiu explicar $35 \%$ da variação do $i V P$ nas quatro datas. $\mathrm{O}$ iVP caiu a uma taxa de 0,0036 por grau de inclinação solar. Diferentes comportamentos na relação AZS-iVP foram verificados em vários estudos, podendo-se citar os trabalhos de Middleton (1991) e Deering et al. (1999). Middleton (1991) observou que, em geral, o iVP em gramíneas aumentou com o aumento do AZS, quando a biomassa verde era relativamente alta, devido à maior quantidade de luz interceptada e ao espalhamento múltiplo pelo dossel em ângulos solares oblíquos. Para dosséis com baixa biomassa, a relação AZS-iVP foi constante ou com comportamento não linear para esta relação, aumentando ou diminuindo o iVP com o aumento do AZS. Já Deering et al. (1999) observaram: i) a diminuição do $i V P$ com o aumento do AZS para abeto negro, como resultado da densa arquitetura do dossel, que resultaria no aumento da absorção da radiação mesmo nesta faixa de comprimento de ondas; ii) iVP quase constante em função do AZS para pinho do Canadá; e iii) aumento de $i V P$ com aumento do AZS para área florestas de choupo. Futuros estudos são sugeridos, com radiometria de campo sob diferentes AZSs e diferentes substratos para as coberturas aqui estudadas, para uma análise mais apropriada dos resultados aqui encontrados.

${ }^{1}$ As médias seguidas pela mesma letra não diferem entre si pelo teste de Tukey, ao nível de $5 \%$ de probabilidade. 


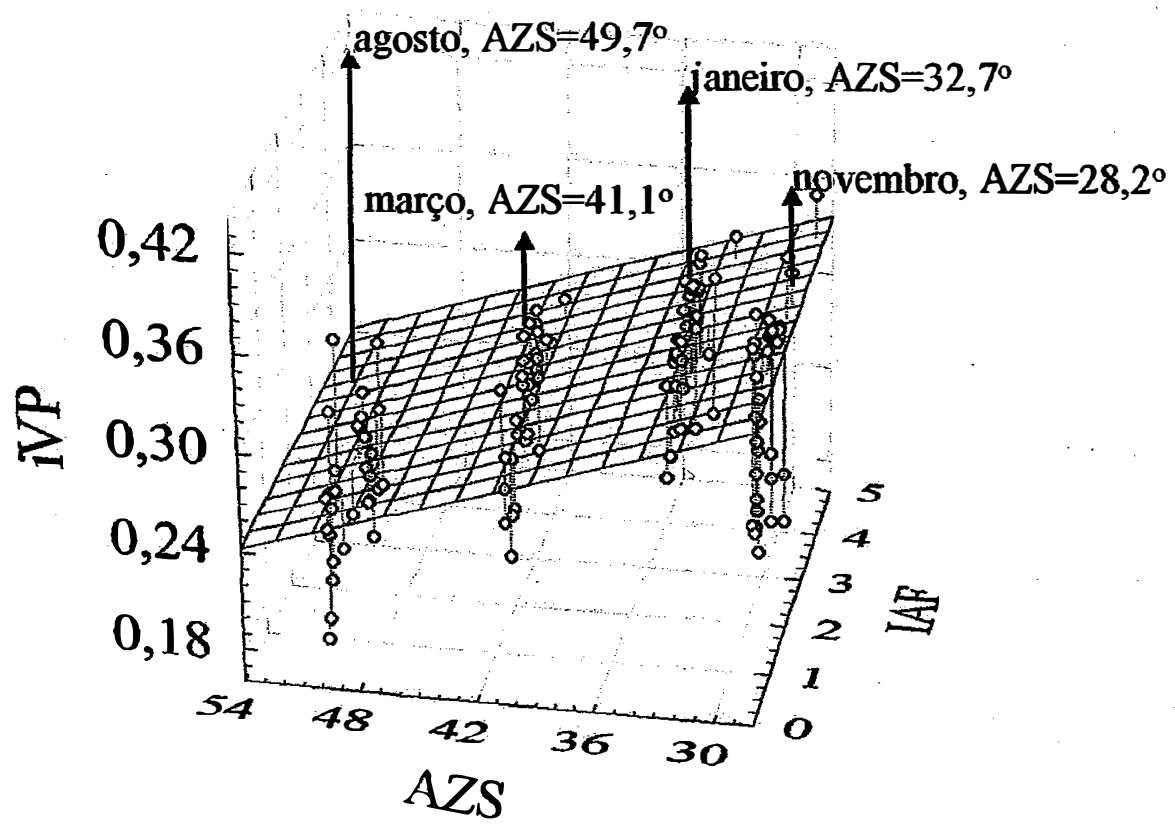

Figura 33 - Relação iVP-AZS-IAF (iVP $=0,4381-0,003625$ AZS; R2=0,35; $s e=0,04$; $P<0,01)$.

Relação LAF-NDVI

O comportamento geral das relações IAF-NDVI das diferentes datas foi similar (Figura 34): $O$ modelo potencial foi o que melhor se ajustou a estas relações. Os coeficientes de determinação (R2) foram estatisticamente iguais, variando de 0,57 (dados de novembro) a 0,72 (dados de janeiro), consistentes com a ordem de grandeza dos R2, para a relação IAF-NDVI, de outros estudos em diferentes espécies vegetais (Peterson et al., 1987; Spanner et al., 1990; Fassnacht et al., 1997; Green et al., 1997; Xavier, 1998; Turner et al., 1999). Os erros padrões das estimativas de NDVI com o IAF variaram de 0,06 a 0,12 (Tabela 11 ). 


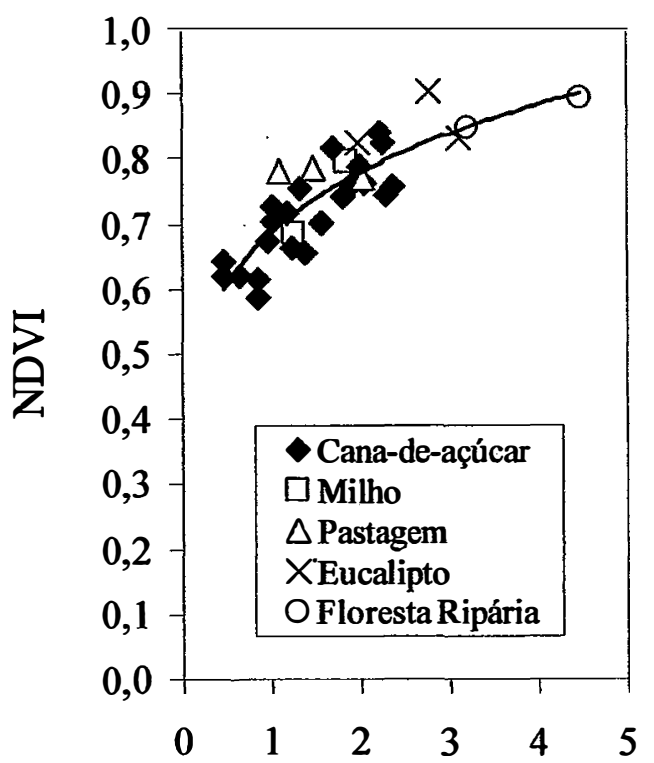

IAF

(a)

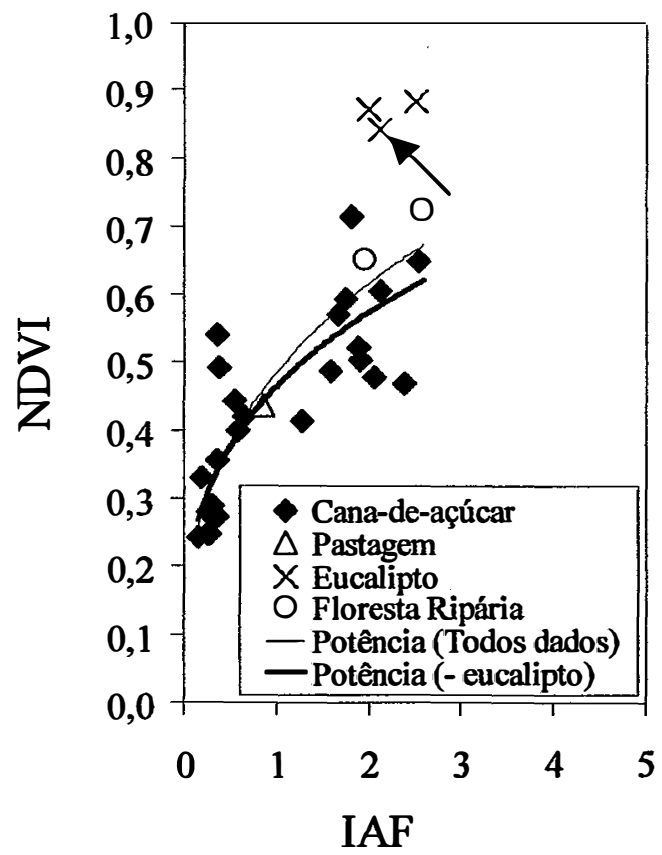

(c)

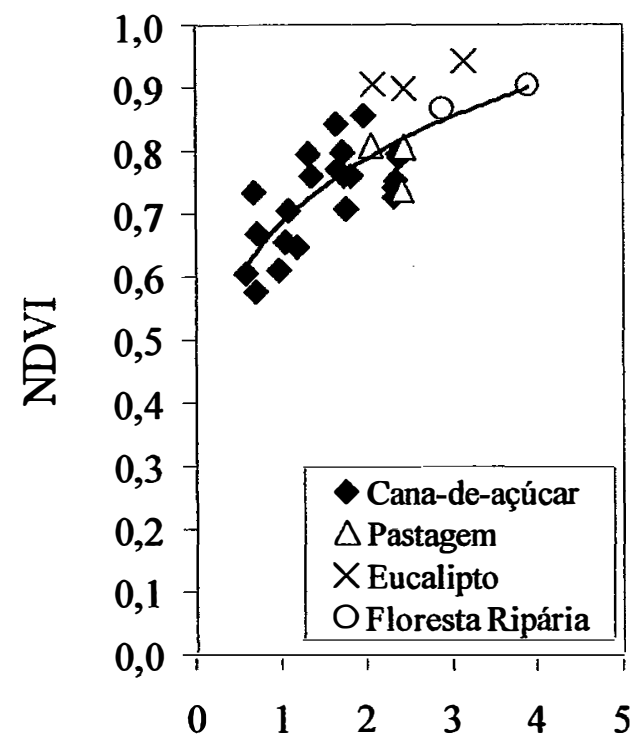

IAF

(b)

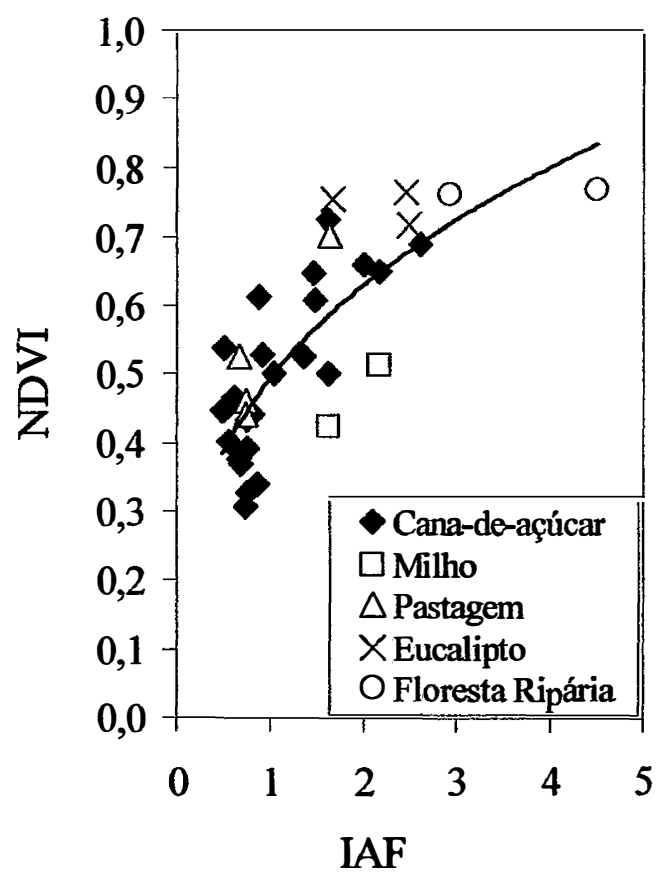

(d)

Figura 34 - Diagrama de dispersão entre IAF e NDVI para os meses de: janeiro (a); março (b); agosto (c); e novembro (d). 
Tabela 11. Modelos para a relação IAF-NDVI para as 4 imagens adquiridas durante o ano.

\begin{tabular}{|c|c|c|c|c|c|c|c|}
\hline Fig. & Data & AZS & Modelo & $N$ & $\mathrm{R} 2$ & $P$ & se \\
\hline $34 a$ & $18 / 01 / 01$ & $32,7^{\circ}$ & $\mathrm{NDVI}=0,687 \mathrm{IAF}^{0,181}$ & 32 & 0,72 & $<0,01$ & 0,06 \\
\hline $34 b$ & $23 / 03 / 01$ & $41,1^{\circ}$ & $\mathrm{NDVI}=0,685 \mathrm{IAF}^{0,200}$ & 31 & 0,62 & $<0,01$ & 0,06 \\
\hline \multirow[t]{2}{*}{$34 c$} & $14 / 08 / 01$ & $49,7^{\circ}$ & $\mathrm{NDVI}=0,486 \mathrm{IAF}^{0,343}$ & 30 & 0,71 & $<0,01$ & 0,12 \\
\hline & & & (a) $\mathrm{NDVI}=0,466 \mathrm{IAF}^{0,302}$ & 27 & 0,70 & $<0,01$ & 0,08 \\
\hline dd & $02 / 11 / 01$ & $28,2^{\circ}$ & $\mathrm{NDVI}=0,496 \mathrm{IAF}^{0,347}$ & 34 & 0,57 & $<0,01$ & 0,09 \\
\hline
\end{tabular}

(a) Modelo com os dados de IAF de eucalipto não sendo considerados.

O NDVI é dependente do comportamento espectral do alvo nas bandas individuais ver e $i V P$, uma vez que NDVI $=f($ ver, $i V P)$, sendo a resposta de cada banda individual o resultado da relação alvo-sensor-fonte. Todavia, estudos relacionando o NDVI com AZS já foram realizados, podendo-se citar: Deering et al. (1999), que observaram que o NDVI aumentou com o aumento do AZS para abeto negro e pinho do Canadá e permaneceu constante para choupo; Middleton (1991), que observou os seguintes comportamentos na relação NDVI/SR-AZS em gramíneas: i) relação linear positiva; ii) relação linear negativa; iii) valor de NDVI alto e constante; e iv) valor de NDVI baixo e constante; todavia, os comportamentos mais comuns foram o i) e iv). Quanto ao brilho do solo tem-se que, com o aumento deste o NDVI diminui (Liu \& Huete, 1995) e diminui, em maior magnitude, para dosséis mais abertos (Bausch, 1993).

Para entender adequadamente a relação IAF-NDVI deste trabalho, precisa-se compreender primeiro a dependência do NDVI às variações de ver e de iVP. Epiphanio \& Huete (1995) já estudaram esta dependência; todavia, neste trabalho, esta relação será avaliada para as amplitudes de valores de ver e iVP aqui encontradas. Na Figura 35 é apresentada a resposta do NDVI em relação a ver e a iVP. O NDVI aumenta com o aumento do iVP e com a diminuição do ver, tornando-se, desta forma, bastante conveniente em estudos de vegetação, uma vez que quanto mais vegetação (em termos 
de IAF ou fração de cobertura vegetal) tem-se, teoricamente, menores valores de ver e maiores de iVP e, conseqüentemente, maiores valores de NDVI.

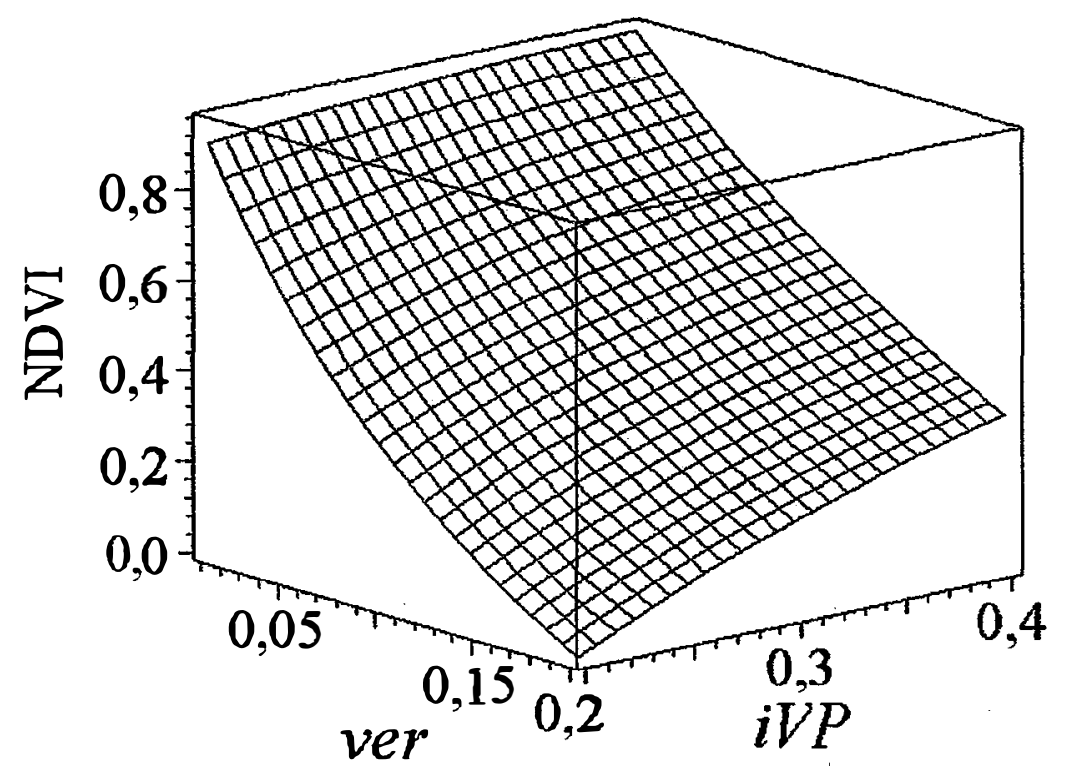

Figura 35 - Resposta do NDVI a variações do ver e do iVP (faixa de valores de ver e iVP similares aos encontrados neste trabalho).

Como pode ser observado na Figura 35, a taxa de crescimento do NDVI não é linear com mudanças de ver e de iVP. Por meio das derivadas parciais do NDVI em relação ao ver $\left(f_{\text {ver }}(v e r, i V P)\right)$ e ao $i V P\left(f_{i V P}(v e r, i V P)\right)$ pode-se notar como o NDVI varia com mudanças no ver e no iVP quando, respectivamente, iVP e ver são constantes. Observa-se que $f_{v e r}(v e r, i V P)$ é maior (em módulo) quando iVP e ver são pequenos, tornando-se menor à medida que estes aumentam (Figura 36a); enquanto $f_{i V P}(v e r, i V P$ ) é maior quando iVP é pequeno e ver é grande (Figura 36b). Todavia, a variação do NDVI é maior para variações do ver (ver magnitude das derivadas). 


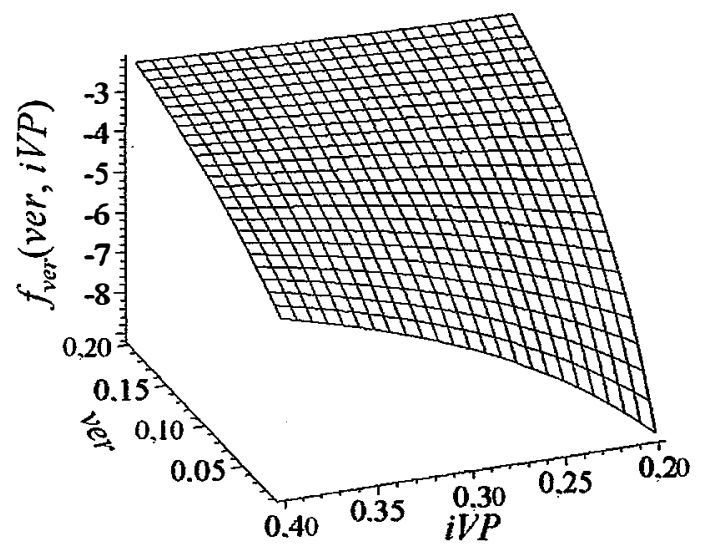

(a)

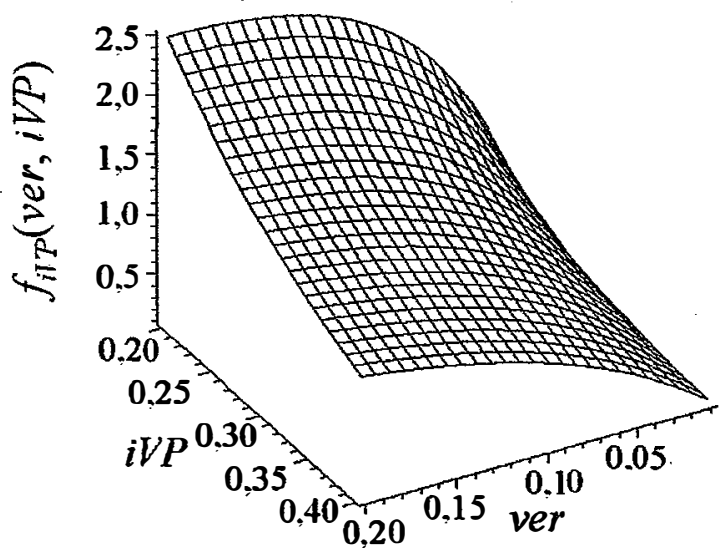

(b)

Figura 36 -Derivadas parciais do NDVI $=f(v e r, i V P)$ em relação a ver (a) e a $i V P(b)$.

Na Figura 37 é apresentado o campo gradiente do NDVI, que visa a avaliar, de forma mais adequada, o comportamento deste índice frente às variações das bandas individuais concomitantemente. Os vetores apontam na direção em que a taxa de aumento do NDVI é máxima. Nota-se que o fator dominante na variação do NDVI é o ver, com exceção de ver alto, ou seja, a taxa de aumento do NDVI está em grande parte relacionada com as variações do ver e não com a do iVP, para as amplitudes de reflectância das bandas individuais obtidas neste rabalho. O NDVI aumenta em uma taxa maior, principalmente quando ver for pequeno, diminuindo com o aumento de $i V P$ e de ver, ou seja, pequenas variações do ver, quando ele é pequeno, fazem com que o NDVI varie muito, quase que independentemente de $i V P$. 


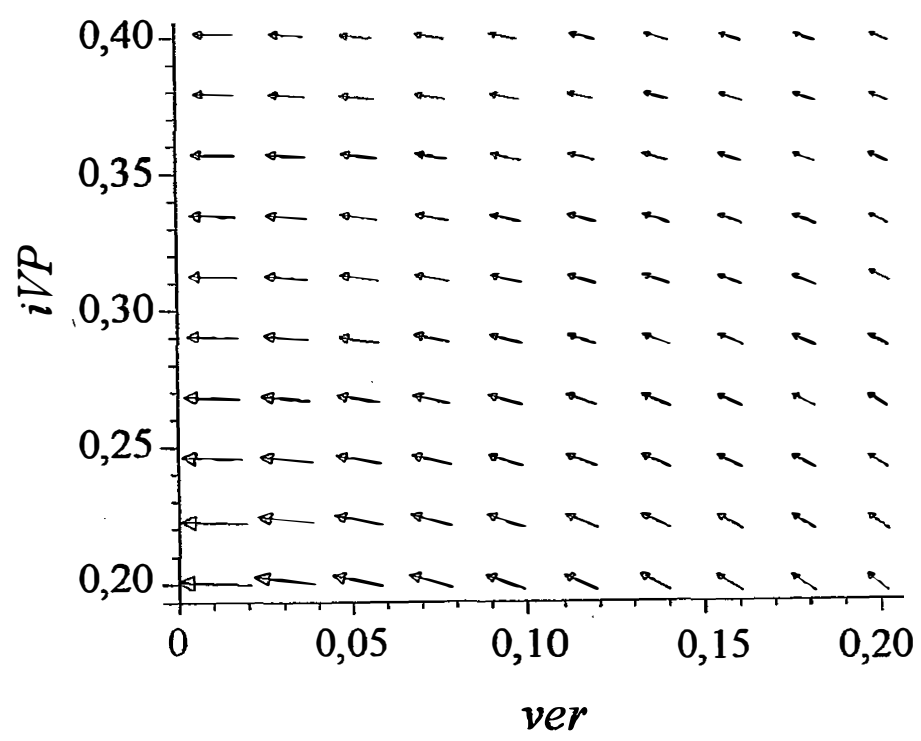

Figura 37 - Campo gradiente do NDVI, ou seja, $\nabla f(v e r, i V P)=f_{v e r}($ ver, $i V P) \mathbf{i}+f_{i V P}($ ver, iVP)j. Os vetores apontam na direção em que a taxa de aumento do NDVI é máxima.

O comportamento do NDVI, em relação às bandas individuais, mostrado anteriormente, explica porque os valores de NDVI de janeiro e março foram maiores do que os dos meses de agosto e novembro (Figura 34), devido, principalmente, aos menores valores de ver de janeiro e março (Figura 30). Também explica por que as plantações de eucalipto geralmente apresentaram maiores valores de NDVI para correspondentes IAFs de outras coberturas, o que pode ser observado com mais clareza no mês de agosto (Figura 34c), sendo resultado dos menores valores de ver encontrados nestas plantações para correspondentes valores das outras culturas (Figura 30c), na mesma faixa de IAF. Retirando-se os valores de IAF de eucalipto de agosto, o modelo não apresentou aumento do R2 (Tabela 11), contudo houve uma queda no erro estimado do NDVI (de 0,12 para 0,08 ).

Por fim, considerando-se que as medições de IAF foram precisas, a não saturação do NDVI para os valores de IAF observados é consistente com outros trabalhos (Gong et 
al., 1996; Spanner et al., 1990; Turner et al., 1999), uma vez que a saturação ocorreria para valores de IAF maiores que 5,00.

\subsubsection{Análise dos mapas de IAF}

A geração de mapas de IAF por meio de relações entre IAF e índices de vegetação vem sendo realizada com bastante sucesso. Um exemplo recente foi o trabalho realizado por Chen et al. (2002), que geraram mapas de IAF para todo o Canadá com auxílio do índice de vegetação SR (iVP/ver). Neste trabalho os modelos utilizados para gerar os mapas de IAF foram avaliados seguindo a metodologia de Gong \& Miller (1995). Os dados de IAF coletados em campo, para cada data, foram divididos em dois grupos: o primeiro (grupo de predição) consistiu dos dados para predição do modelo, com 22, 21, 20 e 24 amostras, nos meses de janeiro, março, agosto e novembro, respectivamente, e o segundo grupo (grupo de teste), com 10 amostras para cada mês, utilizado para teste dos modelos de predição, por meio do se e do R2. A divisão dos dados nos dois grupos foi feita aleatoriamente. Os coeficientes de determinação dos modelos de predição variaram de 0,54 a 0,74 (Tabela 12), sendo que o modelo que melhor se ajustou aos dados de todas as datas foi do tipo potencial. Os se do grupo de teste variaram entre 0,42 a 0,87 (novembro e agosto, respectivamente), com R2 variando de 0,41 a 0,78 (agosto e janeiro, respectivamente).

Tabela 12. Modelos de predição do IAF para as diferentes datas.

\begin{tabular}{llcccc}
\hline Mês & Modelo & $N$ & R2 & $P$ & $s e$ \\
\hline janeiro & $\mathrm{IAF}=4,5459 \mathrm{NDVI}^{3,4957}$ & 22 & 0,74 & $<0,01$ & 0,38 \\
março & $\mathrm{IAF}=4,4864 \mathrm{NDVI}^{3,6161}$ & 21 & 0,59 & $<0,01$ & 0,57 \\
agosto & $\mathrm{IAF}=4,1903 \mathrm{NDVI}^{2,1382}$ & 20 & 0,72 & $<0,01$ & 0,57 \\
novembro & $\mathrm{IAF}=3,6815 \mathrm{NDVI}^{1,7807}$ & 24 & 0,54 & $<0,01$ & 0,67 \\
\hline
\end{tabular}




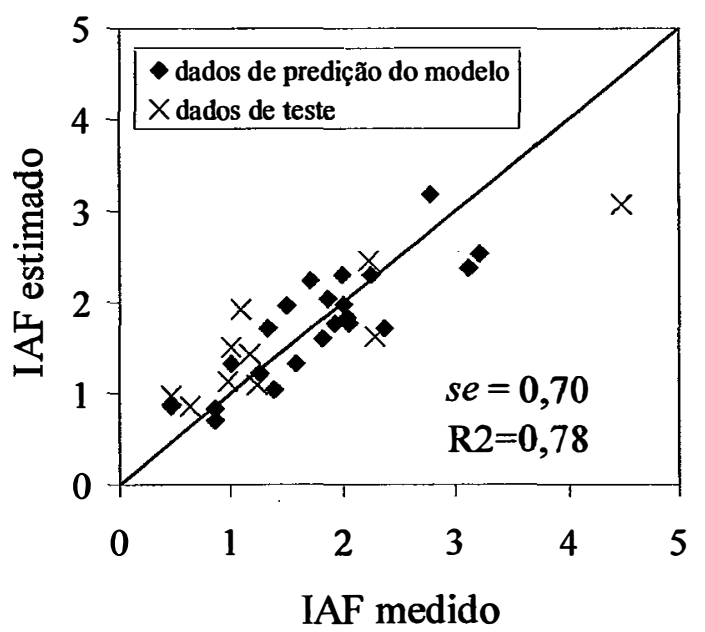

(a)

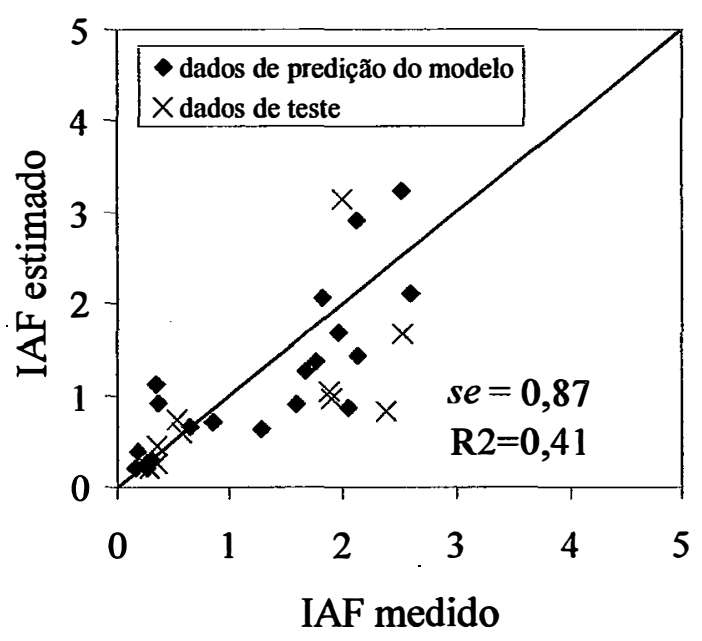

(c)

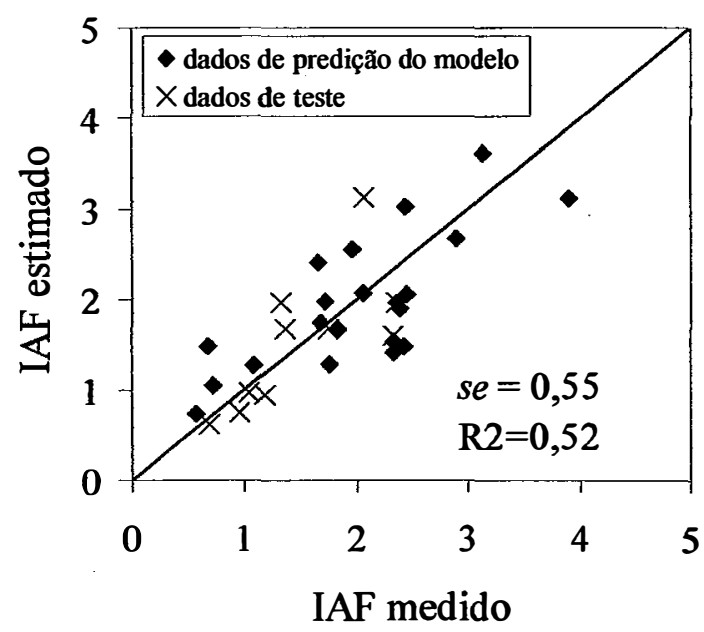

(b)

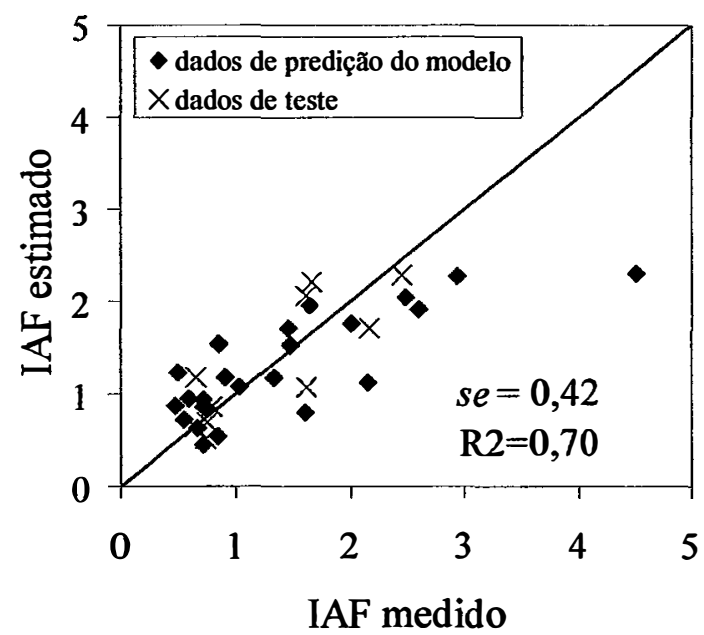

(d)

Figura 38 - Diagramas de dispersão entre IAF medidos e IAF predito a partir dos modelos baseados na relação IAF-NDVI (Tabela 12), para os meses de janeiro (a), março (b), agosto (c) e novembro (d).

Os modelos da Tabela 12 foram aplicados às respectivas imagens NDVI para estimativa do IAF, sendo os mapas apresentados na Figura 39. Os valores de IAF médio 
na bacia, nas datas de janeiro, março, agosto e novembro foram de 1,59, 1,59, 0,97 e 1,28, respectivamente (Tabela 13). Nota-se, em tons escuros (Figura 39) as áreas correspondentes à floresta ripária, que acompanham as margens dos cursos d'água e apresentam maiores valores de IAF.

Tabela 13. Estatística descritiva da estimativa do IAF na bacia por meio das relações IAF-NDVI (Tabela 12) nas diferentes datas.

\begin{tabular}{lcccc}
\hline & janeiro & março & agosto & novembro \\
\hline Figura & $39 \mathrm{a}$ & $39 \mathrm{~b}$ & $39 \mathrm{c}$ & $39 \mathrm{~d}$ \\
Média & 1,59 & 1,59 & 0,97 & 1,28 \\
Mediana & 1,65 & 1,65 & 0,85 & 1,30 \\
Desvio padrão & 0,89 & 0,83 & 0,70 & 0,66 \\
Variância da amostra & 0,78 & 0,69 & 0,49 & 0,43 \\
Máximo & 4,20 & 4,20 & 4,60 & 3,00 \\
\hline
\end{tabular}

A variação de IAF médio na bacia nas quatro datas tem como um dos fatores controladores a precipitação, sendo que à medida que esta aumentou o IAF também aumentou. Um exemplo é a precipitação de dois meses anteriores a cada média de IAF. Para IAF de 0,97, 1,28, 1,59 e 1,59 tem-se uma precipitação acumulada de dois meses de $47,1 \mathrm{~mm}, 217,5 \mathrm{~mm}, 322,3 \mathrm{~mm}$ e $435,3 \mathrm{~mm}$, respectivamente para os meses de agosto, novembro, março e janeiro. O IAF médio de agosto também foi menor, pois grande parte da área de cana-de-açúcar encontrava-se em estádio inicial de desenvolvimento nesta época, enquanto nas demais (janeiro, março e novembro) a tendência foi apresentar um maior IAF, pois esta cultura se encontrava em um estádio mais avançado de desenvolvimento. 


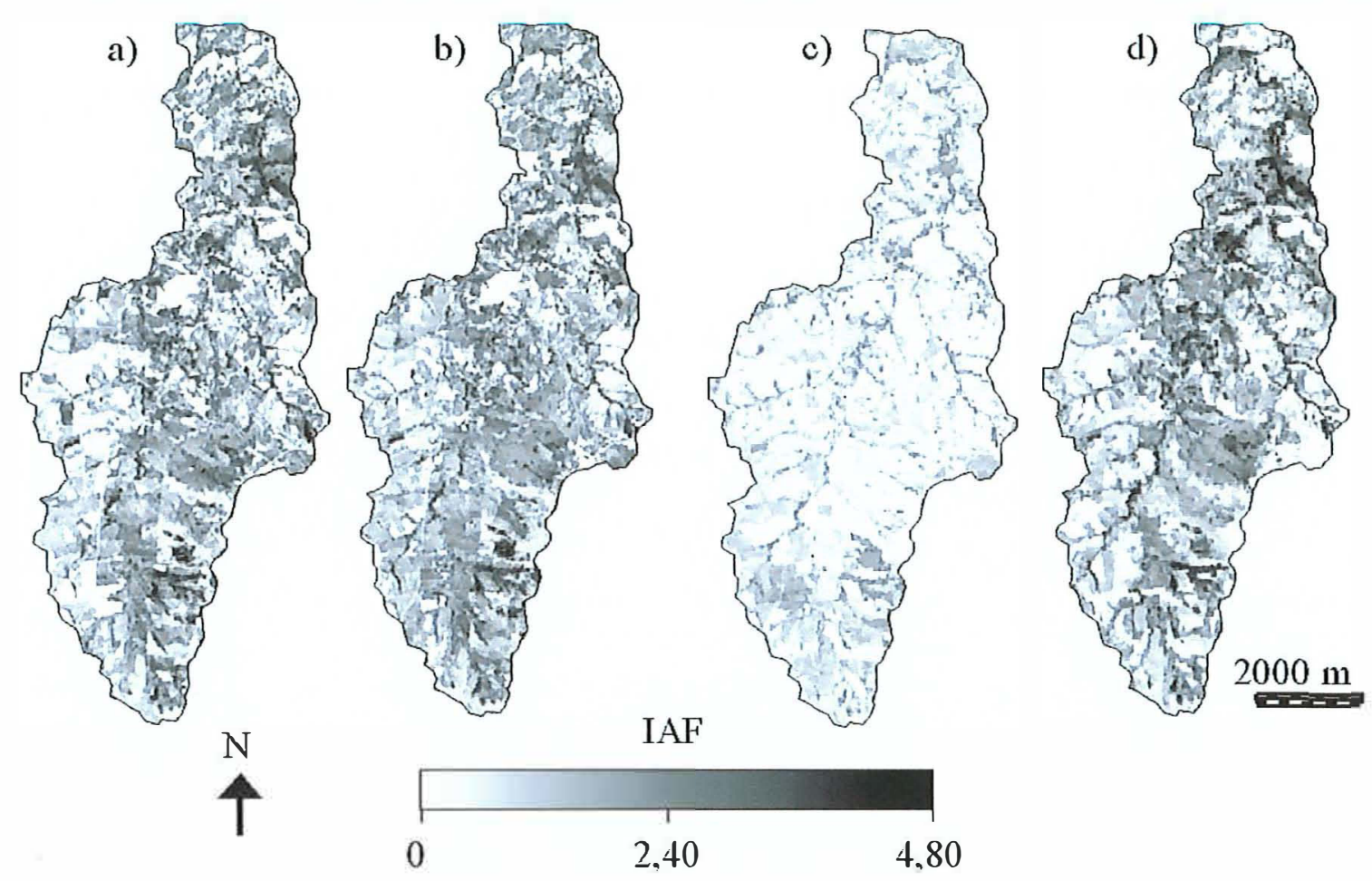

Figura 39 - Mapas de IAF gerados por meio das relações IAF-NDVI (Figura 38), para a área de estudo, nos meses de janeiro (a), março (b), agosto (c) e novembro (d).

Na Figura 40 são apresentados os histogramas do IAF em relação às respectivas percentagens da área ocupada na bacia e seus valores são mostrados na Tabela 14. Notase que no mês de agosto houve uma maior área com menores valores de IAF. No mês de agosto, aproximadamente $88 \%$ da área apresentou IAF menor que 1,80 , enquanto nas demais datas (janeiro, março e novembro), para esta faixa de $\operatorname{IAF}(<1,80)$, a área ocupada foi sempre menor (63\%). Tal resultado está relacionado às condições meteorológicas e ao manejo da cana-de-açúcar, como discutido anteriormente.

Nos meses de janeiro e março, a variação do IAF por área foi bastante similar (Tabela 14), apresentando médias iguais de IAF na bacia $(\mathrm{IAF}=1,59)$. Este resultado está associado ao fato das precipitações e temperaturas serem altas e similares nestes meses, 
assim como a área da cana-de-açúcar, que apresentaria um IAF similar, devido ao estádio de desenvolvimento desta cultura nestas datas estar mais adiantado.

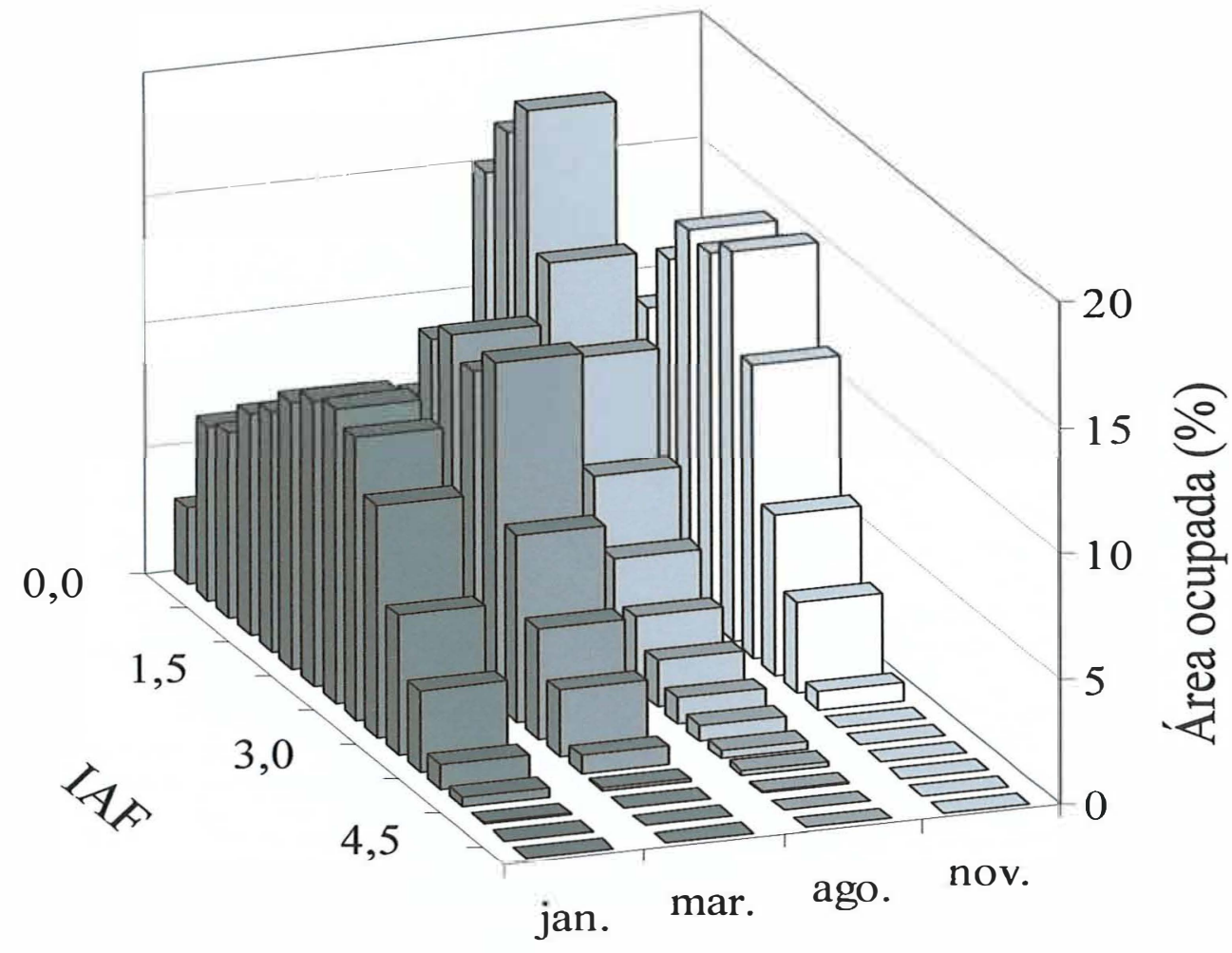

Figura 40 - Distribuição da área ocupada na bacia, por intervalo de IAF para os meses de janeiro, março, agosto e novembro.

A estimativa de IAF por meio do modelo IAF-NDVI para março e agosto apresentou áreas com valores superiores aos máximos medidos em campo, que foram de 3,90 e 2,59, respectivamente, enquanto os IAFs máximos estimados pelo modelo, para esses meses foram de 4,20 e 4,60. Todavia, as áreas com estimativas de IAF superiores às observadas em campo para esses meses foi pequena $(<3 \%)$. Estas áreas correspondem a áreas de floresta ripária. Já para os meses de janeiro e novembro a estimativa do IAF apresentou sempre valores de IAF inferiores aos medidos em campo. As poucas medidas em campo em áreas com valores maiores de IAF podem ter afetado a estimativa dos 
parâmetros dos modelos, prejudicando a estimativa de maiores valores; logo, sugere-se para futuros estudos, um maior volume de coleta de dados de IAF em campo com maiores valores.

Já as áreas com valores inferiores ao IAF mínimo medido em campo foram maiores, correspondendo a aproximadamente $14 \%, 15 \%, 10 \%$ e $13 \%$ da área total para os meses de janeiro, março, agosto e novembro, respectivamente. Na grande maioria estas áreas correspondem desde solo exposto até áreas de cana-de-açúcar e pastagem com baixo porte. Sugere-se que, em estudos futuros, estas áreas sejam avaliadas a fim de aprimorar e verificar os resultados aqui obtidos.

Tabela 14. Área ocupada por intervalo de IAF e sua respectiva percentagem em relação à área total.

\begin{tabular}{|c|c|c|c|c|c|c|c|c|c|c|c|c|}
\hline \multirow[t]{2}{*}{ IAF } & \multicolumn{3}{|c|}{ janeiro } & \multicolumn{3}{|c|}{ março } & \multicolumn{3}{|c|}{ agosto } & \multicolumn{3}{|c|}{ novembro } \\
\hline & $\begin{array}{l}\text { Área } \\
\text { (ha) }\end{array}$ & $\%$ & \% acumulada & $\begin{array}{l}\text { Área } \\
\text { (ha) }\end{array}$ & $\%$ & $\%$ acumulada & $\begin{array}{l}\text { Área } \\
\text { (ha) }\end{array}$ & $\%$ & $\%$ acumulada & $\begin{array}{l}\text { Área } \\
\text { (ha) }\end{array}$ & $\%$ & $\%$ acumulada \\
\hline 0 & 180 & 3,0 & 3,0 & 243 & 4,1 & 4,1 & 111 & 1,9 & 1,9 & 29 & 0,5 & 0,5 \\
\hline $0 \leftrightarrow 0,30$ & 416 & 7,0 & 10,0 & 314 & 5,3 & 9,3 & 948 & 15,9 & 17,7 & 487 & 8,2 & 8,6 \\
\hline $0,30 \hookleftarrow 0,60$ & 438 & 7,3 & 17,3 & .339 & 5,7 & 15,0 & 1083 & 18,1 & 35,9 & 631 & 10,6 & 19,2 \\
\hline $0,60 \leftrightarrow 0,90$ & 524 & 8,8 & 26,1 & 463 & 7,8 & 22,8 & 1178 & 19,7 & 55,6 & 786 & 13,2 & 32,4 \\
\hline $0,90 \leftarrow 1,20$ & 569 & 9,5 & 35,6 & 573 & 9,6 & 32,4 & 854 & 14,3 & 69,9 & 897 & 15,0 & 47,4 \\
\hline $1,20 \leftrightarrow 1,50$ & 634 & 10,6 & 46,2 & 751 & 12,6 & 44,9 & 668 & 11,2 & 81,1 & 881 & 14,8 & 62,2 \\
\hline $1,50 \leftrightarrow 1,80$ & 679 & 11,4 & 57,6 & 800 & 13,4 & 58,3 & 428 & 7,2 & 88,2 & 926 & 15,5 & 77,7 \\
\hline $1,80+2,10$ & 701 & 11,7 & 69,3 & 752 & 12,6 & 70,9 & 272 & 4,6 & 92,8 & 695 & 11,6 & 89,3 \\
\hline $2,10 \leftarrow 2,40$ & 674 & 11,3 & 80,6 & 817 & 13,7 & 84,6 & 174 & 2,9 & 95,7 & 381 & 6,4 & 95,7 \\
\hline $2,40+2,70$ & 552 & 9,2 & 89,8 & 447 & 7,5 & 92,1 & 112 & 1,9 & 97,6 & 214 & 3,6 & 99,3 \\
\hline $2,70 \leftrightarrow 3,00$ & 332 & 5,6 & 95,4 & 264 & 4,4 & 96,5 & 63 & 1,1 & 98,7 & 43 & 0,7 & 100,0 \\
\hline $3,00 \leftarrow 3,30$ & 193 & 3,2 & 98,6 & 158 & 2,6 & 99,1 & 39 & 0,7 & 99,3 & 0 & 0,0 & 100,0 \\
\hline $3,30 \leftarrow 3,60$ & 59 & 1,0 & 99,6 & 44 & 0,7 & 99,9 & 21 & 0,4 & 99,7 & 0 & 0,0 & 100,0 \\
\hline $3,60+3,90$ & 21 & 0,4 & 100,0 & 6 & 0,1 & 100,0 & 13 & 0,2 & 99,9 & 0 & 0,0 & 100,0 \\
\hline $3,90 \leftrightarrow 4,20$ & 1 & 0,0 & 100,0 & 1 & 0,0 & 100,0 & 5 & 0,1 & 100,0 & 0 & 0,0 & 100,0 \\
\hline $4,20+4,50$ & 0 & 0,0 & 100,0 & 0 & 0,0 & 100,0 & 1 & 0,0 & 100,0 & 0 & 0,0 & 100,0 \\
\hline $4,50 \leftrightarrow 4,80$ & 0 & 0,0 & 100,0 & 0 & 0,0 & 100,0 & 1 & 0,0 & 100,0 & 0 & 0,0 & 100,0 \\
\hline
\end{tabular}




\subsubsection{Estimativa do IAF mensal}

Como foi mostrado no ítem 5.4.2 (Avaliação dos dados de IAF), a dinâmica do IAF na bacia foi alta em 2001, para as diferentes coberturas vegetais. A variabilidade deste índice no tempo dependeu, por exemplo, de fatores meteorológicos e, no caso particular da cana-de-açúcar, da sua respectiva época de brotação. Logo, a geração de mapas de IAF para os demais períodos do ano em que não se conta com imagem tornase impraticável, pois não existe outra forma tão eficiente de mapear o uso do solo em determinada época que não com o auxílio do sensoriamento remoto. Haveria, ainda, que se ajustar um modelo IAF-índice de vegetação, pois como visto anteriormente o índice de vegetação NDVI foi influenciado, por exemplo, pela resposta espectral do solo e pelo AZS. Contudo, como observado no ítem anterior, os IAFs médios da bacia, calculados a partir dos modelos IAF-NDVI, mostraram-se relacionados com a precipitação. Outros autores já haviam identificado o aumento da vegetação com a precipitação, como Zeng et al. (1999), que observaram que o crescimento da vegetação nos trópicos respondeu às variações interanuais de água disponível; e Running et al. (1989), que observaram aumento do IAF com a precipitação.

Na Figura 41 são apresentadas as relações do IAF médio, obtidos a partir das funções relacionais IAF-NDVI, com a precipitação acumulada de um, dois, três e quatro meses anteriores às estimativas do IAF médio. Para um e dois meses de chuva acumulada não foi observada relação significativa (Figura 41a, b), mostrando que o IAF da bacia não tem relação com a precipitação acumulada deste número de meses. Já para as precipitações acumuladas de três e quatro meses, as relações com o IAF foram significativas. Os R2 de dois e três meses de precipitação acumulada (Figura 41c e 41d) foram de 0,99 e 0,98 , respectivamente. O se do IAF com a precipitação acumulada de três meses foi de 0,01 . 


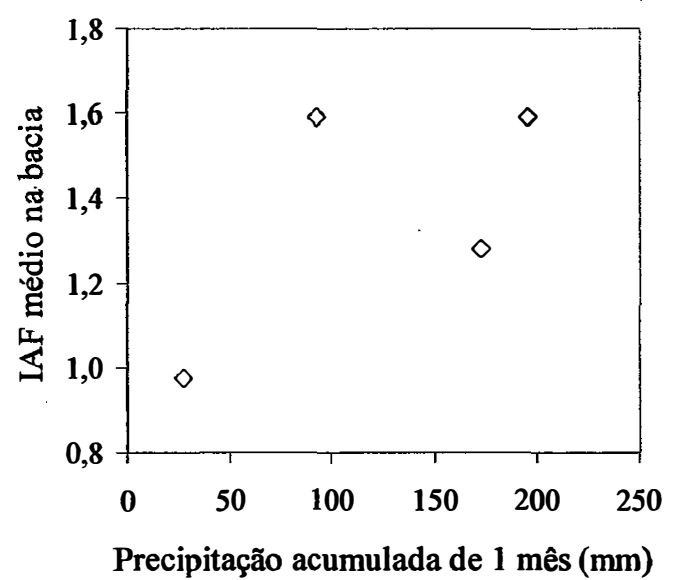

(a)

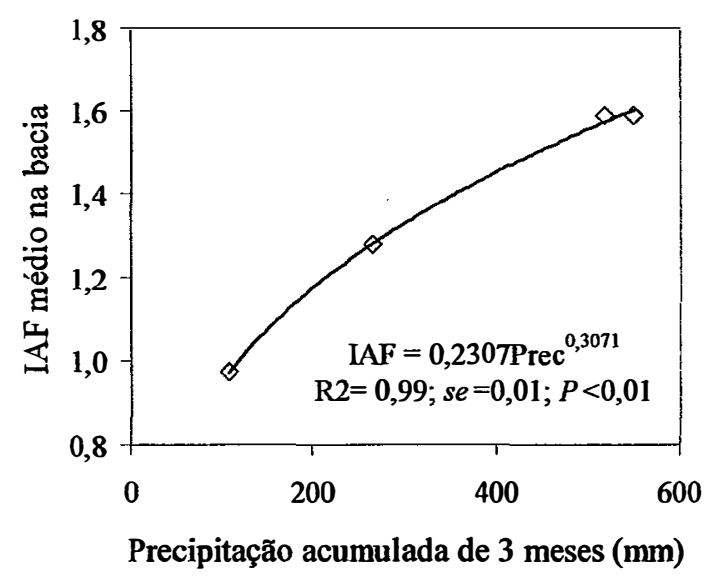

(c)

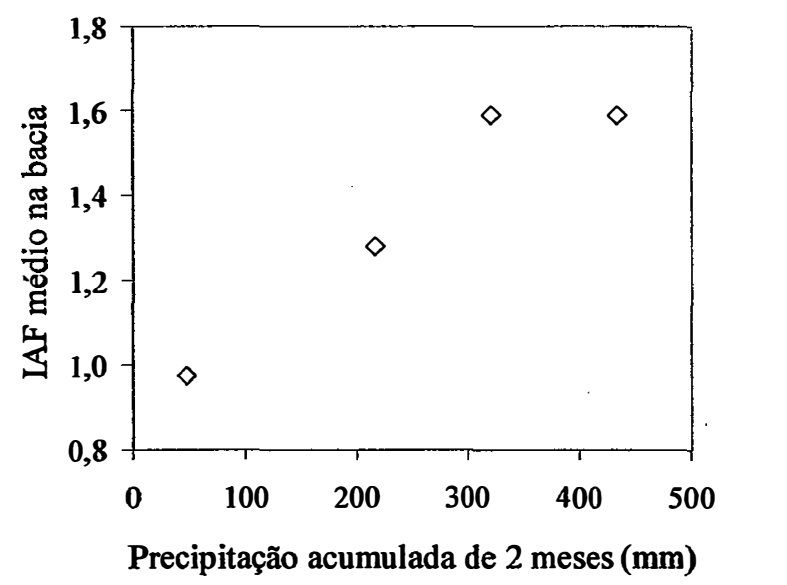

(b)

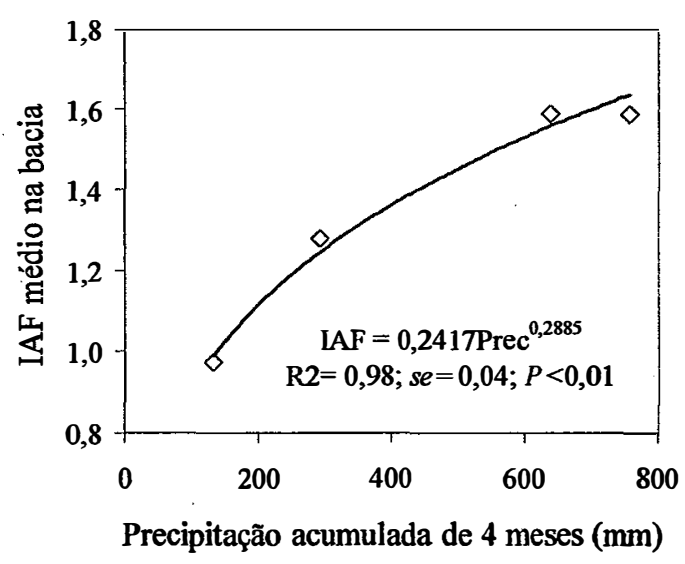

(d)

Figura 41 - Relações entre IAF médio da microbacia (estimado pela relação IAF-NDVI) e a precipitação (mm): do mês anterior à estimativa do IAF (a); acumulada dos dois meses anteriores à estimativa do IAF (b); acumulada dos três meses anteriores à estimativa do IAF (c); e acumulada dos quatro meses anteriores à estimativa do $\operatorname{IAF}(\mathrm{d})$. 
Na Figura 42 é apresentado o IAF da bacia, para cada um dos meses de 2001, estimado por meio da relação IAF médio na bacia "versus" precipitação acumulada de três meses (IAF=0,2307Prec ${ }^{0,3071}$; Figura 41c). O IAF médio na bacia, no ano, foi de 1,28 e o valor máximo e mínimo foram de 1,70 e 0,94 , para os meses de janeiro e setembro, respectivamente. Logicamente que esta estimativa é grosseira, pois já há o erro do modelo e, também, não é levada em consideração a variabilidade de crescimento da área de cana-de-açúcar e a sua época de brotação, assim como a dinâmica da área de pastagem. Contudo, esta estimativa parece bastante conveniente quando nos dá uma ordem da magnitude de IAF na área para se trabalhar em modelos, já que, como demonstrado neste trabalho, para se gerar mapas de IAF, há a necessidade de coleta de dados em campo, aquisição de imagens e geração de modelos relacionais IAF-índice de vegetação.

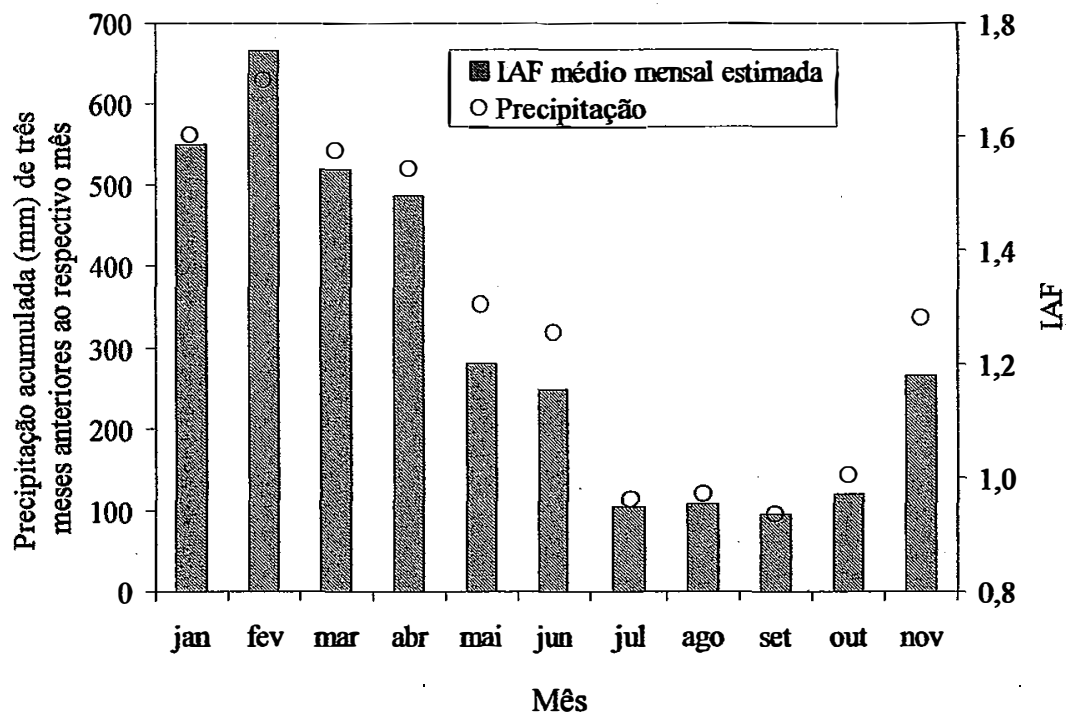

Figura 42 - IAF mensal estimado a partir da precipitação acumulada de três meses (Figura 41c). 


\subsection{Conclusões}

i) os dados de IAF medidos em campo, na microbacia estudada apresentaram grande variabilidade temporal, dependendo do tipo de cobertura, das condições meteorológicas e do tipo de manejo das culturas;

ii) o NDVI mostrou ser afetado pelo IAF, tipo de cobertura, AZS e brilho do solo. As relações IAF-ver, para as quatro datas estudadas apresentaram-se negativas e significativas. Para a relação IAF-iVP não foi observada relação significativa. As plantações de eucalipto apresentaram menores valores de ver, devido à estrutura de seu dossel, o que contribuiu para apresentarem maiores valores de NDVI em relação aos outros tipos de cobertura;

iii) o IAF médio na microbacia, estimado por meio das funções relacionais IAF-NDVI, mostrou-se relacionado com a precipitação acumulada de 3 meses anteriores ao IAF médio. 


\section{CONCLUSÕES GERAIS}

O IAF é uma das principais variáveis estruturais da vegetação, estando diretamente relacionado com a evapotranspiração e a produtividade. Uma das maneiras convenientes de se estimar esta variável biofísica, para grandes áreas, é utilizando índices de vegetação (IVs) e frações de componentes puros (FCPs) de Modelo Linear de Mistura Espectral de dados de sensoriamento remoto. Este trabalho apresenta um estudo das relações do IAF com IVs e FCPs. Foi realizada uma campanha de campo para a coleta mensal do IAF, com o auxílio do equipamento LAI-2000, sendo que os dados de janeiro, março, agosto e novembro foram relacionados com o NDVI destas respectivas datas. Como coclusão geral tem-se que o emprego do NDVI, como técnica de sensoriamento remoto, foi eficaz para mapear o IAF em nível regional, servindo como meio de entrada desta variável em modelos para cálculo regional da evapotranspiração. Como conclusões específicas, têm-se que:

i) os dados de IAF medidos em campo, na microbacia estudada, apresentaram grande variabilidade temporal, dependendo, além do tipo de cobertura, das condições meteorológicas e do tipo manejo das culturas;

ii) dentre os Ivs, Razão Simples (SR), Índice de Vegetação para a Diferença Normalizada (NDVI), Índice de Vegetação Ajustado para a Influência do Solo (SAVI) e as FCPs de vegetação, solo e sombra, o NDVI foi o que apresentou a melhor relação com o IAF;

iii) verificou-se a influência do ângulo zenital solar e do brilho do solo na resposta espectral das bandas individuais (vermelho, ver, e infravermelho próximo, iVP), refletindo na magnitude do NDVI das quatro datas para a mesma ordem de grandeza de IAF; 
iv) os mapas de IAF das quatro datas foram gerados por meio das funções relacionais IAF-NDVI e o IAF médio na microbacia mostrou-se relacionado com a precipitação. 
ANEXO 
Tabela 15. Resultado da coleta de dados de IAF em campo, sendo: PO, pousio; SE, solo exposto; $\mathrm{CC}$, cana-de-açúcar cortada; $\mathrm{CN}$, cana-de-açúcar nova; $\mathrm{PE}$, pastagem seca; ED, eucalipto derrubado; e $\mathrm{MN}$, milho novo.

\begin{tabular}{|c|c|c|c|c|c|c|c|c|c|c|c|c|c|c|c|}
\hline \multirow{2}{*}{ Área } & \multicolumn{2}{|r|}{ as UTM } & & \multirow[t]{2}{*}{ an } & \multirow[b]{2}{*}{ ev } & \multirow[b]{2}{*}{$\operatorname{ar}$} & \multirow[b]{2}{*}{ r } & \multirow{2}{*}{ ai } & \multirow[b]{2}{*}{ n } & \multirow[b]{2}{*}{ jul } & \multirow[b]{2}{*}{ go } & \multirow[b]{2}{*}{ et } & & & \multirow[b]{2}{*}{ ez } \\
\hline & $\mathrm{E}(\mathrm{m})$ & & & & & & & & & & & & & & \\
\hline 1 & 2201 & 7473893 & ana-de-açúcar & 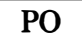 & & 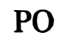 & PO & 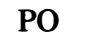 & & & 5 & 7 & 12 & & \\
\hline 2 & & & & & & & & & & & & & & & \\
\hline 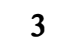 & & & & & & & &, 57 & & & & & & & \\
\hline 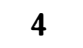 & & & & & & & & & & & $\mathrm{N}$ & 32 & & & \\
\hline 5 & & & & & & 1,05 & 1,03 & 56 & 18 & 15 & $\mathrm{~N}$ &, 4 & 37 & 65 & . \\
\hline 6 & 14 & & & & 0,96 & 0,68 & 6 & 09 & 33 & 42 & 67 & 67 & & & \\
\hline 7 & & & & & & 2,09 & & & & & 1,9 & & & & \\
\hline 8 & & & & & & & & & & & 59 & & & & \\
\hline 9 & & & & & & PO & & & 0 & & & & . & & \\
\hline 10 & & & & 3,21 & 3,26 & 2,89 & 2,48 & 2,34 & 43 & 56 & 1,96 & 71 & 66 & & \\
\hline 11 & & & & & 4,9 & 3,9 & 3,59 & 3,28 & 59 & 3,42 & 2,59 & & & & \\
\hline 12 & & & & & & 1,76 & & & & & 36 & & & & $\mathbf{N}$ \\
\hline ( & & & & & & & & & & & & & & & \\
\hline 14 & & & & & & 1,7 & & & & & & & 0 & & \\
\hline 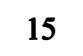 & & & & & & 1,75 & & & & & 82 & 87 & & & $\mathrm{~N}$ \\
\hline 16 & & & & & & 0,72 & & & & & 28 & & & & 86 \\
\hline 17 & & & & & & 1,36 & 1,07 & 1,41 & & & & & & & 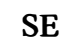 \\
\hline 18 & & & & & & & & & & & & & & & \\
\hline 15 & & & & & & ח & & & & & 0,16 & & & & \\
\hline 20 & & & & & & 1,67 & 2,10 & $2, \boldsymbol{J J}$ & & & (ח) & & & & \\
\hline 21 & & & & 1,39 & 16 & 2,33 & 2 & 2,8 & 31 & 1,46 & 1,76 & & 6 & &, 5 \\
\hline 22 & & & & & 2,06 & 1,83 & 2 & 2,04 & 67 & & 0,28 & 0,86 & & & 0 \\
\hline 2. & & & & & PO & PO & & & & & & & & & \\
\hline 24 & & & & & & 2,00 & & 1,73 & & & PS & & & & \\
\hline 25 & & & & & & & & & & & E & & & & \\
\hline 26 & & & & & 0 , & 2,43 & 0,69 & 1,52 & 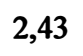 & 34 & $\mathrm{~s}$ & & & & 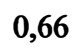 \\
\hline 27 & & & & & 1 , & 2,34 & 1,84 & 2,81 & 5 & 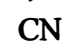 & 26 & 37 & 69 & ( & 1,4 \\
\hline 28 & & & & & 0,8 & 0,69 & 0,85 & 0,84 & & & 0,18 & 77 & 0,74 & & \\
\hline 29 & & & & & & 0,96 & 1,2 & 1,3 & & & 0,58 & & 8 & & \\
\hline 30 & & & & & & & & & & & 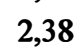 & & & & \\
\hline 31 & & & & & & & & 2,94 & & & 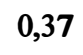 & & & & \\
\hline 32 & 2 & & & 2,78 & 2,86 & 3,13 & 3,00 & 2,74 & 2,4 & 15 & 2,52 & 24 & 2,27 & 2,45 & 2 \\
\hline 33 & 222084 & & & $\mathrm{CN}$ & 0,76 & 0,58 & 1,07 & 1,25 & 1,57 & 1,57 & 2,05 & 1,69 & 1,33 & 2,00 & CN \\
\hline 34 & & & & S & 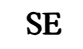 & $\mathrm{SE}$ & SE & $\mathrm{SE}$ & & & 0,36 & & 01 & & \\
\hline 35 & & & & & & & & 1,3 & & & & & & & \\
\hline 36 & & & & & & 2,0 & & 1,1 & & & 0,85 & & & & \\
\hline 37 & & & & 1,09 & 1,65 & 2,45 & 2,18 & 2,28 & 1,96 & 1,78 & PS & ,37 & ,49 & 4 & \\
\hline 38 & 892 & 4086 & . & 2,22 & 2,01 & 1,65 & 2,58 & 2,53 & 2,88 & 3,34 & 2,13 & $\mathrm{CN}$ & $\mathrm{CN}$ & 75 & 1, \\
\hline 35 & & & & $\mathrm{SE}$ & $\mathrm{SE}$ & $\mathrm{SE}$ & SE & SE & $\mathrm{CN}$ & 0,34 & 0,54 & 0,81 & ,18 & 1,62 & \\
\hline 40 & & & & & 2,3 & $2,0^{\circ}$ & 2,05 & 1,9 & 2,20 & 2,19 & 2,0 & &, 84 & 66 & \\
\hline 41 & 2600 & 7474360 & Lucanpe & 3,11 & 3,11 & 2,44 & 2,34 & 2,395 & 2,45 & 1,83 & 2,12 & 2,41 & 2,5 & 2,48 & EL \\
\hline
\end{tabular}




\section{REFERÊNCIAS BIBLIOGRÁFICAS}

ADAMS, J.B.; SABOL, D.E.; KAPOS, V.; FILHO, R.A.; ROBERTS, D.A.; SMITH, M.O.; GILLESPIE, A.R. Classification of multispectral images based on fraction of endmembers: Application to land-cover change in Brazilian Amazon. Remote Sensing of Environment, v.52, p.137-154, 1995.

ADAMS, J.B.; SMITH, M.O.; JOHNSON, P.E. Spectral mixture modeling: a new analysis of rock and soil types at the Viking Lander 1 Site. Journal of Geophysical Research, v.91, p.8098-8122, 1986.

ARES, A.; FOWNES; J.H. Productivity, nutrient and water-use efficiency of Eucalyptus saligna and Toona ciliata in Hawaii. Forest Ecology and Management, v.139, p.227-236, 2000.

ASRAR, G.; KANEMASU, E.T.; YOSHIDA, M. Estimates of leaf area index from spectral reflectance of wheat under different cultural practices and solar angle. Remote Sensing of Environment, v.17, p.1-11, 1985.

ASRAR, G.; FUCHS, M.; KANEMASU, E.T.; HATFELD, J.L. Estimating absorbed photosynthetic radiation and leaf area index from spectral reflectance in wheat. Agronomy Journal, v.76, p.300-306, 1984.

BATTAGLIA, M.; CHERRY, M.L.; BEADLE, C.L.; SANDS, P.J.; HINGSTON A. Prediction of leaf area index in eucalypt plantations: effects of water stress and temperature. Tree Physiology, v.18, p.521-528, 1998. 
BAUSCH, W. Soil background effects on reflectance-based crop coefficients for corn. Remote Sensing of Environment, v.46, p.213-222, 1993.

BERNARDES, S. Índices de vegetação e valores de proporção na caracterização de floresta tropical primária e estágios sucessionais na área de influência da Floresta Nacional do Tapajós - Estado do Pará. São José dos Campos, 1996. 86 p. Dissertação (M.S.) - Instituto Nacional de Pesquisas Espaciais.

BEST, R.G.; HARLAN, J.C. Spectral estimation of green leaf area index of oats. Remote Sensing of Environment, v.17, p.27-36, 1985.

BOEGH, E.; SÓEGAARD, H.; BROGE, N.; HASAGER, C.B.; JENSEN, N.O.; SCHELDE, K.; THONSEN, A. Airborne multispectral data for quantify leaf area index, nitrogen concentration and photosynthetic efficiency in agriculture. Remote Sensing of Environment, v. 81, p.179-193, 2002.

BOREL, C.G.; GERSTL, S.A.W. Nonlinear spectral mixing models for vegetative and soil surfaces. Remote Sensing of Environment, v.47, p.403-416, 1994.

BOUMAN, B.A.M. Linking physical remote sensing models crop growth simulation models, applied for sugar beet. International Journal of Remote Sensing, v.13, p.2565-2581, 1992.

CAMPBELL, G.S.; NORMAN, J.M. The description and measurement of plant canopy structure. In: RUSSEL, G.; MARSHALL, B.; JARVIS, P.G. (Ed.). Plant canopies: their growth, form and function. New York: Cambridge University Press, 1989. cap. 1, p.1-19.

CAMPBELL, J.B. Introduction to remote sensing. 2.ed. New York: Guilford Press, 1996. 622p. 
CARLSON, T.N.; RIPLEY, D. On the relation between NDVI, fractional vegetation cover, and leaf area index. Remote Sensing of Environment, v.62, p.241-252, 1997.

CASALS-CARRASCO, P.; KUBO, S.; MADHAVAN, B.B. Application of spectral mixture analysis for terrain evaluation studies. International Journal of Remote Sensing, v.21, p.3039-3055, 2000.

CHAHINE, M.T. The hydrological cycle and its influence on climate. Nature, v.359, p.373-280, 1992.

CHARNET, R.; FREIRE, C.A.L.; CHARNET, E.M.R.; BONVINO, H. Análise de modelos de regressão linear: com aplicações. Campinas: Editora da Unicamp, 1999. 356p.

CHASON, J.W.; BALDOCCHI, D.D.; HUSTON, M.A. A comparison of direct and indirect methods for estimating forest canopy leaf area. Agricultural and Forest Meteorology, v.57, p.107-128, 1991.

CHEEROO-NAYAMUTH, F.C., ROBERTSON, M.J., WEGENER, M.K.; NAYAMUTH, A.RH. Using a simulation model to assess potential and attainable sugar cane yield in Mauritius. Field Grops Research, v.66, p.225-243, 2000.

CHEN, J.M.; CIHLAR, J. Retrieving Leaf Area Index of Boreal Conifer Forests Using Landsat TM Images. Remote Sensing of Environment, v.55, p.153-162, 1996.

CHEN, J.M.; BLACK, T.A.; ADAMS, R.S. Evaluation of hemispherical photography for determining plant area index and geometry of a forest stand. Agricultural and Forest Meteorology, v.56, p.129-143, 1991. 
CHEN, J.M.; PAVLIC, G.; BROWN, L.; CUHLAR, J.; LEBLANE, S.G.; WHTTE, H.P.; HALL, R.J.; PEDDLE, D.R.; KING, D.J.; TROFYMOW, J.A.; SWIFT, E.; VAN DER SANDER, J.; PELLIKKA, P.K.E. Derivation and validation of Canadawide coarse-resolution leaf area index using high-resolution satellite imargery and ground measurements. Remote Sensing of Environment, v. 80, p.165-184, 2002.

CURRAN, P.J.; WILLIAMSON, H.D. The accuracy of ground data used in remotesensing investigations. International Journal of Remote Sensing, v.6, p.1637$1651,1995$.

CUSACK, G.A., HUTCHINSON, M.F.; KALMA, J.D. Calibrating airborne vegetation data for hydrological applications under dry conditions. International Journal of Remote Sensing, v.20, p.2221-2233, 1999.

DEPARTAMENTO DE ÁGUAS E ENERGIA ELÉTRICA, http://www.daee.sp.gov.br/servicos/tabbmt.htm. (10 jan. 2002).

DAUGHTRY, C.S.T. Direct measurement of canopy structure. In: GOEL, N. S.; NORMAN, J.M. (Ed). Instrumentation for studying vegetation canopies for remote sensing in optical and thermal infrared regions. New York: Harwood Academic, 1990. p.45-60.

DEERING, D.W.; ECK, T.F.; BANERJEE, B. Characterization of the reflectance anisotropy of boreal forest canopy in spring-summer. Remote Sensing of Environment, v.67, p.205-229, 1999.

DIJK, A.I.J.M. van; BRUIJNZEEL, L.A. Modelling rainfall interception by vegetation of variable density using an adapted analytical model. Part 2. Model validation for a tropical upland mixed cropping system. Journal of Hydrology, v.247, p.239-262, 2001.

EMPRESA BRASILEIRA DE PESQUISA AGROPECUÁRIA. Centro Nacional de Pesquisa de Solos. Sistema brasileiro de classificação de solos. Brasília, 
EMBRAPA Produção de Informação; Rio de Janeiro: EMBRAPA Solos, 1999. 412p.

ESCOLA SUPERIOR DE AGRICULTURA “LUIS DE QUEIROZ”. Departamento de Ciências Exatas. http://www.ciagri.usp.br/ emdabreu/ MEDIAS.TXT. (10 jan. 2002).

EPIPHANIO, J.C.N.; HUETE, A.R. Dependence of NDVI and SAVI on sun/sensor geometry and its effect on FAPAR relationships in alfafa. Remote Sensing of Environment, v.51, p.351-360, 1995.

EPIPHANIO, J.C.N., ALMEIDA JUNIOR, A.C.; FORMAGGIO A.R. Wheat development evaluated by remote sensing using two vegetation indices. Anais da Academia Brasileira de Ciências, v.69, p.471-478, 1997.

FASSNACHT, K.S.; GOWER, S.T.; NORMAN, J.M.; MACMURTRIE, R.E. A comparison of optical and direct methods for estimating foliage surface area index in forests. Agricultural and Forest Meteorology, v.71, p.183-207, 1994.

FASSNACHT, K.S.; GOWER, S.T.; MACKENZIE, M.D.; NORDHEIN, E.V.; LILLESAND, T.M. Estimating the leaf area index of north central Wisconsin forests using the Landsat Thematic Mapper. Remote Sensing of Environment, v.61, p.229-245, 1997.

FRANKLIN, S.E.; LAVIGNE, M.B.; DEULING, M.J.; WULDER, M.A.; HUNT JUNIOR, E.R. Estimation of forest Leaf Area Index using remote sensing and GIS data for modelling net primary production. International Journal of Remote Sensing, v.18, p.3459-3471, 1997.

FRIEDL, M.A.; MICHAELSEN, J.; DAVIS, F.W.; WALKER, H.; SCHIMEL, D.S. Estimating grassland biomass and leaf area index using ground and satellite data. International Journal of Remote Sensing, v.15, p.1401-1420, 1994. 
GARCÍA-HARO, F.J.; GILABERT, M.A.; MELIA, J. Linear spectral mixture modeling to estimate vegetation amount from optical spectral data. International Journal of Remote Sensing. v.17, p.3373-3400, 1996.

GARCÍA-HARO, F.J.; GILABERT, M.A.; MELIÁ, J. Extraction of endmembers from spectral mixture. Remote Sensing of Environment, v.68, p.237-253, 1999.

GATES, D.M.; KEEGAN, J.H.; SCHLETER, J.C.; WEIDNER, V.R. Spectral properties of plants. Applied Optics, v.4, p.11-20, 1965.

GOBRON, N.; PINTY, B.; VERSTRAETE, M.M. Theoretical limits to the estimation of the leaf area index on the basis of visible and near-infrared remote sensing data. IEEE Transactions on Geoscience and Remote Sensing, v.35, p.1438-1445, 1997.

GOEL, N.S. Inversion of canopy reflectance models for estimation of biophysical parameters from reflectance data. In: ASRAR G. (Ed.). Theory and applications of optical remote sensing. New York: Wiley, 1989. p. 205-248.

GOETZ, S.J. Multi-sensor analysis of NDVI, surface temperature and biophysical variables at a mixed grassland site. International Journal of Remote Sensing, v.18, p.71-94, 1997.

GONG, P.; PU, R.; MILLER, J.R. Coniferous forest leaf area index estimation along the Oregon transect using compact airborne spectrographic imager data. Photogrammetric Engineering \& Remote Sensing, v.61 p.1107-1117, 1995.

GOWER, S.T.; NORMAN, J.M. Rapid estimation of leaf area index in conifer and broad-leaf plantations. Ecology, v.75, p.1896-1900, 1991.

GREEN, E.P.; MUMBY, P.J.; EDWARDS, A.J.; CLARK, C.D.; ELLIS, A.C. Estimating leaf area index of mangroves from satellite data. Aquatic Botany, v.58, p.11-19, 1997. 
HALL, F.G.; SHIMABUKURO, Y.E.; HUEMMRICH, K.F. Remote sensing forest biophysical structure using mixture decomposition and geometric reflectance models. Ecological Applications, v.5, p.993-1013, 1995a.

HALL, F.G.; TOWNSHEND, J.R.; ENGMAN, E.T. Status of remote sensing algorithms for estimation of land surface state parameters. Remote Sensing of Environment, v.51, p.138-156, 1995b.

HINGSTON, F.J.; GALBRAITH, J.H.; DIMMOCK, G.M. Application of the processbased model BIOMASS to Eucalyptus globulus subsp. globulus plantations on exfarmland in southwestern Australia - I. Water use by trees and assessing risk of losses due to drought. Forest Ecology and Management, v.106, p.141-156, 1998.

HLAVKA, C.A.; SPANNER, M.A. Unmixing AVHRR imagery to assess clearcuts and forest regrowth in Oregon. IEEE Transaction on Geoscience and Remote Sensing, v.39, p.788-795, 1995.

HODGES, T.; KANEMASU, E.T. Modeling daily dry matter production of winter wheat. Agronomy Journal, v.69, p.974-978, 1977.

HOLBEN, B.N.; TUCKER, C.J.; FAN, C.J. Spectral assessment of soybean leaf area and leaf biomass. Photogrammetric Engineering \& Remote Sensing, v.46, p.651$656,1980$.

HONZÁK, M.; LUCAS, R.M.; AMARAL, I. do; CURRAN, P.J.; FOODY, G.M.; AMARAL, S. Estimation of the leaf area index and total biomass of tropical regenerating forests: comparison of methodologies. In: GASH, J.H.C.; NOBRE, C.A.; ROBERTS, J.M.; VICTORIA, R.L. (Ed). Amazon Deforestation and Climate. Chichester: John Wiley, 1996. p. 365-382.

HUETE, A.R. A soil-adjusted vegetation index (SAVI). Remote Sensing of Environment, v.25, p.295-309, 1988. 
INSTITUTO NACIONAL DE PESQUISAS ESPACIAIS. Spring. http://www.dpi.inpe.br/ spring/usuario/indice.htm. (20 nov. 1999).

JACKSON, R.D.; HUETE, A.R. Interpreting vegetation indices. Preventive Veterinary Medicine, v.11, p.185-200, 1991.

JACKSON, R.B; CARPENTER, S.R.; DAHM, C.N.; McKNIGHT, D.M.; NAIMAN, R.J.; POSTEL, S.L.; RUNNING, S.W. Water in a changing world. Ecological Applications, v.11, p.1027-1045, 2001.

JACKSON, R.D.; PINTER, P.J.; IDSO, S.B.; REGINATO, R.J. Wheat spectral reflectance: interactions between crop configuration, sun elevation, and azimuth angle. Applied Optics, v.18, p.3730-3732, 1979.

JOHNSON, R.A.; WICHERN, D.W. Applied multivariate statistical analysis. 4. ed. New Jersey: Prentice Hall, 1998. 816p.

JORDAN, C.F. Derivation of leaf-area index from quality of light on the forest floor. Ecology, v.50, p.663-666, 1969.

KEATING, B.A.; ROBERTSON, M.J.; MUCHOW, R.C.; HUTH, N.I. Modelling sugarcane systems I. Development and performance of the sugarcane module. Field Crops Reasearch, v.61, p.253-271, 1999.

KERGOAT, L. A model for hydrological equilibrium of leaf area index on a global scale. Journal of Hydrology, v.212/213, p.268-286, 1998.

KOFFLER, N.F.; CAVALLI, A.C.; CHIARINI, J.V.; NOGUEIRA, F.P. Inventário canavieiro com o auxílio de fotografias aéreas. Boletim Técnico Planalsucar, v.1, p.3-38, 1979.

LANG, A.R.G; MCMURTRIE, R.E. Total leaf area of single trees of Eucalyptus grandis estimated from transmittances of the sun's beam. Agricultural and Forest Meteorology, v.58, p.79-92, 1992. 
LARCHER, W. Physiological plant ecology. New York: Springer-Verlag, 1975. 251p.

LI-COR. LAI-2000 plant canopy analyser: instruction manual. Nebraska, 1992. 166p.

LIU, H.Q.; HUETE, A.R. A feedback based modification of the NDVI to minimize canopy background and atmosphere noise. IEEE Transactions on Geoscience and Remote Sensing, v.3, p.457-465, 1995.

MACHADO, E.C.; PEREIRA, A.R.; FAHL, J.I.; ARRUDA, H.V.; CIONE J. Índices biométricos de duas variedades de cana-de-açúcar. Pesquisa Agropecuária Brasileira, v.17, p.1323-1329, 1982.

MATSUSHITA, B.; TAMURA, M. Integrating remotely sensed data with an ecosystem model to estimate net primary productivity in East Asia. Remote Sensing of Environment, v. 81, p.58-66, 2002.

McGWIRE, K.; MINOR, T.; FENSTERMAKER, L. Hyperspectral mixture modeling for quantifying sparse vegetation cover in arid environments. Remote Sensing of Environment, v.72, p.360-374, 2000.

METTERNICHT, G.I.; FERMONT A. Estimating erosion surface features by linear mixture modeling. Remote Sensing of Environment, v.64, p.254-265, 1998.

MIDDLETON, E.M. Solar zenith angle effects on vegetation indices in tallgrass prairie. Remote Sensing of Environment, v.38, p.45-62, 1991.

MONTERO, F.J.; MELIÁ, J.; BRASA, A.; SEGARRA, D.; CUESTA, A.; LANJERI, S. Assessment of vine development according to available water resources by using remote sensing in La Mancha, Spain. Agricultural Water Management, v.40, p.363-375, 1999.

MONTGOMERY, D.C. Design and analysis of experiments. New York: John Wiley, 2001.684p. 
MORAN, M.S.; MAAS, S.J.; PINTER JUNIOR, P.J. Combining remote sensing and modeling for estimating surface evaporation and biomass production. Remote Sensing Reviews, v.12, p.335-353, 1995.

MYNENI, R.B.; ASRAR, G. Atmospheric effects and spectral vegetation indices. Remote Sensing of Environment, v.47, p.390-402, 1994.

MYNENI, R.B.; NEMANI, R.R.; RUNNING, S. Estimation of global leaf area index and absorbed PAR using radiative ransfer models. IEEE Transactions on Geoscience and Remote Sensing, v.35, p.1380-1393, 1997.

MYNENI, R.B.; MAGGION, S.; IAQUINTA, J.; PRIVETTE, J.L.; GOBRON, N.; PINTY, B.; KIMES, D.S.; VERSTRAETE, M.M.; WILLAMS, D.L. Optical remote sensing of vegetation: modeling, caveats, and algorithms. Remote Sensing of Environment, v.51, p.169-188, 1995.

NEMANI, R.R.; PIERCE, L.; RUNNING, S.W.; BAND, L. Forest ecosystem processes at the watershed scale: Sensitivity to remotely-sensed leaf area index estimates. International Journal of Remote Sensing, v.14, p.2519-2534, 1993.

NOVO, E.M.; SHIMABUKURO, Y.E. Identification and mapping of the Amazon habitats using a mixing model. International Journal of Remote Sensing, v.18, p.663-670, 1997.

OLIVEIRA, F.A.; SILVA, J.J.S.; CAMPOS T.G.S. Evapotranspiração e desenvolvimento radicular do milho irrigado. Pesquisa Agropecuária Brasileira, v.28, p.1407-1415, 1993.

OLIVEIRA, J.B. Solos da folha de Piracicaba. Campinas: Instituto Agronômico, 1999. 173p. (Boletim Científico, 48).

PERRY, C.R.; LAUTENSHLAGER, L.F. Functional equivalence of spectral vegetation indices. Remote Sensing of Environment, v.14, p.169-182, 1984. 
PETERSON, D.L.; SPANNER, M.A.; RUNNING, S.W.; TEUBER, K.B. Relationship of thematic maper simulater data to leaf area index of temperature coniferous forests. Remote Sensing of Environment, v.22, p.323-341, 1987.

PLUMMER, S.E. Perspectives on combining ecological process models and remotely sensed data. Ecological Modelling, v.129, p.169-186, 2000.

PROJETO PIRACENA. Geoprocessamento. http://www.cena.usp.br/piracena/html/ geopro.htm. (20 mar. 2001).

PUREVDORJ, T.; TATEISHI, R.; ISHIYAMA, T.; HONDA, Y. Relationships between percent vegetation cover and vegetation indices. International Journal of Remote Sensing, v.19, p.3519-3535, 1998.

RAY, T.W.; MURRAY, B.C. Nonlinear spectral mixing in desert vegetation. Remote Sensing of Environment, v.55, p.59-64, 1996.

ROBERTS, D.A.; SMITH, M.O.; ADAMS, J.B. Green vegetation, nonphotosynthetic vegetation, and soils in AVIRIS data. Remote Sensing of Environment, v.44, p.255-269, 1993.

ROBERTS, D.A; GARDNER, M.; CHURCH, R.; USTIN, S.; SCHEER, G.; GREEN, R.O. Mapping Chaparral in the Santa Monica using multiple endmember spectral models. Remote Sensing of Environment, v.65, p.267-279, 1998.

ROBERTS, J.M.; CABRAL, O.M.R.; da COSTA, J.P.; McWILLIAN, A.-L.C.; de A. SÁ, T.D. An overview of the leaf area index and physiological measurements during ABRACOS. In: GASH, J.H.C.; NOBRE, C.A.; ROBERTS, J.M.; VICTORIA, R.L. (Ed.). Amazon deforestation and climate. Chichester: John Wiley, 1996. p.287306. 
ROBERTSON, M.J.; WOOD, A.W.; MUCHOW, R.C. Growth of sugarcane under high input conditions in tropical Australia. I. Radiation use, biomass accumulation and partitioning. Field Crops Reasearch, v.48, p.11-25, 1996.

RODRIGUES, R.R. A vegetação de Piracicaba e municípios do entorno. Piracicaba: IPEF, 1999. 18p. (Circular Técnica, 189)

ROSENBERG, N.J.; BLAD, B.L.; VERMA, S.B. Microclimate: the biological environment. Washington, DC:John Wiley, 1983. 459p.

RUNNING, S.W.; COUGHLAN, J.C. A general model of forest ecosystem processes for regional applications I. hidrological balance, canopy gas exchange and primary production processes. Ecological Modelling, v.42, p.125-154, 1988.

RUNNING, S.W.; PETERSON, D.L.; SPANNER M.A.; TEUBER, K.B. Remote sensing of coniferous forest leaf area. Ecology, v.67, p.273-276, 1986.

RUNNING, S.W.; NEMANI, R.R.; PETERSON, D.L.; BAND, L.E.; POTTS, D.F.; PIERCE, L.L.; SPANNER, M.A. Mapping regional forest evapotranspiration, and photosynthesis by coupling satellite data with ecosystem simulation. Ecology, v.70, p.1090-1101, 1989.

SAS INSTITUTE. SAS/STAT user's guide: version 6. 4. ed. Cary, 1990. 2 v.

SELLERS, P.J.; DICKINSON, R.E.; RANDALL, D.A.; BETTS, A.K.; HALL, F.G.; BERRY, J.A.; COLLATZ, G.J.; DENNING, A.S.; MOONEY, H.A.; NOBRE, C.A.; SATO, N.; FIELD, C.B.; HENDERSON-SELLERS, A. Modeling the exchanges of energy, water, and carbon between continents and the atmosphere. Science. v.275, p.502-509, 1997.

SENTELHAS, P.C.; MARIN, F.R.; PEREIRA, A.R.; ANGELOCCI, L.R.; VILLA NOVA, N.A.; BARBIERI, V. Análise dos dados climáticos e do balanço hídrico climatológico de Piracicaba. Piracicaba: ESALQ, DFM, 1998. 81 p. 
SHARMA, S. Applied multivariate techniques. New York: John Wiley, 1996. 493p.

SHIMABUKURO, Y.E.; SMITH, J.A. The least-square mixing models to generate fraction imagens derived from remote sensing multispectral data. IEEE Transactions on Geoscience and Remote Sensing, v.29, p.16-20, 1991.

SHIMABUKURO, Y.E.; SMITH J.A. Fraction images derived from Landsat TM and MSS data for monitoring reforested areas. Canadian Journal of Remote Sensing, v.21, p.67-74, 1995.

SHIMABUKURO, Y.E., HOLBEN, B.N., TUCKER, C.J. Fraction images derived from NOAA AVHRR data for studying the deforestation in the Brazilian Amazon. International Journal of Remote Sensing, v.15, p.517-520, 1994.

SLATER, P.N.; DOYLE, F.J.; FRITZ, N.L.; WELCH, R. Photographic systems for remote sensing. In: COLWELL, R. N. Manual of remote sensing: theory, instruments and techniques. Falls Church: American Society of Photogrammetry, 1983. v.1, p.231-291.

SMALL, C. Estimation of urban vegetation abundance by spectral mixture analysis. International Journal of Remote Sensing, v.22, p.1305-1334, 2001.

SMITH, M.O.; USTIN, S.L.; ADAMS, J.B.; GILLESPIE, A.R. Vegetation in deserts: I. a regional measure of abundance from multispectral images. Remote Sensing of Environment, v.29, p.1-26, 1990.

SPANNER, M.A.; PIERCE, L.L.; PETERSON, D.L.; RUNNING, S.W. Remote sensing of temperate coniferous forest leaf area index: the influence of canopy closure, understory vegetation, and background reflectance. Remote Sensing of Environment, v.33, p.97-112, 1990.

TERAMOTO, E.R. Relações solo, substrato geológico e superfícies geomorficas na microbacia do Ribeirao Marins (Piracicaba, SP). Piracicaba, 1995. 93p. Dissertação 
(Mestrado) - Escola Superior de Agricultura "Luiz de Queiroz", Universidade de São Paulo.

TIKTAK, A.; GRINSVEN, H.J.M. van. Review of sixteen forest-soil-atmosphere models. Ecological Modelling, v.83, p.35-53, 1995.

TUCKER, C.J. Red and photographic infrared linear combinations for monitoring vegetation. Remote Sensing of Environment, v.8, p.127-150, 1979.

TURNER, D.P.; COHEN, W.B.; KENNEDY, R.E.; FASSNACHT, K.S.; BRIGGS, J.M. Relationships between leaf area index and Landsat TM Spectral Vegetation Indices across three temperate zone sites. Remote Sensing of Environment, v.70, p.52-68, 1999.

VERMOTE, E.F.; TANRÉ, D.; DEUZÉ, J.L.; HERMAN, M.; MORCRETTE, J.J. Second simulation of the satellite signal in the solar spectrum, 6S: An overview. IEEE Transactions on Geoscience and Remote Sensing, v.35, p.675-686, 1997.

VÖRÖSMARTY, C.J.; GREEN, P.; SALISBURY, J.; LAMMERS, R.B. Global water resources: vulnerability from climate change and population growth. Science, v.289, p.284-288, 2000.

WALTER-SHEA, E.A.; PRIVETTE, J.; CORNELL, D.; MESARCH, M.A.; HAYS, C.J. Relations between directional spectral vegetation indices and leaf area and absorbed radiation in alfalfa. Remote Sensing of Environment, v.61, p.162-177, 1997.

WATSON, D.J. Comparative physiological studies on growth of field grops: I. Variation in net assimilation rate and leaf area between species and varieties, and within and between years. Annals of Botany, v.11, p.41-76, 1947. 
WELLES, J.M. Some indirect methods of estimating canopy structure. In: GOEL, N.S.; NORMAN, J.M. Instrumentation for studying vegetation canopies for remote sensing in optical and thermal infrared regions. London: Harwood Academy, 1990. cap.5, p.31-43.

WELLES, J.M.; NORMAN, J.M. Instrument for indirect measurement of canopy architecture. Agronomy Journal, v.83, p.818-825, 1991.

WIEGAND, C.L.; RICHARDSON, A.J. Use of spectral vegetation indices to infer leaf area, evapotranspiration and yield: II. Results. Agronomy Journal, v.82, p.630-636, 1990.

WIEGAND, C.L.; GERBERMANN, A.H.; GALLO, K.P.; BLAD, B.L.; DUSEK, D. Multisite analyses of spectral-biophysical corn data. Remote Sensing of Environment, v.33, p.1-16, 1990.

XAVIER, A.C. Estimativa de propriedades biofísicas de plantações de eucaliptos a partir de dados Landsat-TM. São José dos Campos, 1998. 86p. Dissertação (Mestrado) - Instituto Nacional de Pesquisas Espaciais.

YODER, B.J.; WARING, R.H. The normalized difference vegetation index of small Douglas-Fir canopies with varying chlorophyll concentrations. Remote Sensing of Environment, v.49, p.81-91, 1994.

ZENG, N.; NEELIN, J.D.; LAU, K.-M; TUCKER, C.J. Enhancement of interdecadal climate variability in the Sahel by vegetation interaction. Science, v.19, p.1537-1540, 1999. 